\title{
SOCIEDADES EN TRANSICIÓN HACIA EL DESARROLLO SOSTENIBLE
}

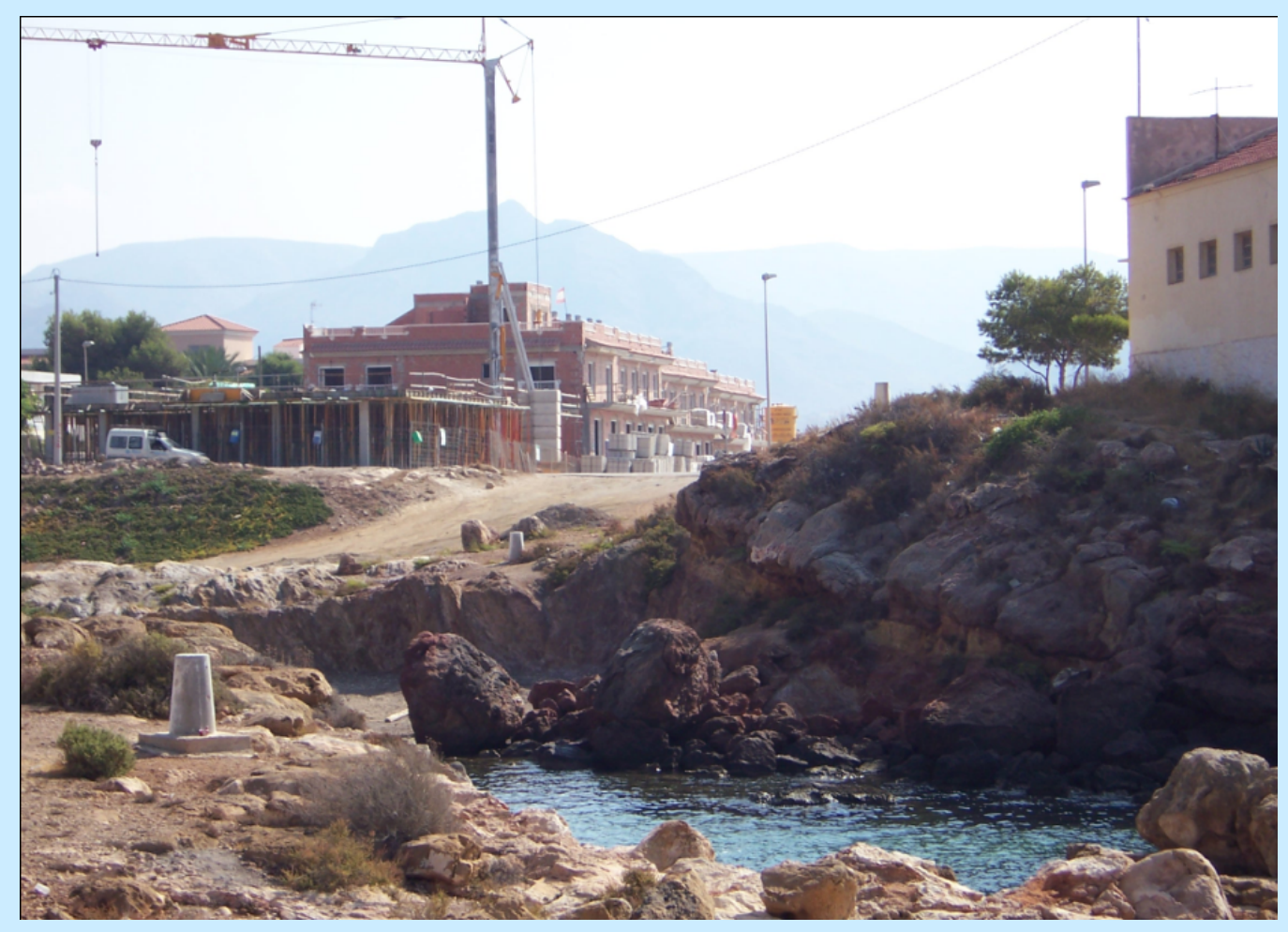

Alumna:

Marta Díaz Benavides

Directores:

José Gutiérrez Pérez

Carmelo Marcén Albero 


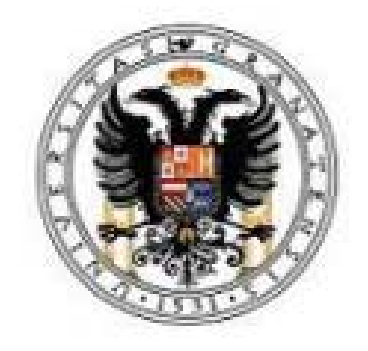

Máster Universitario de Profesorado de Educación

Secundaria Obligatoria, Bachillerato, Formación

Profesional y Enseñanza de Idiomas

\title{
SOCIEDADES EN TRANSICIÓN HACIA EL DESARROLLO SOSTENIBLE
}

\author{
Alumna: \\ Marta Díaz Benavides \\ Directores: \\ José Gutiérrez Pérez ${ }^{1}$ \\ Carmelo Marcén Albero ${ }^{2}$ \\ ${ }^{1}$ Departamento de Métodos de Investigación y Diagnóstico en Educación. \\ Universidad de Granada. ${ }^{2}$ IES “Miguel Catalán”. Zaragoza.
}


RESUMEN: El presente documento pretende aportar una propuesta didáctica para trabajar contenidos relacionados con el desarrollo sostenible. El eje central en torno al que se estructuró la secuenciación de contenidos de la Unidad Didáctica (UD) fue el uso de los recursos y, en consecuencia, el modelo de desarrollo existente en la actualidad. Durante el transcurso de las diferentes sesiones de clase pudieron apreciarse algunas dificultades estableciéndose, como consecuencia, tanto la necesidad de establecer un término medio entre la utilización de clases con recursos tecnológicos y tradicionales como la organización de una atmósfera de constante interacción y respeto entre docente y alumnado. El trabajo comienza con la contextualización, justificación y fundamentación de la UD necesarias para establecer la importancia de la misma, posteriormente se explican la metodología y sus diferentes componentes (objetivos, criterios de evaluación, contenidos, etc.) y se termina con los mecanismos de atención a la diversidad, las actividades extraescolares escogidas y la interdisciplinariedad. También se llevó a cabo a lo largo de la explicación de la UD tanto un análisis de su contenido en los libros de texto como una breve comparación acerca del conocimiento de los principales problemas medioambientales relacionados con el entorno más cercano entre los dos grupos (el grupo de Ciencias y Tecnología y el grupo de Humanidades y Ciencias Sociales) a los que se impartió docencia. El análisis en los libros de texto estableció la importancia de realizar análisis previos (tanto dentro del mismo como con otros libros de texto) mientras que la comparación entre ambos grupos concluyó que los alumnos del grupo CT no presentaron mayor conocimiento que los del grupo HCS como hipotéticamente podría esperarse.

PALABRAS CLAVE: unidad didáctica, desarrollo sostenible, educación ambiental, uso de recursos y proceso de enseñanza-aprendizaje.

\begin{abstract}
The present document provides a methodological approach to work related content to sustainable development. The central axis around which was structured sequencing of the Teaching Unit (TU) was the use of resources and, consequently, the development model that exists today. During the course of several class sessions could be seen settling difficulties, as a result, both the need for a compromise between the use of school technology resources and traditional and the organization of an atmosphere of constant interaction and respect between teacher and students. The work begins with contextualization, justification and foundation of TU necessary to establish the importance of it, then explains the methodology and its components (objectives, evaluation criteria, contents, etc..) and ends with the mechanisms of attention to diversity, extracurricular activities chosen and interdisciplinarity. Also took place along the explanation of the TU as an analysis of it content in the textbooks as a brief comparison on the knowledge of key environmental issues associated with the immediate environment between the two groups (the Science and Technology group and the Humanities and Social Sciences group) which was held teaching. Analysis in textbooks established the importance of previous analyzes (both within the same as with other textbooks) while the comparison between the two groups concluded that the ST group students were no more knowledge than the HSS group as hypothetically could be expected.
\end{abstract}

KEYWORDS: teaching unit, sustainable development, environmental education, resource use and teaching-learning process. 



\section{INDICE}

Pág.

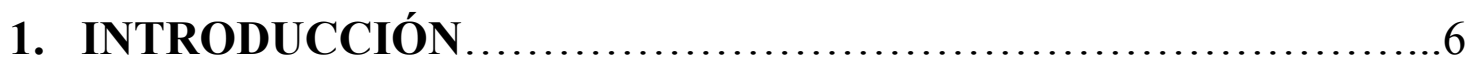

2. CONTEXTO NORMATIVO Y SOCIAL Y JUSTIFICACIÓN DE LA

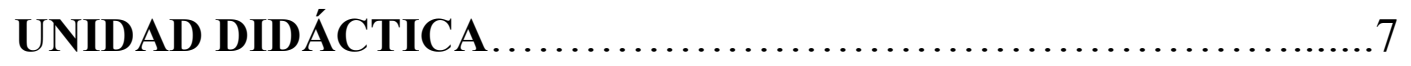

LA UNIDAD DIDÁCTICA EN EL MARCO NORMATIVO: NIVELES DE CONCRECIÓN CURRICULAR..................................... 7

LA UNIDAD DIDÁCTICA EN LA ASIGNATURA Y PLAN CURRICULAR DEL DEPARTAMENTO DE BIOLOGÍA Y GEOLOGÍA................................................. 8

2.1. MOTIVO DE LA ELECCIÓN Y FINALIDAD......................9

2.2. JUSTIFICACIÓN ATENDIENDO A LA LEGISLACIÓN VIGENTE....10

2.3. VIABILIDAD Y OPORTUNIDAD DE LA UNIDAD DIDÁCTICA....................................................11

2.4. RELACIÓN CON EL PROYECTO EDUCATIVO DE CENTRO.........11

2.5. CONTEXTUALIZACIÓN SOCIAL DE LA UNIDAD DIDÁCTICA...................................................

2.5.1. Curso al que va dirigida la Unidad Didáctica....................12

2.5.2. Características del centro y del alumnado.......................12

2.5.3. Duración.............................................. 14

3. ANÁLISIS DEL CONTENIDO DE LA UNIDAD DIDÁCTICA EN LOS LIBROS DE TEXTO .................................. 16

3.1. ANÁLISIS COMPARATIVO CON OTRAS UNIDADES DEL MISMO LIBRO DE TEXTO............................................16

3.2. ANÁLISIS COMPARATIVO CON OTROS LIBROS DE TEXTO.......17

4. FUNDAMENTACIÓN DE LA TEMÁTICA.........................20

4.1. FUNDAMENTOS TEÓRICOS ................................20

4.2. FUNDAMENTOS PEDAGÓGICOS Y DIDÁCTICOS................20

4.3. FUNDAMENTOS PSICOLÓGICOS.............................21 


\section{ESTRUCTURA Y ORGANIZACIÓN DE LA UNIDAD}

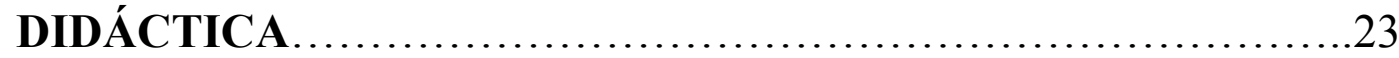

6. METODOLOGÍA DE LA UNIDAD DIDÁCTICA ..................29

7. BREVE COMPARACIÓN ENTRE EL GRUPO CT Y EL GRUPO

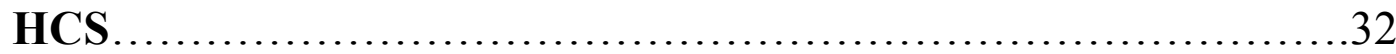

8. COMPONENTES DE LA UNIDAD DIDÁCTICA....................34

8.1. IDENTIFICACIÓN DE LOS ESTÁNDARES DE REFERENCIA......34

8.2. OBJETIVOS...................................................

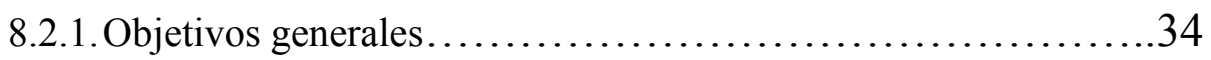

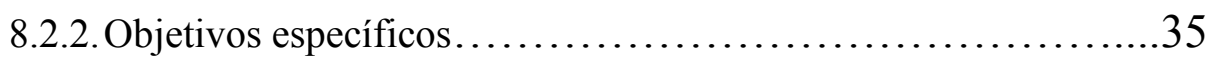

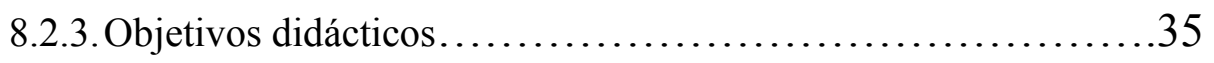

8.2.4. Identificación de objetivos didácticos con las competencias básicas y las inteligencias múltiples.............................. 36

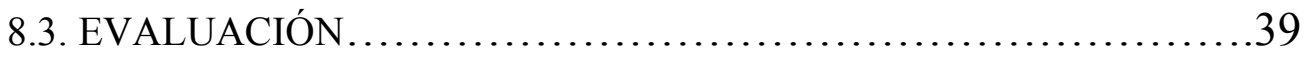

8.3.1. Criterios de evaluación................................41

8.3.1.1. Criterios de evaluación en la legislación............42

8.3.1.2. Criterios de evaluación de la Unidad Didáctica........42

8.3.2. Criterios de calificación...............................46

8.3.3. Procedimientos e instrumentos de evaluación................46

8.3.4. Tabla resumen de la evaluación..........................48

8.4. CONTENIDOS...........................................49

8.4.1. Contenidos en la legislación...........................49

8.4.2. Contenidos de la Unidad Didáctica........................49

8.4.3. Temas transversales..................................51

8.5. ACTIVIDADES Y TAREAS PROPUESTAS....................52

8.6. TABLA RESUMEN RELACIONANDO ACTIVIDADES, CONTENIDOS, OBJETIVOS, Y CRITERIOS DE EVALUACIÓN ENTRE SÍ Y CON LAS

COMPETENCIAS BÁSICAS................................58 
9. ATENCIÓN A LA DIVERSIDAD ............................60

10. ACTIVIDADES EXTRAESCOLARES Y

COMPLEMENTARIAS .....................................62

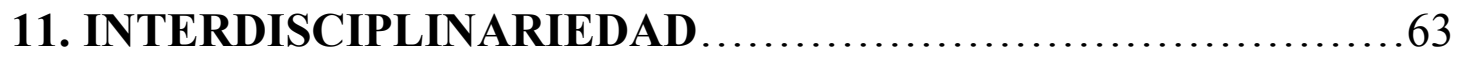

12. COMENTARIOS DIDÁCTICOS ..............................64

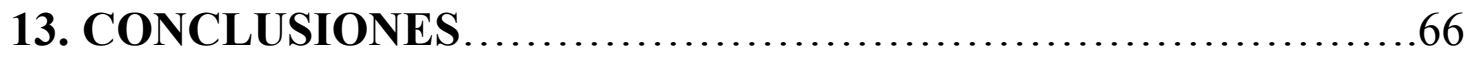

14. FUENTES Y REFERENCIAS BIBLIOGRÁFICAS .................69

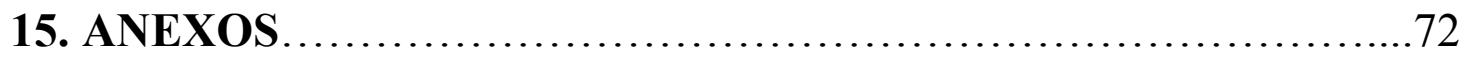

ANEXO I: objetivos generales de etapa del bachillerato...................72

ANEXO II: objetivos generales de etapa del bachillerato en Andalucía..........73

ANEXO III: objetivos específicos de la asignatura de Ciencias para el Mundo Contemporáneo dentro de $1^{\circ}$ de bachillerato ...........................74

ANEXO IV: objetivos específicos de la asignatura de Ciencias para el Mundo Contemporáneo dentro de $1^{\circ}$ de bachillerato en Andalucía....................75

ANEXO V: criterios de evaluación de la asignatura de Ciencias para el Mundo Contemporáneo en $1^{\circ}$ de bachillerato.................................76

ANEXO VI: criterios de evaluación de la asignatura de Ciencias para el Mundo Contemporáneo en $1^{\circ}$ de bachillerato en Andalucía...

ANEXO VII: contenidos de la asignatura de Ciencias para el Mundo Contemporáneo en $1^{\circ}$ de bachillerato.......................................... 78

ANEXO VIII: contenidos de la asignatura de Ciencias para el Mundo Contemporáneo en $1^{\circ}$ de bachillerato en Andalucía. .79

ANEXO IX: relación de actividades y tareas realizadas a lo largo de la UD.....80 


\section{INTRODUCCIÓN}

La elección de la temática de esta UD surgió a raíz de la problemática, cada vez mayor en la sociedad actual, del desarrollo sostenible y la cuestión de si la gestión que se está haciendo de los recursos es la adecuada o si, por el contrario, estamos comprometiendo de manera preocupante el futuro de las generaciones venideras. Este uso de los recursos naturales merece atención especial por varios motivos. En primer lugar por su interés científico, ya que el conocimiento de los equilibrios naturales en los ecosistemas así como los posibles impactos irreversibles que puedan existir como consecuencia de la utilización indiscriminada de los recursos naturales del planeta es tema de trabajo en gran cantidad de foros internacionales; en segundo lugar por presentar un interés tecnológico debido a que las posibilidades que pueden abrirse desde el desarrollo sostenible, pueden constituir la base de la nueva revolución tecnológica del siglo XXI; en tercer lugar por su notable interés social, ya que nuestras acciones en el entorno más próximo, derivadas tanto del consumo como de nuestro papel en la generación de residuos, transcienden a un ámbito mucho más amplio y, por último (y aunque no por ello menos importante), por su indiscutible interés didáctico. La sostenibilidad del planeta es un tema recurrente en todos los medios de comunicación, por lo que es más propicia y favorable al propio interés del alumnado. Además de ello, es un problema que invita a que los estudiantes dispongan de información, puedan analizarla, y adopten actitudes personales como ciudadanos.

Atendiendo a estos primeros interrogantes y puntos de partida se estructuró una UD en la que el eje central en torno al cual se iba a organizar dicha unidad fuese precisamente el uso de los recursos y, en consecuencia, el modelo de desarrollo existente en el mundo desarrollado en el que vivimos que es el que, en última instancia, determina el desarrollo a escala mundial. Para ello los primeros contenidos que se trabajaron en la UD estuvieron relacionados con los modelos de desarrollo existentes hoy en día y a partir de ahí se explicaron las diferentes consecuencias (pérdida de suelos, contaminación atmosférica, ocupación descontrolada del territorio, pérdida de biodiversidad, etc.) que se derivan de la gestión de los recursos realizada a partir del modelo de desarrollo que tenemos.

De esta manera, se pretendió que los alumnos y alumnas fuesen relacionando unos contenidos con otros y entendiesen la importancia de una adecuada gestión de los recursos capaz de asegurar un futuro sostenible y en equilibrio. 


\title{
2. CONTEXTO NORMATIVO Y SOCIAL Y JUSTIFICACIÓN DE LA UNIDAD DIDÁCTICA
}

\author{
LA UNIDAD DIDÁCTICA EN EL MARCO NORMATIVO: NIVELES DE \\ CONCRECION CURRICULAR
}

Los niveles de concreción curricular son los engranajes que unen y relacionan la legislación y las aulas donde se encuentra el alumnado. Estos niveles de concreción son básicamente tres. El Diseño Curricular Base conforma el primero de estos niveles y es el que se encarga de establecer, de forma general, los diferentes elementos curriculares. En segundo lugar, y concretando mas, se encuentra el nivel representado por el Proyecto de Centro, competencia de los equipos docentes que deben encargarse de acomodar dicho Diseño Curricular Base a las características de cada uno de los centros educativos y, en último lugar, se encuentra la Programación de Aula, tercer nivel encargado de concretar los convenios señalados en el Proyecto de Centro en cada uno de los departamentos didácticos para que puedan organizarse, entre otros aspectos, las diferentes programaciones didácticas de las distintas áreas.

En el Artículo 1. Principios generales del REAL DECRETO 1467/2007, de 2 de noviembre, por el que se establece la estructura del bachillerato y se fijan sus enseñanzas mínimas se establece que el bachillerato forma parte de la educación secundaria postobligatoria y que éste o bien ofrecerá al alumnado una preparación especializada acorde con sus perspectivas e intereses de formación o bien permitirá su incorporación, una vez terminado el mismo, a la vida laboral.

Asimismo en el Artículo 2. Fines se indica que la finalidad del bachillerato será proporcionar al alumnado habilidades y conocimientos responsables de su inserción en la vida activa con responsabilidad y competencia además de capacitarlo para acceder a la educación superior de forma responsable, competente y autónoma.

Con respecto a la comunidad autónoma andaluza, la ORDEN de 5 de agosto de 2008, por la que se desarrolla el currículo correspondiente al Bachillerato en Andalucía establece que según el Decreto 416/2008, de 22 de julio, los centros docentes en los que se imparte el bachillerato dispondrán de autonomía para desarrollar un proyecto educativo y de gestión propios, lo que permitirá formas de organización distintas para favorecer la mejora continua de la educación.

En el Artículo 2. Componentes del currículo de dicha orden se establece además que los contenidos propios de Andalucía versarán sobre el tratamiento de la realidad andaluza en diferentes aspectos (geográficos, económicos, sociales, históricos, culturales, científicos y de investigación) para conseguir una mejora de las competencias ciudadanas del alumnado y aportarle los conocimientos y habilidades necesarios para dicha incorporación a la vida activa y a la educación superior.

Asimismo, en el Artículo 3. Principios para el desarrollo de los contenidos se establecen los aspectos necesarios para que el alumnado adquiera las capacidades necesarias para estas incorporaciones. Algunos de estos aspectos son: en primer lugar el aprovechamiento de las diversas fuentes de información, cultura, ocio y estudio presentes en la sociedad del conocimiento, en segundo lugar la toma de conciencia sobre temas y problemas que 
afectan a todas las personas en un mundo globalizado, entre los que se considerarán... el agotamiento de los recursos naturales, la superpoblación, la contaminación, el calentamiento de la Tierra..., en tercer lugar el conocimiento de los procedimientos y de los temas científicos actuales y de las controversias que suscitan, así como la adquisición de actitudes de curiosidad, antidogmatismo y tolerancia y la conciencia de la necesidad de caminar hacia la sostenibilidad del planeta, en cuarto lugar el desarrollo de la capacidad comunicativa y discursiva en diferentes ámbitos... que permita consolidar los aprendizajes realizados por el alumnado en las etapas educativas anteriores y contribuir a su formación integral a través del respeto, el interés y la comunicación con otros hablantes... y, por último, el fomento de la actividad investigadora en el aula como fuente de conocimiento, con objeto de armonizar y conjugar los aprendizajes teóricos con los de carácter empírico y práctico.

\section{LA UNIDAD DIDÁCTICA EN LA ASIGNATURA Y PLAN CURRICULAR DEL DEPARTAMENTO DE BIOLOGÍA Y GEOLOGÍA}

El departamento de Biología y Geología es responsable de la docencia de las asignaturas de Ciencias para el Mundo Contemporáneo y Biología y Geología en el curso de $1^{\circ}$ de bachillerato (curso en el que se ha impartido la presente UD). Los contenidos de las asignaturas que trabaja dicho departamento deben estar orientados hacia la obtención de una visión racional del entorno en el que vivimos, necesaria para poder abordar problemas relacionados con la vida, la salud, el medio y las aplicaciones tecnológicas. Por tanto, la aplicación de dichos contenidos en las aulas debe proporcionar al alumnado un acercamiento realista al método científico y sus diferentes aplicaciones en el entorno de manera que se propicie un enfoque práctico y funcional de la ciencia.

La asignatura de Biología y Geología es una materia propia de la modalidad de Ciencias y Tecnología de $1^{\circ}$ de bachillerato, mientras que la asignatura de Ciencias para el Mundo Contemporáneo es una materia común a todas las modalidades dentro de dicho curso. Debido, por tanto, a que las características de los alumnos/as que cursan ambas asignaturas no son las mismas, éstas no pueden (ni deben) tener la misma estructuración ni los mismos fines.

Con respecto a la materia común de Ciencias para el Mundo Contemporáneo y como se especifica en el REAL DECRETO 1467/2007, los ciudadanos del siglo XXI pueden considerarse integrantes de la "sociedad del conocimiento" y, por tanto, además de tener derecho deben poseer una formación científica que les permita actuar como ciudadanos autónomos y críticos.

En base a ello, resulta imprescindible dotar a los ciudadanos de un saber y una cultura científica, comunes a todos, que propicien una adecuada toma de decisiones críticas y argumentadas acerca de temas de transcendencia social como los relacionados con la ciencia y la tecnología ya que es precisamente esta toma de decisiones a partir de unos conocimientos establecidos como suficientes lo que caracteriza a toda sociedad democrática.

Por ello, esta materia, común para todos los alumnos/as, debe responder a este objetivo de manera adecuada mediante varios mecanismos, ya sea proporcionando respuestas sobre estos temas científico-tecnológicos o aportando herramientas de búsqueda de información a la vez que se suministra una actitud crítica y selectiva frente a dicha información que les 
capacite para reconocer, por ejemplo, el rigor científico o las informaciones verdaderamente relevantes.

En base a todo ello, en este Real Decreto se establece que todos los elementos del currículo están dirigidos a intentar lograr tres grandes objetivos en esta materia: conocer algunos aspectos de los temas científicos actuales objeto de debate con sus implicaciones pluridisciplinares y ser consciente de las controversias que suscitan; familiarizarse con algunos aspectos de la naturaleza de la ciencia y el uso de los procedimientos más comunes que se utilizan para abordar su conocimiento; y, por último, adquirir actitudes de curiosidad, antidogmatismo, tolerancia y tendencia a fundamentar las afirmaciones y las refutaciones.

\subsection{MOTIVO DE LA ELECCIÓN Y FINALIDAD}

El desarrollo sostenible es un concepto de suma importancia hoy en día. En que medios de comunicación no nos encontramos diaria e ininterrumpidamente noticias o artículos alusivos a dicho concepto: desde el problema demográfico existente hoy en día o el uso abusivo e irresponsable de los recursos hasta las pautas de lo que debería ser una gestión sostenible del planeta. A menudo escuchamos noticias sobre desastres naturales acaecidos en lugares totalmente distantes de la Tierra y nos preguntamos constantemente el por qué de dichos acontecimientos destructivos sin pararnos a pensar en el papel que juega nuestra actitud ante tales hechos.

La temática de la presente UD versa precisamente sobre dicho concepto de desarrollo sostenible además de otros aspectos íntimamente ligados con el mismo. Entre dichos aspectos destacan la explosión demográfica, la sostenibilidad, la pérdida de suelo, la contaminación del aire, la ocupación del territorio, la pérdida de biodiversidad, el consumo insostenible, etc.

Muy relacionado con el concepto de desarrollo sostenible está el concepto de educación ambiental. La educación ambiental o E.A. (García, 2002) es un ámbito de pensamiento y acción en el que predomina la heterogeneidad y el debate; la diversidad de paradigmas teóricos, de estrategias de actuación, de practicantes y de escenarios... la E.A. pretende propiciar un cambio del pensamiento y de la conducta de las personas (consideradas individualmente) y de los grupos sociales.

La educación ambiental, por tanto, no debe entenderse como una materia en sí misma sino como una manera de entender y funcionar en el mundo. En relación a ello se deben proporcionar a los alumnos y alumnas todos los recursos necesarios para que entiendan y predigan las causas y consecuencias derivadas de la interacción ser humano-ambiente, ya que solo de esta manera serán capaces de evaluar las acciones negativas de dicha interacción y proponer alternativas que consigan una adecuada recuperación, conservación y mejora del medio ambiente que nos rodea.

Con respecto a la metodología de la educación ambiental, se han definido una serie de principios básicos que la orientan (Novo, 1998): la centralidad del sujeto que aprende haciendo, la comprensión del aprendizaje como proceso, la capacidad de relacionar e integrar el conocimiento del todo y las partes, vincular el pensamiento global a la acción local, contextualizar la educación transformando la escuela en "laboratorio territorial", basar la estrategia metodológica docente en la investigación-acción, orientar el proceso 
educativo hacia la resolución de problemas, favorecer el desarrollo de la creatividad, enseñar a decidir, elaborar alternativas $\mathrm{y}$ anticipar escenarios futuros $\mathrm{y}$ desarrollar modalidades diversas de representación de la realidad y conceptos.

Por otro lado, la Educación Ambiental para el Desarrollo Sostenible (EADS) viene teniendo en los últimos años una importancia creciente y relevante en el marco de la Educación Ambiental. Esta EADS (Gutiérrez y Pozo, 2006) debe ser una educación con vocación de encaminarse hacia la integración del desarrollo humano y promover una progresiva reconciliación con el medio ambiente (tan diezmada en los últimos tiempos).

La materia disciplinar anterior a esta EADS y encargada del estudio de las interacciones en el medio natural es la ecología, no obstante, podríamos decir que la ecología ha olvidado la dimensión social tan importante de su cometido. Según Beck (1998), la ecología ha olvidado a la sociedad del mismo modo que la ciencia y teorías sociales lo han hecho con la ecología, estableciéndose dos territorios que se desprecian mutuamente.

Y es precisamente esta ruptura la que ha hecho que desde el campo de las preocupaciones ambientales se haya olvidado la dimensión social y humana, tan importante para el necesario cambio conceptual y mental sobre el ámbito ambiental. El mundo ambiental no debería ser entendido separado de las dimensiones social y natural y, sin embargo, parece que en los últimos años esta dimensión social ha sido relegada al olvido.

En esta senda, por tanto, es necesaria una nueva revisión y reconceptualización que conlleve un cambio social y ambiental, posibilitando su incursión en una nueva disciplina capaz de entender los pensamientos, sentimientos y actuaciones de las personas frente al ambiente. Y es, precisamente en este sentido, donde la EADS debe aportar nuevas estrategias metodológicas y didácticas capaces de posibilitar la formación de personas que sepan hacer frente al mundo tan cambiante que nos ha tocado vivir, con nuevas y más renovadas perspectivas medioambientales. Es necesario, por tanto cambios, tanto en la dimensión social como en la ambiental, en los que la educación es primordial.

\subsection{JUSTIFICACIÓN ATENDIENDO A LA LEGISLACIÓN VIGENTE}

El que la asignatura de Ciencias para el Mundo Contemporáneo sea una materia común alude al hecho no solo de la cantidad de información que existe hoy en día en los medios de comunicación acerca de temas científicos y tecnológicos de marcada transcendencia sino al espectacular incremento que ha experimentado la humanidad (sobre todo en el siglo XX pasado) no solo en cuanto a conocimiento e información tecnológicos-científicos sino, y lo que es aún más importante, a la aplicación práctica de dichos conocimientos en la vida cotidiana.

Una vez siendo conscientes de estas consideraciones, se hace necesario dotar a los ciudadanos de esa cultura científica imprescindible mencionada en el Real Decreto 1467/2007, un conocimiento que debería ser común y compartido por todos. La concreción de esta idea en las aulas se hace (según establece el Real Decreto) mediante la estructuración de una serie de contenidos (relacionados con la información y la comunicación, la salud como resultado de factores ambientales y responsabilidad personal o la necesidad de caminar hacia la sostenibilidad del planeta) que no solo resultan de gran interés a la sociedad sino que pueden enfocarse de diversas maneras dotando de una mayor divulgación, universalidad y sentido práctico para la vida a esta asignatura. 
Cuando nos centramos en los contenidos relacionados con el desarrollo sostenible, establecidos como mínimos en este Real Decreto, nos percatamos de que se destina todo un bloque (Hacia una gestión sostenible del planeta) a los mismos, aspecto que da una idea de la importancia que se le ha dado en los últimos tiempos a mantener una actitud de respeto y tolerancia capaz de posibilitar la existencia de todos en un mundo sustentable. Entre estos contenidos se encuentran La sobreexplotación de los recursos: aire, agua, suelo, seres vivos..., Los impactos: la contaminación, la desertización, el aumento de residuos y la pérdida de biodiversidad..., El problema del crecimiento ilimitado en un planeta limitad... o Los compromisos internacionales y la responsabilidad ciudadana, todos ellos tratados en esta UD.

Si atendemos a la Orden de Andalucía, estos contenidos se establecen a lo largo de cuatro núcleos temáticos. De dichos núcleos, uno de ellos (¿Es sostenible nuestro desarrollo?) es el que se relaciona de forma directa con esta UD y en él aparecen las siguientes cuestiones: ¿de qué factores depende la sostenibilidad?, ¿qué efectos está produciendo nuestro modelo de desarrollo en el medio físico y en los organismos?, ¿cómo pueden corregirse los efectos negativos?, ¿qué características debe cumplir un modelo de desarrollo para que sea sostenible?. Todas estas preguntas clave también fueron tratadas en la UD.

\subsection{VIABILIDAD Y OPORTUNIDAD DE LA UNIDAD DIDÁCTICA}

El concepto de desarrollo sostenible hoy en día es bastante accesible a la sociedad, y más en concreto, al alumnado. Gran parte de este aspecto está relacionado con el hecho de que los alumnos/as de hoy en día han crecido y aprendido en la denominada "sociedad del conocimiento". Todos los días nos encontramos frente a noticias en los medios de comunicación de masas relacionadas con el mal uso y gestión, desde una perspectiva muy poco sostenible, de los recursos que disponemos. Todo ello indica que esta temática presenta un indiscutible e importantísimo interés didáctico, ya que es necesario hacerles llegar a los alumnos y alumnas (también ciudadanos) unas bases y pilares educativos que les hagan ser capaces de responder, de manera coherente, fundamentada y crítica, a la cantidad de información que día a día se les presenta, aprendiendo a identificar en la misma cuanto de realidad, relevancia y rigor tecnológico, científico y social existe.

En relación con estos datos y concretando en la UD que se ha impartido puede concluirse que esta ha sido viable, se ha podido llevar a cabo sin ningún problema.

Además, y con respecto a la oportunidad de la misma, podría considerarse que tal vez nos encontremos ante uno de los momentos más oportunos y propicios desde que empezó a hablarse de los conceptos de desarrollo sostenible, educación ambiental o educación ambiental para el desarrollo sostenible para trabajar en una UD de estas características.

\subsection{RELACION CON EL PROYECTO EDUCATIVO DE CENTRO}

En el Capítulo 1 del Proyecto Educativo de Centro (PEC) del Instituto perteneciente a los Objetivos generales del centro se establecen algunos objetivos orientados a promover la formación integral del alumnado, su continuidad en el sistema educativo y a mejorar los resultados académicos.

Esta UD contribuye también a algunos de estos objetivos establecidos en el PEC. En primer lugar, en dicho PEC se establece como objetivo el Fomento de la cultura del respeto hacia 
las personas y las cosas..., con la presente UD se ha pretendido, de igual forma, que los alumnos/as desarrollasen una actitud de respeto hacia su entorno más cercano. En base a esto, se han fomentando valores como la responsabilidad, el esfuerzo o la tolerancia para alcanzar la formación integral y crítica del alumnado.

El Perfeccionamiento de la lectura y expresión oral también es uno de los objetivos generales establecidos en el PEC que se han trabajado activamente durante el desarrollo de la UD mediante la lectura en todas las sesiones de fragmentos del libro de texto y posterior extracción de las principales ideas del extracto leído y mediante la expresión oral en actividades como debates y exposiciones de trabajos.

Otro de los objetivos que se han trabajado de manera específica en la UD ha sido el Uso de las TIC como apoyo para la comprensión de los procesos de aprendizaje. El alumnado ha realizado durante el transcurso de la UD varias actividades consistentes en la búsqueda de información mediante las TIC además de tener que realizar un informe científico en el que las TIC han sido su principal fuente de conocimientos.

Además de ello, una línea de actuación establecida en el PEC es La práctica habitual de la solidaridad y la tolerancia en actividades de grupo para propiciar actitudes dialogantes y constructivas basadas en la aceptación crítica de puntos de vista divergentes y en el rechazo de discriminaciones por razón de raza, sexo, clase social, creencias, y otras características individuales y sociales. Para reforzar dicha línea de actuación los alumnos y alumnas han tenido que trabajar en grupos en la elaboración de un informe científico (como se ha mencionado anteriormente). Durante la elaboración de dicho informe han tenido que mantener una actitud dialogante y de respeto hacia el resto de los compañeros que componían el grupo de trabajo necesarias para la realización de una correcta tarea conjunta.

\subsection{CONTEXTUALIZACIÓN SOCIAL DE LA UNIDAD DIDÁCTICA}

\subsubsection{CURSO AL QUE VA DIRIGIDA LA UNIDAD DIDÁCTICA}

La UD va dirigida al curso de $1^{\circ}$ de bachillerato dentro de la asignatura de Ciencias para el Mundo contemporáneo que se imparte como asignatura obligatoria en dicho curso.

\subsubsection{CARACTERÍSTICAS DEL CENTRO Y DEL ALUMNADO}

El centro en el que se ha impartido la docencia de la UD ha sido el Instituto de Enseñanza Secundaria Padre Manjón. Dicho Instituto está situado en la zona centro de la ciudad y según datos de enero de 2011, un tercio del alumnado vive a menos de un kilómetro de distancia del mismo, un $24 \%$ a una distancia entre uno y dos kilómetros y el resto a más de dos kilómetros.

Con respecto a la organización y funcionamiento del I.E.S, el horario de apertura y cierre por la mañana es desde 07.45-15.00 horas y por la tarde-noche desde 16.00 a 22.40. Además de ello, en el centro existe un servicio de guardias del profesorado, tanto durante las horas de clase como durante los recreos. En el caso del profesorado de guardia durante las horas de clase, su cometido es velar por el cumplimiento del normal desarrollo de las actividades docentes y no docentes mientras que si la guardia es durante los períodos de recreo su labor es velar por el normal desarrollo de las actividades en este tiempo, dedicando una mayor atención al alumnado de los primeros cursos de la ESO. 
Los objetivos generales que el Instituto tiene propuestos son los siguientes:

- Fomento de la cultura del respeto hacia las personas y las cosas, así como la concienciación y sensibilización de la Comunidad Educativa sobre la importancia de una adecuada convivencia escolar y sobre los procedimientos para mejorarla.

- Perfeccionamiento de la lectura, expresión oral y el cálculo.

- Uso de las TIC como apoyo para la comprensión de los procesos de aprendizaje.

- Progreso en el aprendizaje de idiomas como medio de promoción del alumnado.

- Mejora de los resultados de las Pruebas de Diagnóstico y PAU.

- Aumento de la satisfacción de las familias en cuanto al desarrollo integral del alumnado.

- Mayor implicación de las familias en el proceso educativo de sus hijos/as.

- Mejora en la organización y funcionamiento del centro: trabajo del profesorado en equipo a través de los órganos de coordinación docente y optimización de los recursos humanos y materiales del centro.

- Respecto a la Formación Profesional Inicial: formación sólida adaptable a una realidad productiva en continuo cambio y adecuada al entorno.

- Disminución del absentismo escolar.

Con respecto a la convivencia escolar en el centro, esta ha sido razonablemente buena en los últimos años, no produciéndose incidentes de especial gravedad, excepto casos puntuales de acusaciones e insultos a través de las redes sociales, algunas sustracciones de dinero, libros, móviles o deterioros en aulas y en servicios. Sin embargo, un análisis de los hechos lleva a la conclusión de que la situación de convivencia en el Instituto es más que aceptable a rasgos generales.

En relación con los recursos materiales y personales existentes en el centro, dentro de los recursos materiales existen además de las aulas ordinarias aulas específicas como el salón de actos, la sala de usos múltiples, la biblioteca, varias aulas de informática y algunas aulas TIC y de tecnología. Además de ello, existen aulas ordinarias dotadas de cañones de proyección y mesas-carro con cañones de proyección y portátiles.

En relación a los recursos personales, dentro de los órganos de gobierno están el equipo directivo constituido por un director y una vicedirectora, una secretaria, un jefe de estudios del diurno y otra jefa de estudios del nocturno y dos jefes de estudios adjuntos y el consejo escolar constituido por un presidente, el jefe de estudios del diurno y la del nocturno, la secretaria, ocho profesores, dos madres y tres padres, cuatro alumnas y un alumno, un representante del P.A.S y un representante del ayuntamiento. Hay dieciocho departamentos didácticos que componen el claustro de profesores; el de biología y geología con siete profesores/as, el de dibujo con dos, el de economía con dos, el de educación física con tres, el de filosofía con cuatro, el de física y química con siete, el de francés con tres, el de geografía e historia con ocho, el de griego con uno, el de inglés con diez, el de latín con dos, el de lengua y literatura con siete, el de matemáticas con ocho, el 
de música con uno, el de orientación con tres, el de religión con una y el de tecnología con tres. La biblioteca también tiene una persona a su cargo.

El centro además participa activamente en algunos programas especiales como programas de bilingüismo, un programa TIC, el plan "El Deporte en la Escuela" y el "Plan de Igualdad entre Hombres y Mujeres en Educación".

Las familias de los alumnos/as pertenecen a la clase media-alta con niveles de estudios elevados, siendo el $45 \%$ licenciados y el $12 \%$ diplomados. La mayoría (41\%) ejercen como funcionarios; destacando también el empresariado autónomo (19\%) y los empleados por cuenta ajena $(19 \%)$.

En general, las familias presentan grandes expectativas con respecto a la continuidad de sus hijos/as en estudios post-obligatorios y universitarios (89\%). La mayoría del alumnado $(75 \%)$ procede de familia tradicional biparental.

Las edades del alumnado, exceptuando el adulto, oscilan entre 12 y 18 años, tratándose, por tanto, de alumnos y alumnas adolescentes. La adolescencia es una etapa de sus vidas en la que se producen cambios importantes a nivel físico, fisiológico y psicológico. Debido a que en esta etapa las estructuras mentales del alumnado cambian de un pensamiento concreto a otro abstracto o formal, y a que dicho cambio no se produce de igual forma en todos los casos, es sobre todo en estos cursos (ESO y bachillerato) en los que aumenta de manera más evidente la heterogeneidad dentro del aula. La incidencia de alumnado inmigrante no es significativa (observándose una presencia más notable de estos alumnos/as en la educación secundaria obligatoria). En relación a la ratio existente por aula, esta oscila en torno a 30 alumnos/as.

En concreto, el alumnado (de $1^{\circ}$ de bachillerato) con el que se ha trabajado esta UD ha mostrado una actitud colaboradora y activa hacia las explicaciones realizadas en clase, demostrando en su comportamiento una mayor madurez y responsabilidad que los grupos de ESO, siendo los principales valores que han caracterizado a estos alumnos/as la tolerancia entre ellos y la responsabilidad ante la realización y entrega de tareas.

El alumnado que accede a las enseñanzas que se imparten en horario de tarde, adultos, ciclos formativos y PCPI vive en su mayoría (55\%), en el extrarradio y pueblos del cinturón de Granada, el 27\% reside a menos de un kilómetro de distancia del Centro de la ciudad. Las expectativas académicas de los padres y madres son: que sus hijos/as acaben un grado universitario $(61 \%)$ y que finalicen un ciclo formativo (31\%). En relación con los hijos/as, el 48\% optan por un título de Formación Profesional mientras que el $45 \%$ quieren acabar un grado universitario. El 47\% de los alumnos/as tiene más de 22 años, solamente el $6 \%$ es menor de edad (en su mayoría alumnado de conservatorio y deportistas de alto rendimiento). Y con respecto a la realización de otras actividades, el $36 \%$ de los alumnos/as tiene que compaginar trabajo y estudios, habiendo tenido (44\%), en algún momento una interrupción en sus estudios, lo que, como es lógico, repercute en los resultados académicos. El 87\% tiene ordenador con acceso a Internet. 


\subsubsection{DURACIÓN}

La duración de la UD ha sido de nueve sesiones de clase (incluyendo la sesión destinada al examen). No obstante, la última de la sesiones de realización de una actividad extraescolar no pudo llevarse a cabo como se comentará más avanzado el trabajo.

En cada una de dichas sesiones se contó aproximadamente con 50 minutos de tiempo. La secuenciación de cada una de las sesiones se detallará también posteriormente. 


\section{ANÁLISIS DEL CONTENIDO DE LA UNIDAD DIDÁCTICA EN LOS LIBROS DE TEXTO}

\subsection{ANÁLISIS COMPARATIVO CON OTRAS UNIDADES DEL MISMO LIBRO DE TEXTO}

El REAL DECRETO 1467/2007 establece como contenidos mínimos relacionados con la temática de esta UD los siguientes:

Bloque 4. Hacia una gestión sostenible del planeta:

- La sobreexplotación de los recursos: aire, agua, suelo, seres vivos y fuentes de energía. El agua como recurso limitado.

- Los impactos: la contaminación, la desertización, el aumento de residuos y la pérdida de biodiversidad. El cambio climático.

- Los riesgos naturales. Las catástrofes más frecuentes. Factores que incrementan los riesgos.

- El problema del crecimiento ilimitado en un planeta limitado. Principios generales de sostenibilidad económica, ecológica y social. Los compromisos internacionales y la responsabilidad ciudadana.

Por otro lado y atendiendo a las aportaciones específicas para la Comunidad Autónoma andaluza desarrolladas en la ORDEN de 5 de agosto de 2008, los núcleos temáticos (dentro de los que se engloban los contenidos equivalentes a los anteriormente establecidos en el Real Decreto) son los siguientes:

- Núcleo 4. ¿Es inevitable el cambio climático?

- Núcleo 5. ¿Qué riesgos naturales son los que más nos pueden afectar?

- Núcleo 6. La crisis energética y cómo afrontarla.

- Núcleo 7. ¿Es sostenible nuestro desarrollo?

En relación a estos contenidos establecidos como mínimos en el Real Decreto y en la Orden de Andalucía y relacionados con el desarrollo sostenible (tema central de dicha UD), los temas que presentan contenidos vinculados con este (tema 11 del libro de texto) situados en dicho libro son los siguientes:

- Tema 7: El cambio climático ya está aquí.

En este tema se encuentran los contenidos pertenecientes al cambio climático. De manera general se encuentran en dicho tema los contenidos especificados como mínimos en el Real Decreto (El cambio climático) y en la Orden en la que se establece el currículo correspondiente al bachillerato en Andalucía. No obstante, faltan, según los contenidos establecidos en el núcleo temático 4 (¿Es inevitable el cambio climático?), algunos contenidos especificados en dicha Orden, como son los que aluden a si las consecuencias del cambio climático afectarán al área mediterránea y, más concretamente, a Andalucía. 


\section{- Tema 8: ¿Son naturales las catástrofes?}

Dicho tema recoge los contenidos establecidos como mínimos tanto en el Real Decreto (Riesgos naturales, Catástrofes más frecuentes y Factores que incrementan los riesgos) como en la Orden de Andalucía (¿qué catástrofes naturales se producen?, ¿qué procesos naturales las originan?, ¿cómo se distribuyen geográficamente y por qué lo hacen así?, ¿pueden predecirse?, ¿pueden prevenirse?, ¿hay actuaciones humanas que influyen?, ¿cómo reducir los efectos catastróficos de los procesos naturales?) no obstante, algunas de estas preguntas no se especifican para todas las catástrofes explicadas en el libro.

\section{- Tema 9: La energía y el problema energético}

Se recogen los contenidos establecidos como imprescindibles en el Real Decreto ( $L a$ sobreexplotación de recursos como fuentes de energía), sin embargo algunos de las preguntas clave en torno a las que se puede estructurar el desarrollo de los contenidos mínimos establecidos en la Orden de Andalucía faltan (¿cuánto nos cuesta poder usar la energía? o ¿crees que los edificios de zonas rurales o de ocio de Andalucía tiene alguna relación con el clima?).

- Tema 10: ¿Hay agua para todos?

Los contenidos pertenecientes al impacto y sostenibilidad del consumo de agua no se establecen de manera específica en ningún núcleo temático en la Orden de Andalucía, no obstante, el Real Decreto si establece contenidos específicos relacionados con el agua ( $L a$ sobreexplotación de recursos como el agua y El agua como recurso limitado) que se tratan en este tema.

En base a este análisis individual de los temas que albergan contenidos relacionados con la temática de desarrollo sostenible, puede establecerse que en este libro de texto existe, al menos, una relación entre los contenidos de algunas de las unidades o temas que lo forman propiciándose una interrelación y consecución entre los mismos así como una complementación de unos con otros conforme se avanza en el número de temas trabajados, requisito indispensable para propiciar en el alumnado un adecuado y significativo proceso de enseñanza-aprendizaje.

\subsection{ANÁLISIS COMPARATIVO CON OTROS LIBROS DE TEXTO}

Además del análisis dentro del mismo libro de texto se va a realizar un análisis entre diferentes libros debido a que la temática relacionada con el desarrollo sostenible no se trata exactamente igual en todo los libros de texto de Ciencias para el Mundo Contemporáneo de $1^{\mathrm{o}}$ de bachillerato.

En este caso se van a analizar tres aspectos en cuatro libros de texto de diferentes editoriales (incluido el utilizado para la explicación de la UD): principales contenidos trabajados, rango más o menos amplio de dichos contenidos y enmarcación en uno u otro modelo de desarrollo. 
Al igual que para el caso del análisis dentro del mismo libro y atendiendo tanto al Real Decreto como a la Orden de Andalucía se ha elaborado una tabla (Tabla 1) de doble entrada en la que se recogen tanto los libros de texto como los diferentes aspectos analizados en los mismos:

\begin{tabular}{|c|c|c|c|c|c|}
\hline & & $\begin{array}{c}\text { Libro } \\
\text { editorial } \\
\text { SM } \\
\text { (libro con el } \\
\text { que se } \\
\text { impartió la } \\
\text { UD) }\end{array}$ & $\begin{array}{c}\text { Libro } \\
\text { editorial } \\
\text { Vicens } \\
\text { Vives }\end{array}$ & $\begin{array}{c}\text { Libro } \\
\text { editorial } \\
\text { ANAYA }\end{array}$ & $\begin{array}{c}\text { Libro } \\
\text { editorial } \\
\text { Bruño }\end{array}$ \\
\hline \multirow[t]{14}{*}{$\begin{array}{l}\text { Principales } \\
\text { contenidos }\end{array}$} & $\begin{array}{l}\text { Factores de los que } \\
\text { depende la sostenibilidad }\end{array}$ & $\mathrm{X}$ & $\mathrm{X}$ & $\mathrm{X}$ & \\
\hline & $\begin{array}{l}\text { Efectos de nuestro modelo } \\
\text { de desarrollo }\end{array}$ & $\mathrm{X}$ & $\mathrm{X}$ & & $\mathrm{X}$ \\
\hline & $\begin{array}{l}\text { Características que hacen } \\
\text { a un modelo de desarrollo } \\
\text { sostenible }\end{array}$ & $\mathrm{X}$ & $\mathrm{X}$ & $\mathrm{X}$ & $\mathrm{X}$ \\
\hline & Sobreexplotación del aire & $\mathrm{X}$ & $\mathrm{X}$ & $\mathrm{X}$ & $\mathrm{X}$ \\
\hline & Sobreexplotación del agua & $\mathrm{X}$ & $\mathrm{X}$ & $\mathrm{X}$ & $\mathrm{X}$ \\
\hline & $\begin{array}{l}\text { El agua como recurso } \\
\text { limitado }\end{array}$ & $\mathrm{X}$ & $\mathrm{X}$ & $\mathrm{X}$ & $\mathrm{X}$ \\
\hline & $\begin{array}{l}\text { Sobreexplotación del } \\
\text { suelo }\end{array}$ & $\mathrm{X}$ & $\mathrm{X}$ & $\mathrm{X}$ & $\mathrm{X}$ \\
\hline & $\begin{array}{l}\text { Sobreexplotación de los } \\
\text { seres vivos }\end{array}$ & & $\mathrm{X}$ & $\mathrm{X}$ & $\mathrm{X}$ \\
\hline & $\begin{array}{l}\text { La pérdida } \\
\text { biodiversidad }\end{array}$ & $\mathrm{X}$ & $\mathrm{X}$ & $\mathrm{X}$ & $\mathrm{X}$ \\
\hline & $\begin{array}{l}\text { Sobreexplotación fuentes } \\
\text { de energía }\end{array}$ & $\mathrm{X}$ & $\mathrm{X}$ & $\mathrm{X}$ & $\mathrm{X}$ \\
\hline & La contaminación & $\mathrm{X}$ & $\mathrm{X}$ & $\mathrm{X}$ & $\mathrm{X}$ \\
\hline & La desertización & $\mathrm{X}$ & $\mathrm{X}$ & $\mathrm{X}$ & $\mathrm{X}$ \\
\hline & El aumento de residuos & $\mathrm{X}$ & $\mathrm{X}$ & $\mathrm{X}$ & $\mathrm{X}$ \\
\hline & Cambio climático & $\mathrm{X}$ & $\mathrm{X}$ & $\mathrm{X}$ & $\mathrm{X}$ \\
\hline
\end{tabular}




\begin{tabular}{|c|c|c|c|c|c|}
\hline & Los riesgos naturales & $\mathrm{X}$ & $X$ & $\mathrm{X}$ & $\mathrm{X}$ \\
\hline & $\begin{array}{l}\text { Factores que aumentan los } \\
\text { riesgos }\end{array}$ & $\mathrm{X}$ & $\mathrm{X}$ & $\mathrm{X}$ & $\mathrm{X}$ \\
\hline & Las catástrofes & $X$ & $X$ & $\mathrm{X}$ & $\mathrm{X}$ \\
\hline & Crecimiento ilimitado & $\mathrm{X}$ & $\mathrm{X}$ & & $\mathrm{X}$ \\
\hline & $\begin{array}{l}\text { Principios generales de } \\
\text { sostenibilidad }\end{array}$ & $\mathrm{X}$ & $\mathrm{X}$ & & $X$ \\
\hline & $\begin{array}{l}\text { Los compromisos } \\
\text { internacionales }\end{array}$ & $\mathrm{X}$ & $\mathrm{X}$ & $\mathrm{X}$ & $\mathrm{X}$ \\
\hline & $\begin{array}{l}\text { La responsabilidad } \\
\text { ciudadana }\end{array}$ & $\mathrm{X}$ & $\mathrm{X}$ & & $X$ \\
\hline Extensión del r & ango de contenidos & $\begin{array}{l}\text { Rango } \\
\text { medio- } \\
\text { extenso }\end{array}$ & $\begin{array}{l}\text { Rango } \\
\text { extenso }\end{array}$ & $\begin{array}{l}\text { Rango } \\
\text { medio- } \\
\text { bajo }\end{array}$ & $\begin{array}{l}\text { Rango } \\
\text { medio- } \\
\text { extenso }\end{array}$ \\
\hline $\begin{array}{l}\text { Enmarcación } \\
\text { desarrollo }\end{array}$ & en un modelo de & Sostenible & Sostenible & Sostenible & Sostenible \\
\hline
\end{tabular}

Tabla 1. Relación libros/aspectos analizados.

En base a los datos obtenidos a partir de la tabla anterior puede concluirse que existen diferencias en cuanto a los principales contenidos trabajados en cada uno de los libros de texto y establecidos como mínimos tanto en el Real Decreto como en la Orden de Andalucía y, por consiguiente, en la extensión del rango de conceptos.

El libro que presenta una mayor extensión en cuanto al rango de contenidos es el de la editorial Vicens Vives, presentando todos los contenidos establecidos como mínimos en la legislación. Los libros de las editoriales SM y Bruño presentan un rango muy similar (aunque inferior al del libro de la editorial Vicens Vives). En el de la editorial SM falta el epígrafe de la sobreexplotación de los seres vivos como recurso, mientras que en el de la editorial Bruño falta el epígrafe de factores de los que depende la sostenibilidad. Por último, el libro que menor número de contenidos trabaja es el de la editorial ANAYA, en él faltan los epígrafes: efectos de nuestro modelo de desarrollo, crecimiento ilimitado, principios generales de sostenibilidad y, por último, responsabilidad ciudadana. 


\section{FUNDAMENTACIÓN DE LA TEMÁTICA}

\subsection{FUNDAMENTOS TEÓRICOS}

En los reales decretos se enmarca la temática de la UD dentro de la asignatura de Ciencias para el Mundo Contemporáneo, asignatura común (no exclusiva de grupos de ciencias) impartida en $1^{\circ}$ de bachillerato.

En el REAL DECRETO 1467/2007 aparece dentro de los contenidos de $1^{\circ}$ de Bachillerato para la asignatura de Ciencias para el Mundo Contemporáneo el Bloque 4: Hacia una gestión sostenible del planeta (cuyos contenidos se han mencionado en el apartado anterior). Dentro de este bloque se incluyen contenidos como la sobreexplotación de los recursos, los impactos ambientales como la desertización, el aumento de los residuos o la pérdida de biodiversidad. También se establecen como contenidos mínimos para este bloque los pertenecientes al cambio climático. Otro apartado dentro de dicho bloque es el perteneciente a los riesgos naturales y los factores que incrementan dichos riesgos. Por último, se establece dentro de este bloque un apartado destinado a la problemática del crecimiento ilimitado en un planeta caracterizado por ser limitado, estableciéndose además como contenidos dentro de este bloque los principios generales de sostenibilidad económica, ecológica y social $\mathrm{y}$, por último, los compromisos internacionales y la responsabilidad ciudadana.

En relación a los objetivos específicos relacionados explícitamente con esta UD establecidos en este Real Decreto cabe destacar el objetivo $\mathrm{n}^{\circ}$ 5: Argumentar, debatir $y$ evaluar propuestas y aplicaciones de los conocimientos científicos de interés social relativos a la salud, el medio ambiente, los materiales, las fuentes de energía, el ocio, etc., para poder valorar las informaciones científicas y tecnológicas de los medios de comunicación de masas y adquirir independencia de criterio así como el objetivo $\mathrm{n}^{\mathrm{o}} 6$ : Poner en práctica actitudes y valores sociales como la creatividad, la curiosidad, el antidogmatismo, la reflexión critica y la sensibilidad ante la vida y el medio ambiente, que son útiles para el avance personal, las relaciones interpersonales y la inserción social.

Ambos objetivos muestran claramente las expectativas que se pretenden para con el alumnado de $1^{\circ}$ de bachillerato en esta asignatura, centrándose estas en la valoración de la información que aparece en los medios de comunicación para llegar a formarse opiniones críticas y consecuentes con la realidad. Además de este enfoque autocrítico y fundamentado en hechos que establece el Real Decreto se establece con el objetivo $n^{\circ} 6$ otra dimensión relacionada con la sensibilización como una de las actitudes fundamentales a llevar a cabo por el alumno tanto ante la vida como ante el propio medio ambiente, relacionada necesariamente con un mayor desarrollo personal y que posibilite su adecuada inserción en la sociedad actual.

\subsection{FUNDAMENTOS PEDAGÓGICOS Y DIDÁCTICOS}

Actualmente nos encontramos inmersos en lo que se ha venido denominando en numerosos medios como "la sociedad del consumo" (comentada anteriormente), una sociedad en la que la riqueza y el nivel de las personas se miden por aquello que compran, aquellos 
recursos que consumen. Estableciéndose una espiral caótica de consumo frenético en la que se nos exige que cambiemos nuestras pertenencias lo antes posible.

Este período de crisis civilizatoria y cultural de la modernidad tecno-desarrollista y consumista (Ángel, 1995; Caride y Meira, 2001; Leff, 2002) está asociada a los procesos de globalización que se han venido desarrollando de forma masiva en los últimos años a lo largo del mundo.

Toda esta vorágine de consumismo materialista requiere de una intervención desde el mundo educativo, una intervención desde una perspectiva del consumo sostenible que conciencie al alumnado de la importancia de mantener una actitud crítica y responsable frente al uso de los recursos, ya que los problemas ambientales son problemas relacionados con la educación de la población y, por tanto, atajables desde el ámbito educativo. Además de ello, estos problemas ambientales están muy relacionados con la propia experiencia personal, y guardan relación con aspectos económicos y culturales de las poblaciones, aspectos que aportan a estos problemas el calificativo de multidisciplinares y que hacen que necesiten de una intervención racional, que abarque todos estos ámbitos, para conseguir la solución.

En este sentido, y para atajar esta problemática que relaciona el ambiente con lo social varias son las soluciones posibles (Mora, 2011). No obstante, la mejor opción sería unir todas estas soluciones en una misma para conseguir una resolución más eficaz.

Estas soluciones abarcan desde una universalización de los derechos humanos que nos permita a todos partir de una misma base democrática, hasta el desarrollo de una investigación e innovación que posibilite el desarrollo de nuevas alternativas tecnológicas y energéticas capaces de enfrentar los problemas ambientales. No obstante, quizás una de las medidas más eficiente sea establecer la educación ambiental como herramienta sensibilizadora que forme a individuos capaces de actuar críticamente y tomar decisiones de forma autónoma a la vez que posibilita un cambio en el pensamiento, necesario para la toma de conciencia y la adopción de nuevos valores sociales.

Dentro de esta intervención desde una perspectiva ambiental no debe olvidarse el desarrollo sostenible como herramienta conceptual. El empleo de este concepto es básico en las acciones educativas ambientales y en una mejor interpretación de la dinámica ambiental.

\subsection{FUNDAMENTOS PSICOLOGICOS}

Las características que conforman la personalidad del alumnado de $1^{\mathrm{o}}$ de bachillerato conforman una realidad que posibilita trabajar temáticas de educación ambiental y, más concretamente, de desarrollo sostenible, con mayor facilidad.

Los alumnos/as de esta edad en su mayoría han estabilizado sus intereses, conductas y valores $\mathrm{y}$, en este punto, presentan una capacidad suficiente para comprender los fenómenos relacionados con el medio ambiente y con su entorno social más cercano, lo que posibilita que puedan emprender el aprendizaje de conocimientos prácticos necesarios para una adecuada actuación social frente a los problemas ambientales.

En relación con ello, la educación ambiental debe estar encaminada hacia la creación de conductas respetuosas con el medio ambiente además de intentar relacionar los conceptos 
de desarrollo y ambiente, estableciendo en los alumnos/as valores y conductas responsables que les hagan desarrollar una acción basada en la armonía tanto con el ambiente como con otras personas y que posibiliten su inclusión efectiva en la sociedad. La adopción de esta metodología será imprescindible para iniciar un adecuado tránsito hacia una cultura de desarrollo sostenible capaz de establecer el respeto, la sostenibilidad y el uso responsable como pilares básicos de la educación. 


\section{ESTRUCTURA Y ORGANIZACIÓN DE LA UNIDAD DIDÁCTICA}

El esquema de la estructura y organización seguido durante las nueve sesiones de clase destinadas a la explicación de la UD fue el siguiente:

\begin{tabular}{|c|c|}
\hline \multirow{7}{*}{$\begin{array}{c}1^{0} \\
\text { Sesión }\end{array}$} & BREVE INTRODUCCIÓN DE LA TEMÁTICA DE LA UD \\
\hline & $\begin{array}{l}\text { NOTICIA } \\
\text { Exposición de una noticia de prensa, con temática motivadora, impactante y cercana al alumnado, } \\
\text { relacionada con la pérdida de biodiversidad en zonas montañosas mediterráneas debido al aumento } \\
\text { de las temperaturas en dichas latitudes. Esta noticia se tomó como primera estrategia para captar la } \\
\text { atención de los alumnos/as. } \\
\text { Se intentó relacionar con la noticia los conceptos de cambio climático y pérdida de biodiversidad y } \\
\text { hacer al alumnado consciente de las repercusiones ambientales relacionadas con el desarrollo } \\
\text { sostenible. }\end{array}$ \\
\hline & $\begin{array}{l}\text { ACTIVIDAD 1.1. (*): “¿QUÉ OPINAS DEL DESARROLLO SOSTENIBLE?” } \\
\text { En esta actividad se preguntó a los alumnos/as acerca del concepto de desarrollo sostenible, } \\
\text { además de que enumerasen los que creían que eran problemas ambientales relacionados con su } \\
\text { entorno más cercano y con el entorno internacional. }\end{array}$ \\
\hline & $\begin{array}{l}\text { EXPICACIÓN CONTENIDOS } \\
\text { - Tipos de modelos de desarrollo } \\
\text {-La explosión demográfica } \\
\text {-El crecimiento exponencial } \\
\text { - El desarrollo sostenible y condiciones que deben cumplirse }\end{array}$ \\
\hline & $\begin{array}{l}\text { INFORME CIENTÍFICO } \\
\text { Introducción del tema del informe de investigación sobre reciclaje que los alumnos y alumnas } \\
\text { tuvieron que exponer por grupos después de concluir el tema así como las normas de estilo y } \\
\text { extensión. También se les explicó los aspectos que se les iba a evaluar, tanto a nivel grupal como } \\
\text { individual. En dicha introducción se explicó al alumnado las diferentes partes, necesarias para } \\
\text { llevar a cabo el método científico, que tenían que llevar a cabo en el informe }\end{array}$ \\
\hline & $\begin{array}{l}\text { DOCUMENTAL: "LA HISTORIA DE LAS COSAS" } \\
\text { Visualización del video "La historia de las cosas". } \\
\text { El video ilustró los pasos necesarios desde la explotación de las materias primas hasta el proceso de } \\
\text { desecho de los productos. } \\
\text { Además de ello, el video introdujo conceptos importantes como la obsolescencia programada y la } \\
\text { obsolescencia percibida. }\end{array}$ \\
\hline & $\begin{array}{l}\text { DUDAS } \\
\text { Últimos minutos destinados a la aclaración de dudas. }\end{array}$ \\
\hline
\end{tabular}

Tabla 2. Estructura de la $1^{0}$ sesión.

(*) Se pretendió que los materiales y recursos didácticos empleados para la realización de las diferentes actividades fuesen variados para evitar caer en tareas demasiado monótonas y rutinarias que hiciesen a los alumnos/as perder la motivación y el interés. Por ello, se trabajó tanto con recursos TIC (documentales, test sobre la huella ecológica, etc.), como con recursos del propio libro de texto (algunas de las actividades realizadas se obtuvieron del libro) y recursos de elaboración propia (actividad de ideas previas, retrospectiva de 
ideas previas, etc.). Además de ello, todas las actividades se adaptaron a los recursos y materiales didácticos disponibles.

\begin{tabular}{|c|c|}
\hline \multirow[t]{3}{*}{$\begin{array}{c}2^{\circ} \\
\text { Sesión }\end{array}$} & $\begin{array}{l}\text { DOCUMENTAL: “COMPRAR, TIRAR, COMPRAR" } \\
\text { Visualización del documental "Comprar, tirar y comprar" sobre la obsolescencia programada }\end{array}$ \\
\hline & $\begin{array}{l}\text { ACTIVIDAD 2.1.: "RELACIONA EL DOCUMENTAL CON LOS MODELOS DE } \\
\text { DESARROLLO" } \\
\text { En esta actividad los alumnos/as tuvieron que realizar un comentario crítico en el que relacionasen } \\
\text { el documental sobre la obsolescencia programada con los diferentes modelos de desarrollo que se } \\
\text { explicaron el día anterior en clase. } \\
\text { El concepto de obsolescencia programada que se introdujo en el video de "La historia de las cosas" } \\
\text { el día anterior tuvieron que relacionarlo con alguno de los modelos de desarrollo. }\end{array}$ \\
\hline & $\begin{array}{l}\text { DUDAS } \\
\text { Últimos minutos destinados a la aclaración de dudas. }\end{array}$ \\
\hline
\end{tabular}

Tabla 3. Estructura de la $2^{\circ}$ sesión.

\begin{tabular}{|c|l|}
\hline \multicolumn{1}{|c|}{$\mathbf{3}^{\mathbf{0}}$ Sesión } & $\begin{array}{l}\text { EXPLICACIÓN CONTENIDOS } \\
\text {-Desertización } \\
\text {-Formación del suelo } \\
\text {-Erosión del suelo } \\
\text {-Contaminación del aire } \\
\text {-La calidad del aire urbano }\end{array}$ \\
\cline { 2 - 3 } & $\begin{array}{l}\text { ACTIVIDAD 3.1.: "SITÚA EL DIBUJO EN UN AÑO Y EN UNA CIUDAD Y PONLE } \\
\text { NOMBRE" } \\
\text { En esta actividad se repartió a los alumnos y alumnas un dibujo de crítica a la contaminación } \\
\text { atmosférica y se les pidió que lo situasen en un lugar y en un año y que le pusiesen un nombre que } \\
\text { creyesen estaba relacionado con la imagen, posteriormente se les preguntó qué aspectos creían que } \\
\text { criticaba el dibujo y si creían que la situación que reflejaba era real en la actualidad. }\end{array}$ \\
\cline { 2 - 3 } & $\begin{array}{l}\text { DUDAS } \\
\text { Úlimos minutos destinados a la aclaración de dudas. }\end{array}$ \\
\hline
\end{tabular}

Tabla 4. Estructura de la $3^{0}$ sesión. 


\begin{tabular}{|c|c|}
\hline \multirow[t]{5}{*}{$\begin{array}{c}4^{\circ} \\
\text { Sesión }\end{array}$} & $\begin{array}{l}\text { EXPLICACIÓN CONTENIDOS } \\
\text {-La ocupación del territorio: ocupación del litoral y desplazamiento a zonas urbanas: } \\
\text { megaciudades y urbanizaciones dispersas } \\
\text {-La pérdida de biodiversidad } \\
\text {-Extinciones de fondo y en masa } \\
\text {-Especies en peligro de extinción }\end{array}$ \\
\hline & $\begin{array}{l}\text { ACTIVIDAD 4.1.: “¿POR QUÉ SON PROPENSOS A LA EXTINCIÓN?” } \\
\text { En esta actividad los alumnos/as tuvieron que indicar razones que justificasen la relación entre las } \\
\text { características de algunas especies (como ballena azul, rinoceronte negro, panda gigante, etc.) que } \\
\text { las hacen especialmente vulnerables a la extinción y dicha vulnerabilidad. }\end{array}$ \\
\hline & $\begin{array}{l}\text { ACTIVIDAD } \\
\text { En esta actividad el alumnado tuvo que realizar un recorrido por las superficies protegidas de cada } \\
\text { una de las comunidades autónomas españolas además de buscar información sobre los espacios } \\
\text { protegidos de Andalucía. }\end{array}$ \\
\hline & $\begin{array}{l}\text { ACTIVIDAD } 4.3 . \quad: \quad \text { “CAMINA } \text { HACIA } \text { LA } \text { SOSTENIBILIDAD?” } \\
\text { En esta actividad los alumnos/as tuvieron que valorar la sostenibilidad de los cambios relacionados } \\
\text { con la ocupación del territorio que habían ocurrido en una determinada comunidad autónoma } \\
\text { española. }\end{array}$ \\
\hline & $\begin{array}{l}\text { DUDAS } \\
\text { Últimos minutos destinados a la aclaración de dudas. }\end{array}$ \\
\hline
\end{tabular}

Tabla 5. Estructura de la $4^{0}$ sesión. 


\begin{tabular}{|c|l|}
\hline $\begin{array}{c}\mathbf{5}^{\circ} \\
\text { Sesión }\end{array}$ & $\begin{array}{l}\text { EXPLICACIÓN CONTENIDOS } \\
\text {-Tipos y gestión de los residuos: el aumento de los residuos } \\
\text { - Consumo sostenible } \\
\text {-"Regla de las tres erres" } \\
\text {-La huella ecológica: cálculo y consideraciones }\end{array}$ \\
\cline { 2 - 3 } & $\begin{array}{l}\text { ACTIVIDAD 5.1.: "CALCULA TU HUELLA ECOLÓGICA" } \\
\text { Realización de un test para que los alumnos/as calculasen de manera individual su huella ecológica } \\
\text { y valorasen las conclusiones obtenidas del mismo. }\end{array}$ \\
\cline { 2 - 3 } & $\begin{array}{l}\text { DOCUMENTAL: "LA PESADILLA DE DARWIN" } \\
\text { Visualización de un fragmento del documental "La pesadilla de Darwin". } \\
\text { Este documental trató sobre las consecuencias medioambientales y humanas que supuso la } \\
\text { Se introdujo al alumnado el tema del documental y se les repartió una ficha con los aspectos que } \\
\text { tenían que trabajar para el debate de la siguiente sesión. }\end{array}$ \\
\cline { 2 - 3 } & $\begin{array}{l}\text { ACTIVIDAD 5.2.: "EXPLICA EL TITULO DEL DOCUMENTAL" } \\
\text { A partir de la visualización del fragmento del documental: "La pesadilla de Darwin" se les pidió a } \\
\text { los alumnos/as que intentasen explicar el título de dicho documental. }\end{array}$ \\
\cline { 2 - 3 } & $\begin{array}{l}\text { DUDAS } \\
\text { Últimos minutos destinados a la aclaración de dudas. }\end{array}$ \\
\hline
\end{tabular}

Tabla 6. Estructura de la $5^{\circ}$ sesión.

\begin{tabular}{|c|c|}
\hline \multirow[t]{3}{*}{$\begin{array}{c}6^{0} \\
\text { Sesión }\end{array}$} & 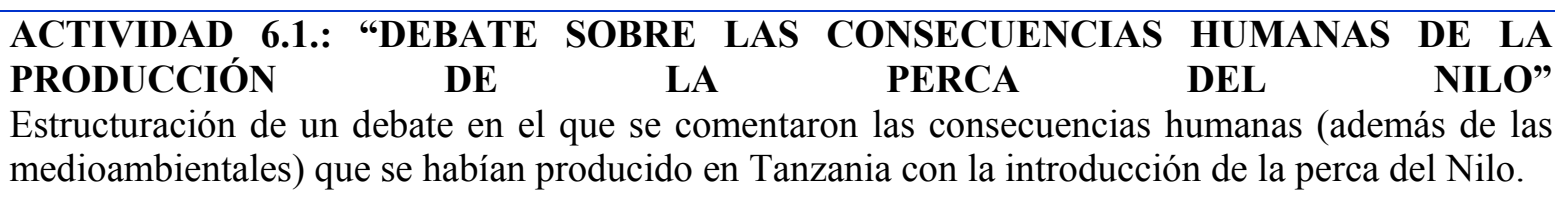 \\
\hline & $\begin{array}{l}\text { ACTIVIDAD } \quad \text { 6.2.: "RETROSPECTIVA } \\
\text { Análisis de las respuestas que dieron el primer día los alumnos y alumnas en la actividad sobre } \\
\text { ideas previas que se les repartió. } \\
\text { Este análisis se realizó mediante una retrospectiva y unión de todos los conceptos que trabajaron } \\
\text { durante el tema para ver si sus ideas iniciales habían variado con respecto al inicio del tema. }\end{array}$ \\
\hline & $\begin{array}{l}\text { DUDAS } \\
\text { Últimos minutos destinados a la aclaración de dudas antes del examen. }\end{array}$ \\
\hline
\end{tabular}

Tabla 7. Estructura de la $6^{0}$ sesión.

\begin{tabular}{c|l}
\hline $\mathbf{7}^{\mathbf{0}}$ & EXAMEN \\
Sesión & Realización del examen de la UD. \\
\hline
\end{tabular}

Tabla 8. Estructura de la $7^{\circ}$ sesión. 


\begin{tabular}{|c|l|}
\hline $\begin{array}{c}\mathbf{8}^{\circ} \\
\text { Sesión }\end{array}$ & $\begin{array}{l}\text { ACTIVIDAD 8.1.: EXPOSICIÓN INFORME DE INVESTIGACIÓN } \\
\text { Se expusieron, por grupos, todos los informes científicos acerca de las prácticas de reciclaje. }\end{array}$ \\
\cline { 2 - 3 } & $\begin{array}{l}\text { DUDAS SOBRE LAS EXPOSICIONES } \\
\text { Después de cada exposición se destinaron unos minutos para la aclaración de las dudas que } \\
\text { surgieron a los alumnos/as sobre los trabajos. }\end{array}$ \\
\hline
\end{tabular}

Tabla 9. Estructura de la $8^{\circ}$ sesión.

\begin{tabular}{|c|l|}
\hline $\begin{array}{c}9^{\circ} \\
\text { Sesión }\end{array}$ & $\begin{array}{l}\text { VISITA AL PARQUE DE LAS CIENCIAS DE GRANADA (no se realizó) } \\
\text { ACTIVIDAD 9.1.: "REFLEXIONA SOBRE TU PAPEL HACIA EL MEDIO AMBIENTE" } \\
\text { (no se realizó) }\end{array}$ \\
\hline
\end{tabular}

Tabla 10. Estructura de la $9^{\circ}$ sesión.

Los criterios que se tomaron (de manera simultánea y relacionada) para la secuenciación de los contenidos fueron los siguientes:

- Relación entre los contenidos de la UD y los conocimientos previos de los alumnos/as.

- Organización y estructuración de la secuencia de contenidos a partir de una idea-eje central.

- Continuidad y coherencia entre los contenidos.

- Adecuación de los contenidos a las capacidades del alumnado.

- Conexión de contenidos propiamente disciplinares con otros transversales.

- La integración y tratamiento equilibrado de los diferentes contenidos.

- La revisión y reelaboración de la secuencia a partir de los resultados de su aplicación al aula.

Atendiendo a ello, se estableció una secuenciación en la que el eje central (como se ha mencionado anteriormente en este trabajo) fue el uso de los recursos que se hace a través de nuestro modelo de desarrollo actual. Debido a ello, lo primero que se explicó fueron los diferentes tipos de modelo de desarrollo existentes y el uso que hacemos dentro del nuestro y posteriormente se clasificaron los efectos, derivados de dicho uso de recursos, en diferentes niveles:

- A nivel de crecimiento: explosión demográfica y crecimiento exponencial

- A nivel de suelo: desertización, erosión del suelo, etc., y medidas para corregir los problemas relacionados con su explotación.

- A nivel del aire: contaminación atmosférica y problemas de salud derivados así como la valoración de la necesidad de una actitud sensible ante la misma. 
- A nivel de la ocupación del territorio: megaciudades y urbanizaciones dispersas y análisis de las consecuencias sostenibles o no de cambios relacionados con la ocupación del territorio.

- A nivel de los seres vivos: características que hacen vulnerables a algunas especies y causas responsables del peligro de extinción. Evaluación de las consecuencias humanas de una de estas causas: introducción de especies invasoras. El problema de la pérdida de biodiversidad.

- A nivel del consumo ciudadano no sostenible: "regla de las tres erres" y las prácticas de reciclaje en la población.

- A nivel de los residuos: tipos, gestión y aumento de los residuos.

- A nivel de la utilización del espacio: la huella ecológica, su cálculo y principales consideraciones. 


\section{METODOLOGÍA DE LA UNIDAD DIDÁCTICA}

Según se establece en el apartado de Sugerencias sobre metodología y utilización de recursos dentro de la ORDEN de 5 de agosto de 2008, dentro de los objetivos que deberían tomarse como prioritarios en esta materia de Ciencias para el Mundo Contemporáneo está el de proporcionar al alumnado una cultura científica que le ayude a integrarse en una sociedad científica y tecnológicamente avanzada. En relación a este aspecto, se exige una metodología en la que tenga un fuerte protagonismo el análisis y la valoración por el alumnado de las informaciones sobre problemas reales y actuales, obtenidas de fuentes diversas, especialmente la prensa y las tecnologías de la información y la comunicación.

La metodología (la cuál responde a la pregunta ¿cómo enseñar?) llevada a cabo en esta UD pretendió servir como estrategia para que los contenidos consiguiesen los objetivos didácticos propuestos.

Dicha metodología de enseñanza practicada pretendió que el alumnado fuese el protagonista, construyese sus propios conocimientos y aprendiese a aprender. Los aspectos principales que caracterizaron a esta metodología fueron los siguientes: partir del nivel de desarrollo del alumno; propiciar la elaboración, a partir de sus conocimientos previos y relacionando estos con los nuevos, de su propio proceso de enseñanza-aprendizaje; atender a sus intereses, capacidades y ritmos de aprendizaje mediante un enfoque globalizador que atendiese la diversidad del alumnado; graduar la dificultad; secuenciar y encadenar contenidos de forma clara, ordenada y significativa; determinar técnicas variadas (expresión oral, expresión escrita, etc.); estimular y valorar sus progresos; flexibilizar los tiempos en el aula y, por último, promover la participación y el diálogo en un ambiente agradable y de respeto mediante la estructuración de una atmósfera propicia para el intercambio recíproco de opiniones y una participación conjunta que facilitase el aprendizaje.

Las características cognitivas que presentaban los alumnos y alumnas (con edades comprendidas entre 16-18 años y que ya se han comentado en el apartado de características del alumnado) destinatarios de las intervenciones permitieron llevar a cabo una secuencia de actividades en las que ellos mismos fueron los responsables de su propio proceso de enseñanza-aprendizaje, siendo dichas características propicias para el desempeño de la metodología llevada a cabo.

Dicha secuencia de actividades comenzó con una fase inicial en la que a los alumnos/as se les presentaron los contenidos de la UD que se iban a trabajar durante las siguientes sesiones. Con esta presentación previa se intentó además de acercar a los alumnos/as a la temática, motivarlos a la vez que se enlazaban dichos contenidos con los previos que ya se habían visto (caso de la noticia de periódico expuesta en la primera clase en la que se relacionó el concepto de cambio climático que ya habían trabajado con el de pérdida de biodiversidad que se iba a trabajar en la UD). También en esta primera fase se realizó una actividad de diagnosis inicial en la que pudiesen reflejarse los conocimientos previos acerca de los principales conceptos de la UD que el alumnado poseía.

La metodología llevada a cabo para la corrección de ideas previas de los alumnos/as consistió en partir de los conocimientos que estos ya poseían, promover el desarrollo de aprendizajes significativos por ellos mismos proporcionándoles las herramientas necesarias 
para tal fin, desarrollar una intensa reflexión sobre lo aprendido y, por último, confrontarlos con sus ideas previas (aquellas erróneas) para posibilitar el cambio conceptual.

Una vez desarrollada esta fase se procedió a trabajar dentro de la siguiente fase en la que se planificaron diferentes actividades, proporcionando los materiales necesarios para su realización, se informó acerca de los contenidos que debían trabajarse con cada una de estas actividades, se ayudó al alumnado en las dificultades surgidas, etc. Con esta fase se pretendió que se consolidasen los aprendizajes y se ampliasen y reforzasen otros, que se clarificasen las ideas de los alumnos/as y que se creasen en ellos conflictos cognitivos necesarios para la confrontación de sus ideas preexistentes con las nuevas tratadas en clase, todo ello inmerso en un ambiente de constante interacción entre profesora y alumnado.

La tercera fase consistió, principalmente, en hacer partícipes y conscientes a los alumnos y alumnas de los conocimientos que poseían, para lo que se realizó un control de evaluación que pudiese constatarlo (examen final).

Por último, y mediante un informe de investigación que los alumnos/as realizaron por grupos, se pretendió realizar una ampliación de algunos de los contenidos trabajados durante las sesiones de clase.

Las orientaciones metodológicas llevadas a cabo para posibilitar la construcción de conocimientos científicos intentaron romper con la transmisión de conocimientos elaborados previamente que caracteriza a las asignaturas de ciencias y centrarse en varios aspectos imprescindibles para la consecución de tal fin:

- Atraer la atención, motivación e interés del alumnado hacia ciertos aspectos mediante actividades con un claro enfoque CTSA (por ejemplo mediante el debate de la actividad $6.1)$.

- Promover la emisión de hipótesis relacionadas con problemas planteados y establecer, mediante la búsqueda y posterior valoración de la fiabilidad de información y análisis detallado de los resultados obtenidos, conclusiones bien argumentadas (mediante la realización del informe de investigación).

- Inculcar el trabajo científico colectivo organizando equipos de trabajo en los que los componentes se complementasen, mediante el trabajo cooperativo, y mejorasen sus aportaciones individuales (a través también del informe científico).

- Potenciar los aspectos comunicativos (tanto orales como escritos) del lenguaje mediante debates en clase sobre los problemas planteados, presentación de informes escritos y orales o comprensión y lectura de fragmentos de texto principalmente.

También se tuvieron en cuenta los planes de mejora en la competencia matemática y lingüística.

En relación con la competencia matemática, se diseñaron estrategias que despertasen la curiosidad y motivación del alumnado (caso de la explicación del concepto de crecimiento exponencial a través de la conexión con una leyenda sobre el ajedrez). Por otro lado, la lectura, la escritura, el habla y la escucha son herramientas fundamentales ya no solo para la adquisición de nuevos saberes (entre ellos, el científico) sino para un correcto desarrollo en la vida cotidiana y el entorno. Debido a ello, las estrategias utilizadas dentro del ámbito 
lingüístico se centraron en promover en el alumnado el interés por la lectura mediante la lectura de textos en clase, en promover su capacidad para expresarse adecuadamente en público (con la realización de exposiciones y actividades orales con toda la clase) y, por último, en la realización de trabajos de investigación tanto a pequeña (pequeño trabajo de indagación) como a gran (informe científico de investigación) escala. También se potenciaron en algunas actividades las habilidades necesarias para el aprovechamiento de los recursos TIC disponibles.

Todos estos aspectos estuvieron encaminados a propiciar la introducción de los alumnos y alumnas en la cultura científica sin olvidar las dimensiones cooperativa y social de la misma y permitiendo además una integración que posibilitase la implicación de la misma en otros campos de conocimientos, requisitos imprescindibles para el desarrollo de todas las competencias básicas, desde la del conocimiento e interacción con el mundo físico propia de toda materia que trabaje contenidos científicos y otras relacionadas con este tipo de asignaturas como la matemática (interpretación de gráficas y tablas), social y ciudadana (crucial para el desempeño de trabajos grupales científicos) y de tratamiento de la información y competencia digital (imprescindible en cualquier investigación) hasta las que, a priori, pudiesen parecer más alejadas, como la cultural y artística (valorando los aspectos básicos de la cultura científica), para aprender a aprender (dotando a los alumnos/as de habilidades para iniciarse en el aprendizaje y ser capaces de continuar aprendiendo) o autonomía e iniciativa personal (proporcionando recursos que posibilitasen la iniciación en el aprendizaje y ser capaz de emprender y desarrollar proyectos con confianza, responsabilidad y sentido crítico). Mención aparte merece la competencia en comunicación lingüística, implícita, por su carácter comunicativo, además de en esta en el resto de materias.

Con respecto a las orientaciones metodológicas llevadas a cabo en el trabajo de los temas transversales, y debido a que estos tienen relación con situaciones problemáticas que se han desencadenado en la sociedad, estas se centraron en propiciar el debate en clase; en la adopción de posturas personales por parte del alumnado; en propiciar su motivación e iniciativa (necesarias en la superación de conflictos) y en establecer actividades cooperativas en las que se propiciase la inserción en un grupo de trabajo. En definitiva, se pretendió establecer un ambiente comunicativo y de participación en el aula. La reflexión que se pretendió con la realización de algunas actividades, por tanto, fue uno de los aspectos fundamentales a promover con las diferentes estrategias metodológicas orientadas a dichas temáticas transversales trabajadas en la UD. 


\section{BREVE COMPARACIÓN ENTRE EL GRUPO CT Y EL GRUPO HCS}

El interrogante principal que se planteó como objeto de ser observado y analizado durante el periodo de la docencia de la UD fue el mayor o menor conocimiento del alumnado sobre los principales problemas ambientales relacionados con el desarrollo insostenible en su entorno más cercano (una de las preguntas de la actividad 1.1 sobre ideas previas).

Esta UD se impartió en dos grupos de $1^{\circ}$ de bachillerato de modalidades diferentes. Uno (CT) de ellos pertenecía a la modalidad de Ciencias y Tecnología (con dibujo, física y química y matemáticas como asignaturas específicas de la modalidad) y el otro (HCS) a la modalidad de Humanidades y Ciencias Sociales (con las materias de historia del mundo contemporáneo, economía y matemáticas de ciencias sociales como específicas).

En base a la trayectoria previa y a las asignaturas cursadas se estableció como premisa (antes de realizar la actividad de ideas previas en la primera sesión) que los alumnos/as del bachillerato científico-tecnológico tendrían un mejor conocimiento de los contenidos de la asignatura de Ciencias para el Mundo Contemporáneo y, más concretamente, de los problemas ambientales relacionados con el desarrollo no sostenible de su entorno más cercano, que los del bachillerato de ciencias sociales.

La metodología empleada en dicha observación previa a la impartición de la UD fue de tipo cualitativa. En concreto, se procedió a analizar las respuestas dadas a la pregunta y agruparlas en diferentes grupos de respuestas para posteriormente realizar, atendiendo a dichas respuestas, la comparación entre los dos grupos de alumnos y alumnas.

Los grupos de respuestas se representan en la siguiente Tabla 11:

\begin{tabular}{|l|l|}
\hline \multicolumn{1}{|c|}{ Bachillerato de Ciencias y Tecnología } & Bachillerato de Humanidades y Ciencias Sociales \\
\hline Contaminación producida por transportes & Contaminación producida por transportes \\
\hline Contaminación producida por industria & \\
\hline Contaminación atmosférica & Contaminación atmosférica \\
\hline Contaminación del agua & Contaminación del agua \\
\hline & Contaminación acústica \\
\hline & Contaminación lumínica \\
\hline Problema de combustibles fósiles & Problema de combustibles fósiles \\
\hline Cambio climático & Cambio climático \\
\hline Sequía & Sequia \\
\hline & Desertización \\
\hline
\end{tabular}

Tabla 11. Grupos de respuestas de los alumnos/as de ambos grupos de $1^{\circ}$ bachillerato. 
Es importante destacar que en el bachillerato científico-tecnológico 5 alumnos y alumnas de los 24 dieron respuestas faltas de coherencia y, en general, todas las respuestas fueron muy escuetas y poco desarrolladas y argumentadas.

En el caso del bachillerato de ciencias sociales solo hubo un alumno de los 27 que respondió con falta de coherencia, otro alumno no respondió a esta pregunta alegando que desconocía la respuesta y las respuestas fueron más elaboradas, argumentadas y más complejas, en general, que el otro grupo. 


\section{COMPONENTES DE LA UNIDAD DIDÁCTICA}

El artículo 9 (Currículo) del REAL DECRETO 1467/2007 establece que el currículo del bachillerato atiende al conjunto de objetivos, contenidos, métodos pedagógicos y criterios de evaluación de estas enseñanzas.

\subsection{IDENTIFICACIÓN DE LOS ESTÁNDARES DE REFERENCIA}

Cuando se decide la enseñanza de un contenido, tema o habilidad concreta (Moral, 2012), el profesor debe preguntarse sobre lo que se pretende alcanzar con la adquisición de este contenido, tema o habilidad.

La identificación de los estándares de referencia es una tarea esencial a la hora de diseñar experiencias de aprendizaje significativas. Dichos estándares, no obstante, deben ser desmenuzados para que puedan identificarse las ideas clave que los sostienen, ya que no debe caerse en una planificación demasiado rígida.

En el caso de los contenidos que se van a trabajar con esta UD, a partir de los objetivos a alcanzar y los criterios de evaluación a seguir para dichos contenidos, se establecen (atendiendo a la ORDEN de 5 de agosto de 2008) como estándares de referencia los siguientes:

- Conocer los factores de los que depende la sostenibilidad

- Comprender los efectos que está produciendo nuestro modelo de desarrollo en el medio físico y en los organismos

- Reconocer las características que debe cumplir un modelo de desarrollo para que sea sostenible

- Indicar cómo pueden corregirse los efectos negativos producidos por un modelo de desarrollo inadecuado

- Conocer conceptos relevantes (como la desertización, la pérdida de biodiversidad, la ocupación del territorio, etc.) y aplicarlos a situaciones concretas

- Saber reconocer situaciones problemáticas medioambientales e identificar las variables que inciden en ellas

- Elaborar argumentos y conclusiones y comunicarlos a los demás utilizando códigos de lenguaje apropiados

- Analizar y valorar los argumentos aportados por los demás

\subsection{OBJETIVOS}

\subsubsection{Objetivos generales}

En el ANEXO I de este trabajo se fijan los objetivos generales de etapa establecidos en el artículo 3 (Objetivos del bachillerato) de dicho Real Decreto.

Con respecto a la comunidad autónoma andaluza, en el ANEXO II del presente trabajo se fijan los objetivos generales de etapa establecidos en el artículo 4 (Objetivos) del DECRETO 416/2008, de 22 de julio, por el que se establece la ordenación y las enseñanzas correspondientes al Bachillerato en Andalucía. 


\subsubsection{Objetivos específicos}

En el ANEXO III de este trabajo se fijan los objetivos específicos de la asignatura de Ciencias para el Mundo Contemporáneo en $1^{\circ}$ de bachillerato establecidos en este $R E A L$ DECRETO 1467/2007.

Con respecto a Andalucía, en el ANEXO IV del presente trabajo se fijan los objetivos específicos de la asignatura de Ciencias para el Mundo Contemporáneo en $1^{\circ}$ de bachillerato establecidos en dicha Orden de Andalucía.

\subsubsection{Objetivos didácticos}

Estos objetivos son los que contribuirán al desarrollo de unas competencias básicas concretas y los que se conseguirán por medio de los contenidos (que se especificarán más tarde) de la UD y son los que responden a la pregunta ¿para qué enseñar?. Dichos objetivos, al igual que el resto de los componentes del currículo, deberán contribuir al desarrollo de todas las competencias básicas, tanto las pertenecientes al ámbito de la expresión y comunicación (matemática, cultural y artística, en comunicación lingüística y tratamiento de la información y competencia digital), como al de la relación y la interacción (conocimiento e interacción con el mundo físico y natural y social y ciudadana) y, por último, al del desarrollo personal (autonomía e iniciativa personal y para aprender a aprender).

Dichos objetivos didácticos para la UD presente son los siguientes:

1. Conocer el significado cualitativo del concepto de desarrollo sostenible, y otros conceptos relacionados, y los problemas ambientales vinculados con dicho concepto en el entorno más próximo para formarse opiniones fundamentadas sobre los mismos.

2. Utilizar y seleccionar de forma crítica información sobre el consumismo descontrolado y las estrategias para atenuarlo y plantearse preguntas sobre el modelo de desarrollo existente en la actualidad en los países desarrollados.

3. Identificar las causas de la pérdida de suelo y aportar propuestas para su corrección.

4. Desarrollar la reflexión crítica y la sensibilidad hacía el medio ambiente y la contaminación atmosférica y valorar sus efectos.

5. Entender las especies protegidas así como las características que las hacen vulnerables y las causas que las amenazan y apreciar su valor, asociándolas a una buena salud medioambiental.

6. Conocer la abundancia de espacios naturales protegidos en las diferentes comunidades autónomas españolas y reconocer los existentes en Andalucía.

7. Valorar la sostenibilidad o no de cambios relacionados con la ocupación del territorio.

8. Organizar informaciones sobre los residuos sólidos urbanos mediante su representación en esquemas.

9. Aprender a calcular individualmente la huella ecológica y saber razonar las conclusiones de dicho cálculo. 
10. Argumentar las consecuencias sociales y humanas de la introducción de especies invasoras y su relación con el medio ambiente y la economía y valorar las informaciones mostradas, desarrollando criterios propios.

11. Ser capaz de modificar conocimientos previos erróneos de forma coherente y fundamentada.

12. Saber analizar informaciones de contenido científico, formular hipótesis y obtener conclusiones fundamentadas que puedan ser comunicadas a los demás con coherencia y claridad.

13. Desarrollar una actitud de respeto hacia el medio ambiente, necesaria para la atenuación de los problemas ambientales surgidos a partir del modelo de desarrollo actual, para la construcción de un futuro sostenible y en equilibrio $(*)$.

(*) Este último objetivo número 13 corresponde con una actividad extraescolar que se programó para la sesión $9^{\circ}$, no obstante, debido a que dicha actividad no llegó a desarrollarse no se mencionarán los instrumentos y procedimientos de evaluación, criterios de calificación ni la metodología empleada en la misma.

8.2.4. Identificación de objetivos didácticos con las competencias básicas y las inteligencias múltiples

Las competencias básicas e inteligencias múltiples que se quieren desarrollar con la UD y que están expresadas en cada uno de los objetivos didácticos se enumeran en la siguiente Tabla 12:

\begin{tabular}{|c|c|c|}
\hline Objetivo & $\begin{array}{c}\text { Competencias Básicas } \\
\text { trabajadas }\end{array}$ & $\begin{array}{c}\text { Inteligencias Múltiples } \\
\text { trabajadas }\end{array}$ \\
\hline $\begin{array}{l}\text { 1.Conocer el significado } \\
\text { cualitativo del concepto de } \\
\text { desarrollo sostenible, y otros } \\
\text { conceptos relacionados, y } \\
\text { los problemas ambientales } \\
\text { vinculados con dicho } \\
\text { concepto en el entorno más } \\
\text { próximo para formarse } \\
\text { opiniones fundamentadas } \\
\text { sobre los mismos }\end{array}$ & $\begin{array}{l}\text {-Competencia en el } \\
\text { conocimiento e interacción } \\
\text { con el mundo físico }\end{array}$ & -Inteligencia naturalista \\
\hline $\begin{array}{l}\text { 2.Utilizar y seleccionar de } \\
\text { forma crítica información } \\
\text { sobre el consumismo } \\
\text { descontrolado y las } \\
\text { estrategias para atenuarlo y } \\
\text { plantearse preguntas sobre } \\
\text { el modelo de desarrollo } \\
\text { existente en la actualidad en }\end{array}$ & $\begin{array}{l}\text {-Competencia en el } \\
\text { conocimiento e interacción } \\
\text { con el mundo físico } \\
\text {-Tratamiento de la } \\
\text { información y competencia } \\
\text { digital }\end{array}$ & $\begin{array}{l}\text { - Inteligencia naturalista } \\
\text { - Inteligencia verbal- } \\
\text { lingüística }\end{array}$ \\
\hline
\end{tabular}




\begin{tabular}{|c|c|c|}
\hline los países desarrollados & & \\
\hline $\begin{array}{l}\text { 3.Identificar las causas de la } \\
\text { pérdida de suelo y aportar } \\
\text { propuestas } \\
\text { corrección }\end{array}$ & $\begin{array}{l}\text {-Competencia en el } \\
\text { conocimiento e interacción } \\
\text { con el mundo físico }\end{array}$ & $\begin{array}{l}\text {-Inteligencia naturalista } \\
\text {-Inteligencia visual-espacial }\end{array}$ \\
\hline $\begin{array}{l}\text { 4.Desarrollar la reflexión } \\
\text { crítica y la sensibilidad } \\
\text { hacía el medio ambiente y la } \\
\text { contaminación atmosférica y } \\
\text { valorar sus efectos }\end{array}$ & $\begin{array}{l}\text {-Competencia en el } \\
\text { conocimiento e interacción } \\
\text { con el mundo físico } \\
\text {-Competencia cultural y } \\
\text { artística }\end{array}$ & $\begin{array}{l}\text {-Inteligencia naturalista } \\
\text {-Inteligencia visual-espacial }\end{array}$ \\
\hline $\begin{array}{l}\text { 5.Entender las especies } \\
\text { protegidas así como las } \\
\text { características que las hacen } \\
\text { vulnerables y las causas que } \\
\text { las amenazan y apreciar su } \\
\text { valor, asociándolas a una } \\
\text { buena salud medioambiental }\end{array}$ & $\begin{array}{l}\text {-Competencia en el } \\
\text { conocimiento e interacción } \\
\text { con el mundo físico }\end{array}$ & -Inteligencia naturalista \\
\hline $\begin{array}{l}\text { 6.Conocer la abundancia de } \\
\text { espacios naturales } \\
\text { protegidos en las diferentes } \\
\text { comunidades autónomas } \\
\text { españolas y reconocer los } \\
\text { existentes en Andalucía }\end{array}$ & $\begin{array}{l}\text {-Competencia en el } \\
\text { conocimiento e interacción } \\
\text { con el mundo físico } \\
\text {-Tratamiento de la } \\
\text { información y competencia } \\
\text { digital } \\
\text {-Competencia cultural y } \\
\text { artística } \\
\text {-Competencia matemática }\end{array}$ & $\begin{array}{l}\text {-Inteligencia naturalista } \\
\text {-Inteligencia } \\
\text { lingüística } \\
\text {-Inteligencia verbal- } \\
\text { matemática }\end{array}$ \\
\hline $\begin{array}{l}\text { 7. Valorar la sostenibilidad o } \\
\text { no de cambios relacionados } \\
\text { con la ocupación del } \\
\text { territorio }\end{array}$ & $\begin{array}{l}\text {-Competencia en el } \\
\text { conocimiento e interacción } \\
\text { con el mundo físico }\end{array}$ & -Inteligencia naturalista \\
\hline $\begin{array}{l}\text { 8. Organizar informaciones } \\
\text { sobre los residuos sólidos } \\
\text { urbanos mediante su } \\
\text { representación en esquemas }\end{array}$ & $\begin{array}{l}\text {-Competencia en el } \\
\text { conocimiento e interacción } \\
\text { con el mundo físico }\end{array}$ & $\begin{array}{l}\text {-Inteligencia naturalista } \\
\text {-Inteligencia visual-espacial }\end{array}$ \\
\hline $\begin{array}{l}\text { 9. Aprender a } r \text { calcular } \\
\text { individualmente la huella } \\
\text { ecológica y saber razonar } \\
\text { las conclusiones de dicho }\end{array}$ & $\begin{array}{l}\text {-Competencia en el } \\
\text { conocimiento e interacción } \\
\text { con el mundo físico }\end{array}$ & $\begin{array}{l}\text {-Inteligencia naturalista } \\
\text {-Inteligencia lógico- }\end{array}$ \\
\hline
\end{tabular}




\begin{tabular}{|c|c|c|}
\hline cálculo & -Competencia matemática & matemática \\
\hline $\begin{array}{l}\text { 10.Argumentar las } \\
\text { consecuencias sociales y } \\
\text { humanas de la introducción } \\
\text { de especies invasoras y su } \\
\text { relación con el medio } \\
\text { ambiente y la economía y } \\
\text { valorar las informaciones } \\
\text { mostradas, desarrollando } \\
\text { criterios propios }\end{array}$ & $\begin{array}{l}\text {-Competencia en el } \\
\text { conocimiento e interacción } \\
\text { con el mundo físico } \\
\text {-Competencia } \\
\text { comunicación lingüística } \\
\text {-Autonomía e iniciativa } \\
\text { personal } \\
\text {-Competencia social y } \\
\text { ciudadana }\end{array}$ & $\begin{array}{l}\text {-Inteligencia naturalista } \\
\text {-Inteligencia verbal- } \\
\text { lingüística } \\
\text {-Inteligencia intrapersonal } \\
\text {-Inteligencia interpersonal }\end{array}$ \\
\hline $\begin{array}{l}\text { 11.Ser capaz de modificar } \\
\text { conocimientos previos } \\
\text { erróneos de forma coherente } \\
\text { y fundamentada }\end{array}$ & $\begin{array}{l}\text {-Competencia en el } \\
\text { conocimiento e interacción } \\
\text { con el mundo físico } \\
\text {-Competencia en } \\
\text { comunicación lingüística } \\
\text {-Competencia para aprender } \\
\text { a aprender }\end{array}$ & $\begin{array}{l}\text {-Inteligencia naturalista } \\
\text {-Inteligencia verbal- } \\
\text { lingüística } \\
\text {-Inteligencia intrapersonal }\end{array}$ \\
\hline $\begin{array}{lr}\text { 12.Saber } & \text { analizar } \\
\text { informaciones de contenido } \\
\text { científico, formular } \\
\text { hipótesis y obtener } \\
\text { conclusiones fundamentadas } \\
\text { que puedan ser comunicadas } \\
\text { a los demás con coherencia } \\
\text { y claridad }\end{array}$ & $\begin{array}{l}\text {-Competencia en el } \\
\text { conocimiento e interacción } \\
\text { con el mundo físico } \\
\text {-Competencia } \\
\text { comunicación lingüística } \\
\text {-Autonomía e iniciativa } \\
\text { personal } \\
\text {-Competencia social y } \\
\text { ciudadana } \\
\text {-Tratamiento de la } \\
\text { información y competencia } \\
\text { digital } \\
\text {-Competencia matemática } \\
\text {-Competencia cultural y } \\
\text { artística }\end{array}$ & $\begin{array}{l}\text {-Inteligencia naturalista } \\
\text {-Inteligencia verbal- } \\
\text { linguistica } \\
\text {-Inteligencia lógico- } \\
\text { matemática } \\
\text {-Inteligencia intrapersonal } \\
\text {-Inteligencia interpersonal } \\
\text {-Inteligencia corporal- } \\
\text { cinestésica }\end{array}$ \\
\hline $\begin{array}{l}\text { 13.Desarrollar una actitud } \\
\text { de respeto hacia el medio } \\
\text { ambiente, necesaria para la }\end{array}$ & $\begin{array}{l}\text {-Competencia en el } \\
\text { conocimiento e interacción }\end{array}$ & $\begin{array}{l}\text {-Inteligencia naturalista } \\
\text {-Inteligencia intrapersonal }\end{array}$ \\
\hline
\end{tabular}




\begin{tabular}{|l|ll|l|}
\hline atenuación de los problemas & con el mundo físico & \\
ambientales surgidos a partir & & & \\
del modelo de desarrollo & - Tratamiento & de & la \\
actual, para la construcción & información y competencia & \\
de un futuro sostenible y en & digital & & \\
equilibrio & $\begin{array}{l}\text {-Autonomía } \\
\text { personal }\end{array}$ & e iniciativa & \\
-Competencia & social & y & \\
ciudadana & & & \\
\hline
\end{tabular}

Tabla 12. Relación de cada objetivo con las competencias básicas e inteligencias múltiples que trabaja.

\subsection{EVALUACIÓN}

El REAL DECRETO 1467/2007, establece que la evaluación del aprendizaje será continua y diferenciada según las distintas materias y se llevará a cabo teniendo en cuenta los diferentes elementos del currículo.

La evaluación llevada a cabo en la UD sirvió para saber si se habían alcanzado las capacidades expresadas tanto en los objetivos como en las competencias básicas desarrolladas a través de dichos contenidos.

Con respecto a la identificación de dicha evaluacióna lo largo de las diferentes actividades, se llevaron a cabo cinco tipos de evaluación:

- Evaluación inicial

Este tipo de evaluación se llevó a cabo a través de la actividad inicial para ver las ideas previas del alumnado de la primera sesión. Con este tipo de evaluación se pretendieron evaluar contenidos conceptuales (*) (las relaciones con estos contenidos quedan expresadas en la tabla del punto 8.3.4 de este trabajo) mostrando especial atención a la evaluación de la competencia en el conocimiento e interacción con el mundo físico.

(*) Aunque en algunas de las evaluaciones no se evaluaron todos los tipos de contenidos. En el proceso de evaluación general si se establecieron instrumentos para la evaluación de los tres tipos de contenidos: conceptuales, procedimentales y actitudinales.

Con respecto a las estrategias de registro para la obtención de información para este tipo de evaluación, se realizó un análisis de las actividades previas que realizaron los alumnos/as además de la observación del comportamiento y actitud de los mismos.

Esta evaluación inicial sirvió para saber si se habían alcanzado las capacidades expresadas en el objetivo $\mathrm{n}^{\circ} 1$ (las relaciones entre objetivos didácticos y criterios de evaluación se establece en la siguiente tabla del apartado 8.3.1). 


\section{- Evaluación formativa}

Este tipo de evaluación se llevó a cabo con un seguimiento diario del alumnado relacionado con los objetivos didácticos, ya comentados anteriormente, que se querían alcanzar. La recogida de información a través de este tipo de evaluación fue rápida y sobre todo sin interrumpir la dinámica de clase, posibilitando que se tuviese un análisis de datos casi automático. Además de la recogida de información, dicha evaluación formativa posibilitó que pudiesen desarrollarse las estrategias personalizadas pertinentes posibilitadoras de un mejor aprendizaje. Con este tipo de evaluación continua se pretendieron evaluar conocimientos tanto conceptuales como procedimentales y actitudinales mostrando especial atención a la evaluación de las competencias de conocimiento e interacción con el mundo físico, en comunicación lingüística, digital y de tratamiento de la información, cultural y artística, matemática y competencia para aprender a aprender.

Con respecto a las estrategias de registro para este tipo de evaluación, estas consistieron fundamentalmente en la observación del alumnado tanto durante el trabajo individual de las actividades en clase como de sus actitudes y comportamientos; el análisis realizado de esta evaluación mediante los cuadernos para tener un registro de las actividades realizadas tanto en el aula como en casa y, por último, la participación a la hora de realizar las actividades orales.

Esta evaluación formativa sirvió para saber si se habían alcanzado las capacidades expresadas en los objetivos $\mathrm{n}^{\circ} 2,4,5,6,7,9,11$ y 13 .

\section{- Evaluación sumativa}

Este tipo de evaluación final o sumativa sirvió para complementar la evaluación formativa anteriormente mencionada (y realmente importante en el proceso de evaluación), estando ambas encaminadas a la misma meta. Los datos aportados por la evaluación sumativa fueron usados para la mejora del diseño de la UD así como para la mejora del proceso formativo acerca de la misma.

Dentro de este tipo de evaluación sumativa, los procedimientos de evaluación estuvieron conectados a las metas y estándares de aprendizaje en el denominado "Diseño hacia atrás" (Wiggins y Mctighe, 2005), es decir, partir de los criterios de evaluación hacia el diseño de actividades de aprendizaje.

Esta evaluación se centró en una prueba final escrita en la se pretendieron evaluar conocimientos conceptuales y procedimentales. Dicha prueba escrita utilizada como estrategia de registro se realizó para garantizar la valoración de estos conocimientos. En este caso la evaluación de las competencias se centró en la de conocimiento e interacción con el mundo físico y la cultural y artística.

La evaluación sumativa sirvió para comprobar si se habían alcanzado las capacidades expresadas en los objetivos $\mathrm{n}^{\mathrm{o}} 1,3,4,5$ y 8 . 


\section{- Evaluación del debate}

Para dicha evaluación se realizó una observación del alumnado durante el debate en clase anotando las actitudes que llevaron a cabo. En este tipo de evaluación se evaluaron conocimientos procedimentales y actitudinales, mostrando especial énfasis en la evaluación de las competencias en el conocimiento e interacción con el mundo físico, en comunicación lingüística, autonomía e iniciativa personal y en la competencia social y ciudadana.

Las estrategias de registro para esta evaluación fueron principalmente (y como se ha mencionado anteriormente), la observación de la actitud del alumnado en el debate; la participación y, por último, la calidad de sus aportaciones y sugerencias dentro de los diferentes momentos en los que el debate se dividió.

Esta evaluación sirvió para comprobar si se habían alcanzado las capacidades expresadas en el objetivo $\mathrm{n}^{\mathrm{o}} 10$.

\section{- Evaluación del informe de investigación}

En relación con esta evaluación, se recogió al finalizar la exposición del informe por grupos, un documento en PowerPoint y otro en Word de cada uno de los grupos. Se evaluaron conocimientos conceptuales, procedimentales y actitudinales así como las competencias de conocimiento e interacción con el mundo físico, en comunicación lingüística, autonomía e iniciativa personal, social y ciudadana, cultural y artística tratamiento de la información y competencia digital y, por último, la competencia matemática.

La estrategias de registro para la evaluación de dicho informe de investigación consistieron en el análisis del trabajo grupal mediante la entrega de los mismos (en formato PowerPoint y Word) y en la calidad de las aportaciones y la colaboración entre los alumnos/as dentro del grupo.

Esta evaluación sirvió para comprobar si se habían alcanzado las capacidades expresadas en el objetivo $\mathrm{n}^{\mathrm{o}} 12$.

En relación con la recuperación de los alumnos y alumnas cuya calificación fuese suspensa se estableció realizar un examen unos días después de la prueba correspondiente a la UD en el que se evaluasen los contenidos mínimos requeridos, no obstante, no fue necesaria la realización de dicho examen.

También se planificó el establecimiento de un examen en septiembre para evaluar a aquel alumnado que no hubiese superado los contenidos mínimos durante el curso.

\subsubsection{Criterios de evaluación}

Según se establece en el Real Decreto, el docente de cada asignatura decidirá si el alumno o la alumna han superado los objetivos de la misma, tomando como referente fundamental los criterios de evaluación. 
Asimismo en el DECRETO 416/2008 se establece que los criterios de evaluación de las materias serán el referente fundamental para valorar el grado de consecución de los objetivos previstos para cada una de ellas.

\subsubsection{Criterios de evaluación en la legislación}

En el ANEXO $V$ de este trabajo se fijan los criterios de evaluación para la asignatura de Ciencias para el Mundo Contemporáneo de $1^{\circ}$ de bachillerato establecidos en el REAL DECRETO 1467/2007.

En el ANEXO VI de este trabajo se fijan los criterios de evaluación para la asignatura de Ciencias para el Mundo Contemporáneo de $1^{\circ}$ de bachillerato establecidos en la ORDEN de 5 de agosto de 2008.

\subsubsection{Criterios de evaluación de la Unidad Didáctica}

A partir de dichos criterios establecidos en el Real Decreto se establecieron los siguientes criterios de evaluación para esta UD (estos criterios responden a la pregunta ¿qué evaluar? y constituirán la referencia principal para la valoración del grado de consecución de las competencias básicas):

1. Identifica los principales problemas ambientales relacionados con un desarrollo no sostenible, las causas que los provocan y los factores que los intensifican, siendo consciente de la importancia de la sensibilización ciudadana para actuar sobre los problemas ambientales locales.

Con este criterio de evaluación se pretende desarrollar en los alumnos y alumnas la competencia en el conocimiento e interacción con el mundo físico.

2. Analiza y critica las consecuencias económicas que tiene nuestro modelo de desarrollo y la importancia del contexto político-social en la puesta en práctica de dicho modelo, considerando sus ventajas e inconvenientes desde un punto de vista económico, medioambiental y social.

Se pretende desarrollar las competencias de conocimiento e interacción con el mundo físico y la de tratamiento de la información y competencia digital.

3. Identifica los problemas y las causas que provocan algunos desastres ambientales, predice sus consecuencias y establece propuestas de mejora argumentadas, reconociendo la relevancia de la acción humana tanto en el origen como en la resolución de los mismos.

Se pretende desarrollar la competencia de conocimiento e interacción con el mundo físico.

4. Reconoce y selecciona información sobre la repercusión ambiental de la contaminación atmosférica, realizando una reflexión crítica constructiva y valorando los principales efectos.

Se pretende desarrollar la competencia en el conocimiento e interacción con el mundo físico y la competencia cultural y artística. 
5. Identifica los problemas medioambientales que afectan a las especies en peligro y las características que las hacen vulnerables, siendo consciente de la importancia de la sensibilización social para mantener su valor.

Se pretende desarrollar la competencia de conocimiento e interacción con el mundo físico.

6. Conoce la abundancia de espacios naturales protegidos en España y obtiene información acerca del territorio protegido dentro de la comunidad autónoma andaluza, reconociendo las características que hacen que sea una de las regiones de mayor diversidad biológica de la Península.

Se pretende desarrollar la competencia en el conocimiento e interacción con el mundo físico, la de tratamiento de la información y competencia digital, la cultural y artística y la matemática.

7. Valora la contribución de la ciencia y tecnología a la resolución de los problemas de las personas y de su calidad de vida mediante el razonamiento, aceptando sus limitaciones y equivocaciones propias de toda actividad humana.

Se pretende desarrollar la competencia en el conocimiento e interacción con el mundo físico.

8. Conoce el destino de algunos tipos de residuos, siendo capaz de representar y esquematizar mediante un mapa conceptual su separación, utilización y distribución.

Se pretende desarrollar la competencia en el conocimiento e interacción con el mundo físico.

9. Conoce los aspectos considerados para el cálculo de la huella ecológica de una persona, siendo consciente de que la existencia de una economía planetaria sostenible exige la reducción del consumo de la minoría acomodada perteneciente a los países más ricos.

Se pretende desarrollar la competencia en el conocimiento e interacción con el mundo físico y la competencia matemática.

10. Obtiene, selecciona y valora informaciones sobre la introducción de especies invasoras y comunica conclusiones e ideas en distintos soportes a públicos diversos para formarse opiniones propias argumentadas.

Se pretende desarrollar la competencia en el conocimiento e interacción con el mundo físico, la competencia en comunicación lingüística, la social y ciudadana y la autonomía e iniciativa personal.

11. Modifica las concepciones erróneas preexistentes mediante la incorporación de nuevos conocimientos y la sustitución de la información antigua por la más reciente, realizando una tarea comparativa y argumentada. 
Se pretende desarrollar la competencia en el conocimiento e interacción con el mundo físico, la competencia en comunicación lingüística y la de para aprender a aprender.

12. Realiza estudios sencillos, utilizando eficazmente las tecnologías de la información y comunicación, sobre cuestiones sociales con base científico-tecnológica de ámbito local, haciendo predicciones y valorando las posturas individuales o de pequeños colectivos en su posible evolución.

Se pretende desarrollar la competencia en el conocimiento e interacción con el mundo físico, la competencia en comunicación lingüística, la de tratamiento de la información y competencia digital, la matemática, la social y ciudadana, la cultural y artística y la de autonomía e iniciativa personal.

13. Valora la conservación y mejora del medio ambiente estableciéndolas como requisitos imprescindibles para llevar a cabo un modelo de desarrollo sostenible.

La relación entre cada objetivo didáctico y su correspondiente criterio de evaluación se refleja en la siguiente Tabla 13:

\begin{tabular}{|c|c|c|}
\hline Objetivo didáctico & & Criterio de evaluación \\
\hline $\begin{array}{l}\text { 1.Conocer el significado cualitativo del } \\
\text { concepto de desarrollo sostenible, y otros } \\
\text { conceptos relacionados, y los problemas } \\
\text { ambientales vinculados con dicho } \\
\text { concepto en el entorno más próximo para } \\
\text { formarse opiniones fundamentadas sobre } \\
\text { los mismos }\end{array}$ & $\rightarrow$ & $\begin{array}{l}\text { 1.Identifica los principales problemas } \\
\text { ambientales relacionados con un } \\
\text { desarrollo no sostenible, las causas que los } \\
\text { provocan y los factores que los } \\
\text { intensifican, siendo consciente de la } \\
\text { importancia de la sensibilización } \\
\text { ciudadana para actuar sobre los problemas } \\
\text { ambientales locales }\end{array}$ \\
\hline $\begin{array}{l}\text { 2.Utilizar y seleccionar de forma crítica } \\
\text { información sobre el consumismo } \\
\text { descontrolado y las estrategias para } \\
\text { atenuarlo y plantearse preguntas sobre el } \\
\text { modelo de desarrollo existente en la } \\
\text { actualidad en los países desarrollados }\end{array}$ & $\rightarrow$ & $\begin{array}{l}\text { 2.Analiza y critica las consecuencias } \\
\text { económicas que tiene nuestro modelo de } \\
\text { desarrollo y la importancia del contexto } \\
\text { político-social en la puesta en práctica de } \\
\text { dicho modelo, considerando sus ventajas e } \\
\text { inconvenientes desde un punto de vista } \\
\text { económico, medioambiental y social }\end{array}$ \\
\hline $\begin{array}{l}\text { 3.Identificar las causas de la pérdida de } \\
\text { suelo y aportar propuestas para su } \\
\text { corrección }\end{array}$ & $\rightarrow$ & $\begin{array}{l}\text { 3.Identifica los problemas y las causas que } \\
\text { provocan algunos problemas ambientales, } \\
\text { predice sus consecuencias y establece } \\
\text { propuestas de mejora argumentadas, } \\
\text { reconociendo la relevancia de la acción } \\
\text { humana tanto en el origen como en la } \\
\text { resolución de los mismos }\end{array}$ \\
\hline $\begin{array}{l}\text { 4.Desarrollar la reflexión crítica y la } \\
\text { sensibilidad hacía el medio ambiente } \\
\text { como herramientas de avance personal } \\
\text { frente a la contaminación atmosférica y }\end{array}$ & $\rightarrow$ & $\begin{array}{l}\text { 4.Reconoce y selecciona información } \\
\text { sobre la repercusión ambiental de la } \\
\text { contaminación atmosférica, realizando } \\
\text { una reflexión crítica constructiva y } \\
\text { valorando los principales efectos }\end{array}$ \\
\hline
\end{tabular}




\begin{tabular}{|c|c|c|}
\hline valorar sus efectos & & \\
\hline $\begin{array}{l}\text { 5.Entender las especies protegidas así } \\
\text { como las características que las hacen } \\
\text { vulnerables y las causas que las } \\
\text { amenazan y apreciar su valor, } \\
\text { asociándolas a una buena salud } \\
\text { medioambiental }\end{array}$ & $\rightarrow$ & $\begin{array}{l}\text { 5.Identifica } \\
\text { medioambientales que afectan a las } \\
\text { especies en peligro y las características } \\
\text { que las hacen vulnerables, siendo } \\
\text { consciente de la importancia de la } \\
\text { sensibilización social para mantener su } \\
\text { valor }\end{array}$ \\
\hline $\begin{array}{l}\text { 6.Conocer la abundancia de espacios } \\
\text { naturales protegidos en las diferentes } \\
\text { comunidades autónomas españolas y } \\
\text { reconocer los existentes en Andalucía }\end{array}$ & $\rightarrow$ & $\begin{array}{l}\text { 6.Conoce la abundancia de espacios } \\
\text { naturales protegidos en España y obtiene } \\
\text { información acerca del territorio protegido } \\
\text { dentro de la comunidad autónoma } \\
\text { andaluza, reconociendo las características } \\
\text { que hacen que sea una de las regiones de } \\
\text { mayor diversidad biológica de la } \\
\text { Península }\end{array}$ \\
\hline $\begin{array}{l}\text { 7.Valorar la sostenibilidad o no de } \\
\text { cambios relacionados con la ocupación } \\
\text { del territorio }\end{array}$ & $\rightarrow$ & $\begin{array}{l}\text { 7.Valora la contribución de la ciencia y } \\
\text { tecnología a la resolución de los } \\
\text { problemas de las personas y de su calidad } \\
\text { de vida mediante el razonamiento, } \\
\text { aceptando sus limitaciones y } \\
\text { equivocaciones propias de toda actividad } \\
\text { humana }\end{array}$ \\
\hline $\begin{array}{l}\text { 8. Organizar informaciones sobre los } \\
\text { residuos sólidos urbanos mediante su } \\
\text { representación en esquemas }\end{array}$ & $\rightarrow$ & $\begin{array}{l}\text { 8.Conoce el destino de algunos tipos de } \\
\text { residuos, siendo capaz de representar y } \\
\text { esquematizar mediante un mapa } \\
\text { conceptual su separación, utilización y } \\
\text { distribución }\end{array}$ \\
\hline $\begin{array}{l}\text { 9. Aprender a calcular individualmente la } \\
\text { huella ecológica y saber razonar las } \\
\text { conclusiones de dicho cálculo }\end{array}$ & $\rightarrow$ & $\begin{array}{l}\text { 9. Conoce los aspectos considerados para } \\
\text { el cálculo de la huella ecológica de una } \\
\text { persona, siendo consciente de que la } \\
\text { existencia de una economía planetaria } \\
\text { sostenible exige la reducción del consumo } \\
\text { de la minoría acomodada perteneciente a } \\
\text { los países más ricos }\end{array}$ \\
\hline $\begin{array}{l}\text { 10.Argumentar las consecuencias } \\
\text { sociales y humanas de la introducción de } \\
\text { especies invasoras y su relación con el } \\
\text { medio ambiente y la economía y valorar } \\
\text { las informaciones mostradas, } \\
\text { desarrollando criterios propios }\end{array}$ & $\rightarrow$ & $\begin{array}{l}\text { 10.Obtiene, selecciona y valora } \\
\text { informaciones sobre la introducción de } \\
\text { especies invasoras y comunica } \\
\text { conclusiones e ideas en distintos soportes } \\
\text { a públicos diversos para formarse } \\
\text { opiniones propias argumentadas }\end{array}$ \\
\hline
\end{tabular}




\begin{tabular}{|c|c|c|}
\hline $\begin{array}{l}\text { 11.Ser capaz de modificar conocimientos } \\
\text { previos erróneos de forma coherente y } \\
\text { fundamentada }\end{array}$ & $\rightarrow$ & $\begin{array}{l}\text { 11. Modifica las concepciones erróneas } \\
\text { preexistentes mediante la incorporación de } \\
\text { nuevos conocimientos y la sustitución de } \\
\text { la información antigua por la más reciente, } \\
\text { realizando una tarea comparativa y } \\
\text { argumentada }\end{array}$ \\
\hline $\begin{array}{l}\text { 12.Saber analizar informaciones de } \\
\text { contenido científico, formular hipótesis y } \\
\text { obtener conclusiones fundamentadas que } \\
\text { puedan ser comunicadas a los demás con } \\
\text { coherencia y claridad }\end{array}$ & $\rightarrow$ & $\begin{array}{l}\text { 12.Realiza estudios sencillos, utilizando } \\
\text { eficazmente las tecnologías de la } \\
\text { información y comunicación, sobre } \\
\text { cuestiones sociales con base científico- } \\
\text { tecnológica de ámbito local, haciendo } \\
\text { predicciones y valorando las posturas } \\
\text { individuales o de pequeños colectivos en } \\
\text { su posible evolución }\end{array}$ \\
\hline $\begin{array}{l}\text { 13.Desarrollar una actitud de respeto } \\
\text { hacia el medio ambiente, necesaria para } \\
\text { la atenuación de los problemas } \\
\text { ambientales surgidos a partir del modelo } \\
\text { de desarrollo actual, para la construcción } \\
\text { de un futuro sostenible y en equilibrio }\end{array}$ & $\rightarrow$ & $\begin{array}{l}\text { 13.Valora la conservación y mejora del } \\
\text { medio ambiente estableciéndolas como } \\
\text { requisitos imprescindibles para llevar a } \\
\text { cabo un modelo de desarrollo sostenible }\end{array}$ \\
\hline
\end{tabular}

Tabla 13. Relación de cada objetivo con su correspondiente criterio de evaluación.

\subsubsection{Criterios de calificación}

Con respecto a los criterios de calificación, los porcentajes (sobre el 100\%) que correspondieron a cada uno de dichos criterios fueron los siguientes:

- Actividades realizadas en clase y casa: $10 \%$

- Debate: $10 \%$

- Trabajo de investigación: $30 \%$

- Prueba final: $40 \%$

- Actitud y comportamiento: $10 \%$

\subsubsection{Procedimientos e instrumentos de evaluación}

Atendiendo a lo mencionado en el apartado anterior, los procedimientos llevados a cabo dentro de la evaluación de la UD fueron los siguientes:

- Observación sistemática del trabajo individual de las actividades en clase, de la participación, de las actitudes de los alumnos/as y de la cooperación en el trabajo en grupo.

- Establecimiento de entrevistas para el seguimiento de los aspectos positivos y los problemas surgidos (individuales o en grupo) durante el aprendizaje de los contenidos. 
- Revisión de cuadernos de actividades y trabajos.

- Autoevaluación del alumnado en la actividad de ideas previas.

- Actividad de evaluación final o sumativa.

En relación a los instrumentos de evaluación empleados, estos fueron los siguientes:

- Indagación de los conocimientos previos.

- Registro de las actividades de clase y entrevistas.

- Actividad final de evaluación.

- Rúbrica del trabajo de investigación, en la que se evaluaron los siguientes aspectos: cantidad y calidad de la información utilizada en la realización del informe, análisis y uso de la información y exposición individual de cada alumno el día de la exposición por grupos.

- Dosier de trabajos de los alumnos/as. 
8.3.4. Tabla resumen de la evaluación

\begin{tabular}{|c|c|c|c|c|c|c|c|c|}
\hline \multicolumn{3}{|c|}{ ASPECTO A EVALUAR } & CONTENIDO(S) & TIPO EVALUACIÓN & $\begin{array}{l}\text { CRITERIO(S) DE } \\
\text { FVALIACIÓN }\end{array}$ & \multicolumn{2}{|c|}{ PORCENTAJE } & COMPETENCIAS BÁSICAS \\
\hline \multirow{8}{*}{$\begin{array}{l}\text { Actividades } \\
\text { realizadas en } \\
\text { clase y casa }\end{array}$} & & Act. 1.1. & 1a/1e/1f/1i(*) & Inicial & 1 & \multirow{7}{*}{\multicolumn{2}{|c|}{$10 \%$}} & $\mathrm{~A}(+)$ \\
\hline & & Act. 2.1 & $1 b / 2 a / 3 a$ & \multirow[t]{7}{*}{ Formativa } & 2 & & & A y $\mathrm{C}$ \\
\hline & & Act. 3.1 & $1 \mathrm{e} / 3 \mathrm{~b}$ & & 4 & & & A y D \\
\hline & & Act. 4.1 & $1 \mathrm{~h}$ & & 5 & & & A \\
\hline & & Act. 4.2 & $1 \mathrm{~h}$ & & 6 & & & $\mathrm{~A}, \mathrm{C}, \mathrm{D}$ y $\mathrm{E}$ \\
\hline & & Act. 4.3 & $1 \mathrm{j} / 2 \mathrm{~b}$ & & 7 & & & A \\
\hline & & Act. 6.2 & $1 \mathrm{~h} / 1 \mathrm{j} / 2 \mathrm{e}$ & & 11 & & & A, B y H \\
\hline & & Act. 9.1 & $3 \mathrm{f}$ & & 13 & & evaluado & A, C, F y G \\
\hline \multirow[t]{2}{*}{ Debate } & & Act. 5.2 & $2 \mathrm{~d}$ & \multirow[t]{2}{*}{ Evaluación del debate } & \multirow[t]{2}{*}{10} & \multirow{2}{*}{\multicolumn{2}{|c|}{$10 \%$}} & A, B, F y G \\
\hline & & Act. 6.1 & $2 d / 3 c / 3 d$ & & & & & \\
\hline \multirow[t]{3}{*}{$\begin{array}{c}\text { Trabajo de } \\
\text { investigación }\end{array}$} & Act. 8.1 & $\begin{array}{l}\text { Cantidad y calidad } \\
\text { de información }\end{array}$ & \multirow[t]{3}{*}{$11 / 2 \mathrm{~g} / 3 \mathrm{c} / 3 \mathrm{~d} / 3 \mathrm{e}$} & \multirow[t]{3}{*}{$\begin{array}{l}\text { Evaluación del informe de } \\
\text { investigación }\end{array}$} & \multirow[t]{3}{*}{12} & $10 \%$ & \multirow[t]{3}{*}{$30 \%$} & \multirow[t]{3}{*}{$\mathrm{A}, \mathrm{B}, \mathrm{C}, \mathrm{D}, \mathrm{E}, \mathrm{F}$ y G } \\
\hline & Act. 8.1 & $\begin{array}{l}\text { Análisis y uso de la } \\
\text { información }\end{array}$ & & & & $10 \%$ & & \\
\hline & Act. 8.1 & $\begin{array}{c}\text { Exposición } \\
\text { individual }\end{array}$ & & & & $10 \%$ & & \\
\hline Prueba final & & Act. 7.1 & $1 \mathrm{a} / 1 \mathrm{c} / 1 \mathrm{~d} / 1 \mathrm{f} / 1 \mathrm{~g} / 1 \mathrm{~h} / 1 \mathrm{k} / 11 / 2 \mathrm{f}$ & Sumativa & $1,3,4,5$ y 8 & & $40 \%$ & A y D \\
\hline \multicolumn{3}{|c|}{ Actitud y comportamiento } & & Todas las evaluaciones & & & $10 \%$ & $\mathrm{~F}$ \\
\hline
\end{tabular}

Tabla 14. Principales aspectos de la evaluación llevada a cabo. 
(*) El significado de estas claves de contenidos viene explicado en el apartado 6.4.2 siguiente.

(+) El significado de cada letra con su correspondiente competencia básica es el siguiente:

- A: competencia en el conocimiento e interacción con el mundo físico.

- B: competencia en comunicación lingüística.

- C: tratamiento de la información y competencia digital.

- D: competencia cultural y artística.

- E: competencia matemática.

- F: competencia social y ciudadana.

- G: autonomía e iniciativa personal.

- H: competencia para aprender a aprender.

\subsection{CONTENIDOS}

\subsubsection{Contenidos en la legislación}

En el ANEXO VII de este trabajo se fijan los contenidos de la asignatura de Ciencias para el Mundo Contemporáneo en $1^{\circ}$ de bachillerato establecidos en el REAL DECRETO 1467/2007 dentro del bloque 4 (Hacia una gestión sostenible del planeta).

En el ANEXO VIII de este trabajo se fijan los contenidos de la asignatura de Ciencias para el Mundo Contemporáneo en $1^{\circ}$ de bachillerato establecidos en la ORDEN de 5 de agosto de 2008 dentro del núcleo temático 7 (¿Es sostenible nuestro desarrollo?).

\subsubsection{Contenidos de la Unidad Didáctica}

El artículo 2 (Componentes del currículo) de la ORDEN de 5 de agosto de 2008 establece que los contenidos propios de la Comunidad Autónoma de Andalucía versarán sobre el tratamiento de la realidad andaluza en sus aspectos geográficos, económicos, sociales, históricos, culturales, científicos y de investigación a fin de mejorar las competencias ciudadanas del alumnado, su madurez intelectual y humana, y los conocimientos y habilidades que le permitan desarrollar las funciones sociales precisas para incorporarse a la vida activa y a la educación superior con responsabilidad, competencia y autonomía.

Los objetivos didácticos mencionados anteriormente se pretendieron conseguir con el establecimiento de los siguientes contenidos (¿qué enseñar?):

1. Conceptuales:

a) El concepto de desarrollo sostenible. Factores de los que depende la sostenibilidad.

b) Modelos de desarrollo: características del modelo de desarrollo sostenible. Efectos de nuestro modelo de desarrollo: la obsolescencia programada. 
c) La sobreexplotación del aire.

d) Sobreexplotación del suelo: los riesgos y correcciones a la erosión del suelo. Edafogénesis y tipos de suelo.

e) La contaminación como impacto: contaminación atmosférica, acústica y lumínica.

f) La desertización como impacto.

g) El aumento de los residuos como impacto: gestión de los residuos sólidos urbanos.

h) La pérdida de biodiversidad como impacto. Características que hacen vulnerables a las especies y causas que las amenazan. Espacios naturales protegidos en España y Andalucía.

i) El cambio climático.

j) El problema del crecimiento ilimitado en un planeta limitado. Ocupación del territorio y desarrollo urbanístico descontrolado.

k) La huella ecológica: consideraciones.

1) Los compromisos internacionales y la responsabilidad ciudadana: "regla de las tres erres" y consumo sostenible.

Las competencias trabajadas con los contenidos conceptuales son la competencia en el conocimiento e interacción con el mundo físico, la competencia lingüística, el tratamiento de la información y competencia digital, la cultural y artística, la matemática, la social y ciudadana, la de autonomía e iniciativa personal y aprender a aprender.

2. Procedimentales:

a) Utilización de métodos interpretativos para entender una información.

b) Análisis de las consecuencias sostenibles o no de cambios relacionados con la ocupación del territorio.

c) Cálculo de la huella ecológica.

d) Evaluación de las consecuencias sociales y humanas de la introducción de especies invasoras.

e) Demostración de la modificación de conocimientos previos erróneos.

f) Organización de información acerca de la separación y destino de los residuos sólidos urbanos mediante esquemas.

g) Análisis de informaciones de contenido científico sobre las prácticas de reciclaje.

Las competencias trabajadas con los contenidos procedimentales son la competencia en el conocimiento e interacción con el mundo físico, la competencia en comunicación lingüística, el tratamiento de la información y competencia digital, la cultural y artística, la matemática, la social y ciudadana, la de autonomía e iniciativa personal y la de aprender a aprender. 
3. Actitudinales:

a) Valoración de la importancia de adoptar un modelo de desarrollo sostenible.

b) Valoración de la necesidad de mantener una sensibilidad y visión real hacia el medio ambiente.

c) Tolerancia y respeto hacia las diferentes opiniones de otros compañeros.

d) Mejora de la autoestima ante la expresión en público.

e) Aceptación de las limitaciones (tanto propias como ajenas) en la valoración y realización de tareas grupales.

f) Problemas ambientales surgidos a raíz del modelo de desarrollo actual. Valoración de sus consecuencias mediante la adopción de una actitud de respeto.

Las competencias trabajadas con los contenidos actitudinales son la de conocimiento e interacción con el mundo físico, la lingüística, la de tratamiento de la información, la cultural y artística, la social y ciudadana, la matemática, autonomía e iniciativa personal y aprender a aprender.

\subsubsection{Temas transversales}

Cuando hablamos de contenidos transversales nos referimos a aquellos que recogen demandas y problemáticas sociales que tienen relación con temas de interés general. A la hora de trabajar dichos contenidos se requiere de un encuadre ético que sea capaz de desarrollar actitudes cuidadosas y de valoración del alumnado hacia la propia persona, la comunidad y el ambiente natural.

Los temas recogidos como transversales dentro de esta UD fueron los siguientes:

\section{- Educación moral y cívica}

Para posibilitar la existencia de un planeta sostenible y equilibrado es necesario el compromiso de todos. Se requiere, por tanto, de unos fundamentos para vivir correctamente en sociedad.

\section{- Educación para la salud}

El aumento de la contaminación atmosférica está propiciando el aumento de la incidencia de ciertas enfermedades. La Organización Mundial de la Salud considera que este tipo de contaminación es responsable del 1,4\% de las muertes mundiales además de contribuir a la aparición de asma, bronquitis, enfermedades pulmonares crónicas, enfermedades cardiovasculares y ciertos tipos de cáncer.

Con estos datos se pretendió que los alumnos/as recapacitasen acerca de las consecuencias para la salud que tienen las emisiones de contaminantes a la atmósfera además de que fuesen conscientes de su propio papel en evitar tales actitudes no saludables para los habitantes del planeta. 


\section{- Educación ambiental}

Para trabajar este tema transversal los alumnos y alumnas realizaron un informe científico en el que tuvieron que analizar el problema que supone la falta de reciclaje además de establecer conclusiones y soluciones frente a dicho problema ambiental.

- Educación al consumidor

La educación al consumidor es uno de los objetivos declarados de la Unión Europea. Los objetivos de la UE establecen que tiene que desarrollarse en un área económica sostenible y próspera.

Con la exposición en clase de los documentales "La historia de las cosas" y "Comprar, tirar, comprar" durante las primeras sesiones se pretendió inculcar al alumnado las habilidades, actitudes y conocimientos requeridos para vivir en una sociedad de consumo ya que para el desarrollo de un área económica sostenible y próspera es necesario que la calidad y bases de la vida de los ciudadanos no se destruyan por una excesiva demanda de consumo.

Con el tratamiento de estos temas transversales así como de los contenidos comentados anteriormente se intentó educar a los alumnos/as en valores como la tolerancia, el respeto o la responsabilidad.

\subsection{ACTIVIDADES Y TAREAS PROPUESTAS}

El artículo 9 (Currículo) del REAL DECRETO 1467/2007 establece que las administraciones educativas promoverán las medidas necesarias para que en las distintas materias se desarrollen actividades que estimulen el interés y el hábito de lectura y la capacidad de expresarse correctamente en público así como el uso de las tecnologías de la información y la comunicación.

Los modelos de enseñanza que se trabajaron en la secuenciación de actividades llevada a cabo con la UD fueron dos: Modelo de Enseñanza Directa con toda la clase y el Modelo de Enseñanza a través de la Indagación y el Descubrimiento (Modelo Inductivo).Las actividades realizadas además intentaron ser realistas con el tiempo que implicaban, teniendo a veces que incluirse el trabajo en casa.

Los contenidos (conceptuales, procedimentales y actitudinales) comentados anteriormente se secuenciaron en las siguientes actividades (mencionadas en el apartado 5 de estructura y organización):

$1^{\mathrm{o}}$ Sesión:

ACTIVIDAD 1.1. (“¿QUÉ OPINAS DEL DESARROLLO SOSTENIBLE?”) (En las tablas 15 y 16 se establecen las características de las actividades/tareas llevadas a cabo en clase y las competencias básicas desarrolladas con las mismas respectivamente) (*): actividad para saber los conocimientos previos de los alumnos/as sobre desarrollo sostenible y los problemas ambientales relacionados con un desarrollo insostenible. También se les pidió que intentasen 
concretar algún problema medioambiental de ámbito internacional reciente en su entorno más cercano.

En el ANEXO IX de este trabajo aparecen las tareas y actividades llevadas a cabo a lo largo de la UD.

(*) Además de ello (y como queda reflejado en la tabla 17) todas las actividades (tanto las realizadas en clase como las preguntas que conformaron el examen final) presentan correspondencia con los objetivos didácticos establecidos anteriormente.

$2^{\circ}$ Sesión:

ACTIVIDAD 2.1. ("RELACIONA EL DOCUMENTAL CON LOS MODELOS DE DESARROLLO"): actividad en la que los alumnos y alumnas tuvieron que realizar un comentario crítico acerca del documental: "Comprar, tirar, comprar" (sobre la obsolescencia programada). Dicho comentario crítico tuvieron que realizarlo relacionando los tres modelos de desarrollo explicados en la anterior sesión, y cuya comprensión era básica para la del resto de la unidad, con la repercusión social, económica y ambiental que cada uno de ellos podía tener en el planeta. Para ello, tuvieron que relacionar dicho concepto de obsolescencia programada con los modelos de desarrollo, valorando las consecuencias de la utilización de uno u otro $\left(^{*}\right)$.

(*) Cada una de las actividades se intentó relacionar con los contenidos trabajados en clase para que los alumnos y alumnas entendiesen que se trataba de una secuencia de aprendizaje y no exclusivamente de un grupo de actividades.

$3^{\circ}$ Sesión:

ACTIVIDAD 3.1. ("SITÚA EL DIBUJO EN UN AÑO Y EN UNA CIUDAD Y PONLE NOMBRE"): actividad en la que los alumnos/as tuvieron que nombrar y situar en un lugar y en un año un dibujo de marcada crítica medioambiental. Además de ello, se les pidió que indicasen que aspectos y efectos concretos creían que pretendía criticar el dibujo y si pensaban que dicho dibujo reflejaba la realidad actual. Esta actividad se realizó para trabajar el concepto de contaminación atmosférica explicado en clase a la vez que se relacionó con la pregunta de ideas previas de la primera sesión.

$4^{\circ}$ Sesión:

ACTIVIDAD 4.1. (“¿POR QUÉ SON PROPENSOS A LA EXTINCIÓN?”): actividad en la que los alumnos/as tuvieron que indicar razones que justificasen la relación entre las características de algunas especies (como ballena azul, rinoceronte negro, panda gigante, etc.) que las hacen especialmente vulnerables a la extinción y a dicha vulnerabilidad. Dicha actividad se realizó para aplicar los conocimientos trabajados en clase sobre pérdida de biodiversidad y las especies en peligro de extinción a la vez que se relacionaron estos con la actividad de ideas previas. Se pretendió que los alumnos y alumnas fuesen conscientes de la cercanía de dichos problemas.

ACTIVIDAD 4.2. (“LAS ÁREAS PROTEGIDAS"): actividad en la que el alumnado tuvo que realizar un análisis geográfico (por comunidades autónomas) de los espacios protegidos naturales en España y buscar información sobre los espacios naturales protegidos en Andalucía. 
Esta actividad (relacionada también con la anterior) se realizó para que los alumnos/as conociesen la cantidad de espacios protegidos en España y Andalucía así como la importancia de dicha protección para salvaguardar la pérdida de biodiversidad.

ACTIVIDAD 4.3. (“¿CAMINA HACIA LA SOSTENIBILIDAD?”): actividad en la que los alumnos y alumnas tuvieron que valorar la sostenibilidad o no de los cambios realizados en una determinada comunidad autónoma española. La actividad fue una buena forma de trabajar las consecuencias sostenibles o no de algunos cambios, explicados en clase, relacionados con la ocupación del terreno. Con esta actividad se pretendió que el alumnado viese el problema de la ocupación del territorio como algo cercano, conectando dicho concepto también con la actividad de ideas previas de la primera sesión.

\section{$5^{\circ}$ Sesión:}

ACTIVIDAD 5.1. (“CALCULA TU HUELLA ECOLÓGICA”): actividad para calcular la huella ecológica individualmente a partir de un test de preguntas. Se pretendió que los alumnos/as aprendiesen a calcular su huella ecológica y aprendiesen a interpretar las conclusiones derivadas de dicho cálculo, relacionando las mismas con las consideraciones de dicho concepto de huella ecológica explicadas en clase acerca de la importancia de los hábitos de las personas en la sostenibilidad del planeta.

ACTIVIDAD 5.2. (“EXPLICA EL TITULO DEL DOCUMENTAL”): actividad en la que a partir de la visualización de un fragmento del documental: "La pesadilla de Darwin" se pidió a alumnado que intentase explicar el título de dicho documental. Se pretendió que los alumnos/as entendiesen el título del documental y estableciesen relaciones entre el mismo y la pérdida de biodiversidad, además de establecer si creían que este problema podía llevar implícito consecuencias sociales.

$6^{\circ}$ Sesión:

ACTIVIDAD 6.1. ("DEBATE SOBRE LAS CONSECUENCIAS HUMANAS DE LA PRODUCCIÓN DE LA PERCA DEL NILO”): actividad consistente en la realización de un debate entre toda la clase para analizar si además de las consecuencias medioambientales (pérdida de biodiversidad, contaminación, deforestación o agotamiento de recursos) que trataba el documental existían consecuencias sociales en los diferentes colectivos perjudicados (niños, trabajadores, mujeres, etc.). Con esta actividad se pretendió evaluar las consecuencias humanas de una de las causas responsables de la extinción de las especies (la introducción de especies invasoras) explicada en clase a la vez que re realizaba un repaso general de los principales conceptos trabajados en clase, relacionándolos con sus consecuencias reales en el planeta.

ACTIVIDAD 6.2. (“RETROSPECTIVA DE IDEAS PREVIAS"): actividad que consistió en que los alumnos y alumnas, a partir de las respuestas que habían dado en la tarea de ideas previas de la primera sesión, reflexionasen acerca de si dichas respuestas las cambiarían o modificarían después de haberse explicado el tema. Con esta actividad se pretendió que los alumnos/as, a partir de los contenidos trabajados en clase, fuesen capaces de modificar y complementar a modo de resumen (ya que durante todas las sesiones se intentó confrontarlos con sus ideas) algunas ideas previas.

$7^{\circ}$ Sesión: 
ACTIVIDAD 7.1. (EXAMEN): actividad de evaluación final. Se pretendió evaluar los conocimientos del alumnado sobre algunos de los principales contenidos trabajados en clase y en las diferentes actividades (conceptos básicos, pérdida de suelo, etc.)

\section{$8^{\circ}$ Sesión:}

ACTIVIDAD 8.1. (EXPOSICIÓN INFORME DE INVESTIGACIÓN): actividad consistente en la exposición por grupos de los informes de investigación acerca del reciclaje. Con esta actividad se pretendió que los alumnos/as fuesen conscientes de las prácticas de reciclaje tanto en su entorno más cercano como a nivel global para comprender la importancia del reciclaje y la acción ciudadana en el concepto de consumo sostenible explicado en clase.

\section{9o Sesión:}

ACTIVIDAD 9.1. ("REFLEXIONA SOBRE TU PAPEL HACIA EL MEDIO AMBIENTE"): actividad consistente en la realización de una reflexión acerca de las medidas que los ciudadanos pueden adoptar ante los problemas ambientales ocasionados por nuestro modelo de desarrollo mediante la salida al Parque de las Ciencias de Granada.

En la siguiente Tabla 15 se especifican las características de las actividades y tareas llevadas a cabo durante esta UD:

\begin{tabular}{|c|c|c|c|c|c|c|c|c|}
\hline Actividad & $\begin{array}{c}\text { Contenidos } \\
\text { trabajados }\end{array}$ & Recursos & Estilo & Espacios & Tiempos & $\begin{array}{c}\text { Agrupam } \\
\text { iento }\end{array}$ & Rol docente & Tipo \\
\hline 1.1 & $1 \mathrm{a} / 1 \mathrm{e} / 1 \mathrm{f} / 1 \mathrm{i}$ & $\begin{array}{c}\text { De } \\
\text { elaboración } \\
\text { propia }\end{array}$ & $\begin{array}{c}\text { De } \\
\text { conexión- } \\
\text { interpretaci } \\
\text { ón }\end{array}$ & Aula & $\begin{array}{c}\text { De trabajo } \\
\text { autónomo }\end{array}$ & Individual & $\begin{array}{c}\text { Directivo } \\
\text { (convergente) }\end{array}$ & Inicio \\
\hline 2.1 & $1 \mathrm{~b} / 2 \mathrm{a} / 3 \mathrm{a}$ & $\mathrm{TIC}$ & $\begin{array}{c}\text { De } \\
\text { reflexión- } \\
\text { valorativa }\end{array}$ & $\begin{array}{c}\text { Interno al } \\
\text { centro } \\
\text { (laboratorio } \\
\text { de Biología } \\
\text { y Geología) }\end{array}$ & $\begin{array}{c}\text { De trabajo } \\
\text { autónomo }\end{array}$ & Individual & $\begin{array}{c}\text { Asesoramiento } \\
\text {-guía } \\
\text { (divergente) }\end{array}$ & Reflexión \\
\hline 3.1 & $1 \mathrm{e} / 3 \mathrm{~b}$ & TIC & $\begin{array}{c}\text { De } \\
\text { reflexión- } \\
\text { valorativa }\end{array}$ & Aula & $\begin{array}{c}\text { De trabajo } \\
\text { autónomo }\end{array}$ & Individual & $\begin{array}{c}\text { Directivo } \\
\text { (convergente) }\end{array}$ & $\begin{array}{c}\text { Comprensión } \\
\text { /reflexión }\end{array}$ \\
\hline 4.1 & $1 \mathrm{~h}$ & $\begin{array}{c}\text { Libro de } \\
\text { texto }\end{array}$ & $\begin{array}{c}\text { De } \\
\text { reflexión- } \\
\text { valorativa }\end{array}$ & Aula & De trabajo \\
dirigido & $\begin{array}{c}\text { Gran } \\
\text { grupo }\end{array}$ & $\begin{array}{c}\text { Asesoramiento } \\
\text {-gúá } \\
\text { (divergente) }\end{array}$ & $\begin{array}{c}\text { Comprensión } \\
\text { /refuerzo/co } \\
\text { municación }\end{array}$ \\
\hline 4.2 & $1 \mathrm{~h}$ & $\begin{array}{c}\text { Libro de } \\
\text { texto/ TIC }\end{array}$ & $\begin{array}{c}\text { Reproducti } \\
\text { vo }\end{array}$ & Aula & $\begin{array}{c}\text { De trabajo } \\
\text { autónomo }\end{array}$ & $\begin{array}{c}\text { Individual } \\
\text { Directivo } \\
\text { (convergente) }\end{array}$ & $\begin{array}{c}\text { Desarrollo/a } \\
\text { mpliación }\end{array}$ \\
\hline 4.3 & $1 \mathrm{j} / 2 \mathrm{~b}$ & Libro de \\
texto & $\begin{array}{c}\text { De } \\
\text { conexión- } \\
\text { interpretaci } \\
\text { ón }\end{array}$ & Aula & $\begin{array}{c}\text { De trabajo } \\
\text { autónomo }\end{array}$ & Individual & $\begin{array}{c}\text { Directivo } \\
\text { (convergente) }\end{array}$ & $\begin{array}{c}\text { Desarrollo/re } \\
\text { fuerzo }\end{array}$ \\
\hline
\end{tabular}




\begin{tabular}{|c|c|c|c|c|c|c|c|c|}
\hline 5.1 & $1 \mathrm{k} / 2 \mathrm{c}$ & TIC & $\begin{array}{c}\text { De } \\
\text { reflexión- } \\
\text { valorativa }\end{array}$ & $\begin{array}{c}\text { Interno al } \\
\text { centro } \\
\text { (laboratorio } \\
\text { de Biología } \\
\text { y Geología) }\end{array}$ & $\begin{array}{c}\text { De trabajo } \\
\text { dirigido }\end{array}$ & $\begin{array}{l}\text { Cooperati } \\
\text { vo }\end{array}$ & $\begin{array}{c}\text { Asesoramiento } \\
\text {-guía } \\
\text { (divergente) }\end{array}$ & Aplicación \\
\hline 5.2 & $2 d$ & TIC & $\begin{array}{c}\text { De } \\
\text { conexión- } \\
\text { interpretaci } \\
\text { ón }\end{array}$ & $\begin{array}{l}\text { Interno al } \\
\text { centro } \\
\text { (laboratorio } \\
\text { de Biología } \\
\text { y Geología) }\end{array}$ & $\begin{array}{l}\text { De trabajo } \\
\text { autónomo }\end{array}$ & Individual & $\begin{array}{c}\text { Asesoramiento } \\
\text {-guía } \\
\text { (divergente) }\end{array}$ & Comprensión \\
\hline 6.1 & $2 d / 3 c / 3 d$ & $\begin{array}{c}\text { De } \\
\text { elaboración } \\
\text { propia }\end{array}$ & $\begin{array}{l}\quad \text { De } \\
\text { reflexión- } \\
\text { valorativa }\end{array}$ & Aula & $\begin{array}{c}\text { De trabajo } \\
\text { dirigido }\end{array}$ & $\begin{array}{l}\text { Gran } \\
\text { grupo }\end{array}$ & $\begin{array}{c}\text { Asesoramiento } \\
\text {-guía } \\
\text { (divergente) }\end{array}$ & $\begin{array}{c}\text { Comunicació } \\
\text { n/reflexión }\end{array}$ \\
\hline 6.2 & $1 \mathrm{~h} / 1 \mathrm{j} / 2 \mathrm{e}$ & $\begin{array}{c}\text { De } \\
\text { elaboración } \\
\text { propia }\end{array}$ & \begin{tabular}{l}
\multicolumn{1}{c}{ De } \\
reflexión- \\
valorativa
\end{tabular} & Aula & $\begin{array}{c}\text { De trabajo } \\
\text { dirigido }\end{array}$ & $\begin{array}{l}\text { Gran } \\
\text { grupo }\end{array}$ & $\begin{array}{c}\text { Asesoramiento } \\
\text {-guía } \\
\text { (divergente) }\end{array}$ & $\begin{array}{l}\text { Aplicación/c } \\
\text { omunicación/ } \\
\text { reflexión }\end{array}$ \\
\hline 7.1 & $\begin{array}{c}1 \mathrm{a} / 1 \mathrm{c} / 1 \mathrm{~d} / 1 \mathrm{f} / \\
1 \mathrm{~g} / 1 \mathrm{~h} / 1 \mathrm{k} / 1 \mathrm{l} / \\
2 \mathrm{f}\end{array}$ & $\begin{array}{c}\text { De } \\
\text { elaboración } \\
\text { propia }\end{array}$ & $\begin{array}{l}\text { Reproducti } \\
\text { vo }\end{array}$ & Aula & $\begin{array}{l}\text { De trabajo } \\
\text { autónomo }\end{array}$ & Individual & $\begin{array}{c}\text { Directivo } \\
\text { (convergente) }\end{array}$ & $\begin{array}{c}\text { Desarrollo/m } \\
\text { emoria/organ } \\
\text { ización/aplic } \\
\text { ación/compre } \\
\text { nsión }\end{array}$ \\
\hline 8.1 & $\begin{array}{c}11 / 2 \mathrm{~g} / 3 \mathrm{c} / 3 \mathrm{~d} / \\
3 \mathrm{e}\end{array}$ & TIC & $\begin{array}{l}\text { Reproducti } \\
\text { vo }\end{array}$ & Aula & $\begin{array}{c}\text { De trabajo } \\
\text { dirigido }\end{array}$ & $\begin{array}{l}\text { Cooperati } \\
\text { vo }\end{array}$ & $\begin{array}{c}\text { Asesoramiento } \\
\text {-guía } \\
\text { (divergente) }\end{array}$ & $\begin{array}{c}\text { Aplicación/c } \\
\text { omunicación/ } \\
\text { investigación } \\
\text { /organización } \\
\text { /ampliación/ } \\
\text { desarrollo/cie } \\
\text { rre }\end{array}$ \\
\hline 9.1 & $3 f$ & TIC & $\begin{array}{l}\quad \mathrm{De} \\
\text { reflexión- } \\
\text { valorativa }\end{array}$ & $\begin{array}{l}\text { Externo al } \\
\text { centro }\end{array}$ & $\begin{array}{l}\text { De trabajo } \\
\text { autónomo }\end{array}$ & Individual & $\begin{array}{c}\text { Asesoramiento } \\
\text {-guía } \\
\text { (divergente) }\end{array}$ & $\begin{array}{c}\text { Reflexión/in } \\
\text { vestigación }\end{array}$ \\
\hline
\end{tabular}

Tabla 15. Características de las actividades/tareas llevadas a cabo. 
En la siguiente Tabla 16 se especifican las competencias trabajadas en cada una de las actividades y tareas:

\begin{tabular}{|c|c|c|c|c|c|c|c|c|c|c|c|c|c|}
\hline \multirow{4}{*}{$\begin{array}{c}\text { COMPETENCIAS } \\
\text { BÁSICAS }\end{array}$} & \multicolumn{13}{|c|}{ ACTIVIDADES/TAREAS } \\
\hline & \multirow{3}{*}{$\begin{array}{c}\begin{array}{c}1^{\circ} \\
\text { sesión }\end{array} \\
\text { Act. } \\
1.1\end{array}$} & \multirow{3}{*}{$\begin{array}{c}\begin{array}{c}2^{\circ} \\
\text { sesión }\end{array} \\
\text { Act. } \\
2.1\end{array}$} & \multirow{3}{*}{$\begin{array}{c}\begin{array}{c}3^{\circ} \\
\text { sesión }\end{array} \\
\text { Act. } \\
3.1\end{array}$} & \multicolumn{3}{|c|}{$\begin{array}{l}4^{\circ} \\
\text { sesión }\end{array}$} & \multicolumn{2}{|c|}{$\begin{array}{l}5^{\circ} \\
\text { sesión }\end{array}$} & \multicolumn{2}{|c|}{$\begin{array}{c}6^{\circ} \\
\text { sesión }\end{array}$} & \multirow{2}{*}{$\begin{array}{c}\begin{array}{c}7^{\circ} \\
\text { sesión }\end{array} \\
\text { Act. }\end{array}$} & \multirow{2}{*}{$\begin{array}{c}8^{\circ} \\
\text { sesión } \\
\text { Act. }\end{array}$} & \multirow{2}{*}{$\begin{array}{c}\begin{array}{c}9^{\circ} \\
\text { sesión }\end{array} \\
\text { Act. }\end{array}$} \\
\hline & & & & Act. & Act. & Act. & Act. & Act. & Act. & Act. & & & \\
\hline & & & & 4.1 & 4.2 & 4.3 & 5.1 & 5.2 & 6.1 & 6.2 & 7.1 & 8.1 & 9.1 \\
\hline Lingüística $(*)$ & & & & & & & & $X$ & $X$ & $X$ & & $X$ & \\
\hline $\begin{array}{l}\text { En el conocimiento } \\
\text { e interacción con el } \\
\text { mundo físico }\end{array}$ & $X$ & $X$ & $X$ & $X$ & $X$ & $X$ & $X$ & $X$ & $X$ & $X$ & $X$ & $X$ & $X$ \\
\hline $\begin{array}{l}\text { Tratamiento de la } \\
\text { información } \\
\text { competencia digital }\end{array}$ & & $X$ & & & $X$ & & & & & & & $X$ & $\mathrm{X}$ \\
\hline Cultural y artística & & & $\mathrm{X}$ & & $X$ & & & & & & $X$ & $X$ & \\
\hline Social y ciudadana & & & & & & & & $\mathrm{X}$ & $\mathrm{X}$ & & & $X$ & $\mathrm{X}$ \\
\hline Matemática & & & & & $\mathrm{X}$ & & $\mathrm{X}$ & & & & & $\mathrm{X}$ & \\
\hline $\begin{array}{l}\text { Autonomía e } \\
\text { iniciativa personal }\end{array}$ & & & & & & & & $\mathrm{X}$ & $X$ & & & $\mathrm{X}$ & $X$ \\
\hline $\begin{array}{l}\text { Para aprender a } \\
\text { aprender }\end{array}$ & & & & & & & & & & $\mathrm{X}$ & & & \\
\hline
\end{tabular}

Tabla 16. Competencias básicas trabajadas en cada una de las actividades/tareas.

(*) Debido a que tanto la comprensión lectora como la expresión escrita son fundamentales en la construcción de los conocimientos, la competencia lingüística se encuentra implícita en todas las actividades realizadas, no obstante, se ha indicado específicamente en aquellas en las que además se requirió, por parte de los alumnos y alumnas, de otras habilidades comunicativas como la expresión y comunicación oral. 


\subsection{TABLA RESUMEN RELACIONANDO ACTIVIDADES, CONTENIDOS, OBJETIVOS Y CRITERIOS DE EVALUACIÓN ENTRE SÍ Y CON LAS COMPETENCIAS BÁSICAS}

En la siguiente Tabla 17 resumen se esquematizan las actividades, contenidos, objetivos y criterios de evaluación y su relación con las competencias básicas:

\begin{tabular}{|c|c|c|c|c|}
\hline ACTIVIDAD & CONTENIDO(S) & OBJETIVO(S) & $\begin{array}{c}\text { CRITERIO(S) } \\
\text { DE } \\
\text { EVALUACIÓN }\end{array}$ & $\begin{array}{c}\text { COMPETENCIA(S) } \\
\text { BÁSICA(S) }\end{array}$ \\
\hline 1.1 & $1 \mathrm{a} / 1 \mathrm{e} / 1 \mathrm{f} / 1 \mathrm{i}$ & 1 & 1 & A \\
\hline 2.1 & $1 b / 2 a / 3 a$ & 2 & 2 & A y $C$ \\
\hline 3.1 & $1 \mathrm{e} / 3 \mathrm{~b}$ & 4 & 4 & A y D \\
\hline 4.1 & $1 \mathrm{~h}$ & 5 & 5 & A \\
\hline 4.2 & $1 \mathrm{~h}$ & 6 & 6 & $\mathrm{~A}, \mathrm{C}, \mathrm{D}$ y E \\
\hline 4.3 & $1 \mathrm{j} / 2 \mathrm{~b}$ & 7 & 7 & $\mathrm{~A}$ \\
\hline 5.1 & $1 \mathrm{k} / 2 \mathrm{c}$ & 9 & 9 & A y E \\
\hline 5.2 & $2 \mathrm{~d}$ & \multirow[t]{2}{*}{10} & \multirow[t]{2}{*}{10} & \multirow[t]{2}{*}{$\mathrm{A}, \mathrm{B}, \mathrm{F}$ y $\mathrm{G}$} \\
\hline 6.1 & $2 d / 3 c / 3 d$ & & & \\
\hline 6.2 & $1 \mathrm{~h} / 1 \mathrm{j} / 2 \mathrm{e}$ & 11 & 11 & $\mathrm{~A}, \mathrm{~B}$ y $\mathrm{H}$ \\
\hline 7.1 & $1 \mathrm{a} / 1 \mathrm{c} / 1 \mathrm{~d} / 1 \mathrm{f} / 1 \mathrm{~g} / 1 \mathrm{~h} / 1 \mathrm{k} / 1 \mathrm{l} / 2 \mathrm{f}$ & $1,3,4,5$ y 8 & $1,3,4,5$, y 8 & A y D \\
\hline 8.1 & $11 / 2 g / 3 c / 3 d / 3 e$ & 12 & 12 & $\mathrm{~A}, \mathrm{~B}, \mathrm{C}, \mathrm{D}, \mathrm{E}, \mathrm{F}$ y $\mathrm{G}$ \\
\hline 9.1 & $3 f$ & 13 & 13 & A, C, F y G \\
\hline
\end{tabular}

Tabla 17. Tabla resumen relacionando actividades, contenidos, objetivos y criterios entre sí y con las competencias básicas.

\subsection{ESPACIOS Y RECURSOS}

Los espacios y recursos didácticos (como ya se ha comentado anteriormente en el apartado 8.5 de actividades y tareas propuestas) fueron variados a lo largo de la UD.

Con respecto a los espacios, se utilizaron dos internos al centro: el aula ordinal y el laboratorio de Biología y Geología. Las aulas ordinarias (en general) se utilizaron en las sesiones destinadas al trabajo de las actividades de clase y cuando se trató de sesiones más "tradicionales" en las que la primera parte de la misma consistió en la explicación de los contenidos y la segunda en el trabajo de los alumnos/as mientras que el laboratorio se utilizó para la realización de actividades de visualización de documentales, utilización de recursos TIC y trabajos con toda la clase 
(debate, cálculo de la huella ecológica y posterior exposición de los resultados, retrospectiva de ideas previas, etc.). La disposición del alumnado en el aula ordinaria fue por parejas, mientras que en laboratorio fue en los bancos del mismo.

En relación a los recursos utilizados, estos fueron de diferente naturaleza según la actividad o tarea desarrollada: recursos de elaboración propia (presentaciones en PowerPoint, etc.), libro de texto y recursos TIC. 


\section{ATENCIÓN A LA DIVERSIDAD}

En lo referente a la atención a la diversidad en el bachillerato, la ORDEN de 5 de agosto de 2008 en el punto 3 del artículo 5 (Autonomía de los centros) establece que los departamentos de coordinación didáctica desarrollarán las programaciones de las materias que les correspondan... Asimismo, se incluirán las distintas medidas de atención a la diversidad que pudieran llevarse a cabo.

La atención a la diversidad debe entenderse como una necesidad en todas las etapas educativas y en todos los alumnos y alumnas. Esta atención implica no solo reconocer a la otra persona, sino también saber reconocer y apreciar su individualidad, originalidad e irrepetibilidad.

El alumnado presenta una diversidad de necesidades educativas y dicha diversidad es consecuencia de muchos factores de naturaleza diferente (familiares, sociales, económicos, etc). Por ello, la atención a la diversidad debe tener en cuenta todos estos factores para propiciar una adaptación desde la educación a la diversidad individual de alumnos/as.

En relación a los mecanismos de atención a la diversidad llevados a cabo durante la UD, y debido a no existir ningún alumno al que se le tuviese que hacer una adaptación curricular significativa ni alumnos/as con altas capacidades o necesidades especiales, podría establecerse que dichos mecanismos atendieron a la diversidad "natural" (existente siempre) del aula. Se adoptó un enfoque globalizador (comentado anteriormente en el apartado 6 de metodología) que permitiese esta atención a la diversidad del alumnado caracterizado por seguir unos principios de actividad y participación que asegurasen la igualdad de oportunidades para todos los alumnos/as.

Las medidas tomadas de atención a la diversidad además tuvieron en cuenta varios aspectos. El primero de ellos atendió a la diversidad del alumnado, tanto en lo referente a capacidades como intereses y perspectivas de futuro; el segundo de dichos aspectos se refirió al contexto escolar (mencionado en el apartado 2.5.2 referente a las características del centro y alumnado) y, por último, se tuvo en cuenta el contexto socio-familiar de los alumnos y alumnas (explicado también en dicho apartado).

Con respecto a esta atención "natural" a la diversidad se realizaron actividades en las que se flexibilizó la dificultad en función de las necesidades del alumnado. Las estrategias para dicha flexibilización fueron variadas:

- Realización de actividades que exigían diferentes habilidades manuales e intelectuales (de relación, análisis, escuchar, leer, ver, etc.).

Por ejemplo, mientras que en la actividad 2.1 (comentario crítico relacionando la obsolescencia programada con los modelos de desarrollo) solo se requirió reflexionar sobre conceptos explicados en clase en un comentario crítico, en la actividad 8.1 (realización de un informe científico) se requirió de mayor número de habilidades como analizar, aplicar, hablar, etc.

- Realización de actividades con niveles bajo, medio y alto de dificultad. 
Esta estrategia estuvo ligada a la anterior ya que mientras que en la actividad 2.1 el nivel de razonamiento fue medio en la actividad 8.1 se requirió el manejo de varias fuentes bibliográficas, propiciando que el nivel de dificultad aumentase.

- Realización de actividades de evaluación con variados instrumentos de medida siempre cercanos a la actividad habitual de la clase, estableciendo mínimos y valorando todo tipo de contenidos.

La prueba final estuvo integrada por preguntas en las que se trabajaron contenidos de diferente tipología además de establecerse unos mínimos.

- Realización de actividades con diferente número de componentes (se realizaron actividades tanto individuales como con toda la clase).

Por ejemplo, la actividad 8.1 por grupos consistió en un trabajo base con unos mínimos. No obstante, presentó diferentes posibilidades de ampliación permitiendo integrar a alumnado con distintas capacidades.

- Realización de actividades de refuerzo (para el alumnado con dificultades de aprendizaje) y ampliación (para el alumnado que podía avanzar a un mayor ritmo) que implicasen, por su diferente dificultad, esfuerzos de diferente naturaleza, aspecto que propició que todos los alumnos/as pudiesen participar y realizar las actividades planteadas.

Un ejemplo de actividad de ampliación fue la actividad 4.2 (de búsqueda de información sobre espacios protegidos en Andalucía), mientras que la actividad 4.3 (sobre la valoración de la sostenibilidad de algunos cambios) constituyó un ejemplo de actividad de refuerzo de los contenidos trabajados en clase.

También se intentó establecer una organización flexible del aula que propiciase una mayor atención a los diferentes ritmos de aprendizaje, realizando refuerzos positivos para reconocer el esfuerzo de todos los alumnos/as y, más especialmente, de aquellos que tenían un ritmo más lento de aprendizaje.

En definitiva, y aunque los elementos del currículo fueron en esencia los mismos para todos los alumnos y alumnas, se intentó dar respuesta a todas las necesidades del alumnado a través de las diferentes orientaciones metodológicas (anteriormente mencionadas) llevadas a cabo durante el desarrollo de esta UD. 


\section{ACTIVIDADES COMPLEMENTARIAS

Quizás el aspecto más importante de las actividades extraescolares sea el papel como complementos del currículo que presentan a la hora de contribuir a la formación integral del alumnado. En concreto, las asignaturas con contenidos científicos cuentan con un gran número de propuestas didácticas a las que poder recurrir en este aspecto. Ejemplos de dichas propuestas son las granjas-escuela, las aulas de la naturaleza, los ecomuseos o museos interactivos.

La actividad extraescolar planificada para la última sesión consistió en realizar una visita al Parque de las Ciencias de Granada, uno de los museos interactivos más importantes de España.

Con esta actividad se pretendió que el alumnado reflexionase acerca de los problemas, trabajados en clase, ocasionados como consecuencia del uso de los recursos y del modelo de desarrollo que se está llevando a cabo en la actualidad.

El planteamiento de la actividad fue que primero, y antes de la visita, los alumnos/as repasasen los problemas trabajados en el aula relacionados con la adopción de un modelo no sostenible.

Posteriormente se realizaría la visita al Parque de las Ciencias, visitándose preferentemente la sala (Biosfera) que albergaba los contenidos específicos de esta actividad. Durante la visita se realizaría un recorrido, a modo de síntesis final después del examen, en el que se prestaría especial atención a las partes de la sala relacionadas con los contenidos trabajados en clase: importancia de la diversidad y biodiversidad de especies, crecimiento ilimitado en un planeta limitado, gestión de los residuos, etc.

La última parte de la actividad, consistiría en que los alumnos/as entregasen (pudiéndose ayudar también de información y bibliografía buscada) una reflexión acerca de las principales medidas que podían tomar los ciudadanos para desarrollar una actuación dirigida a la conservación y mejora del medio ambiente así como de la importancia de dichas actuaciones en la consecución de un futuro sostenible y necesario para la humanidad. 


\section{INTERDISCIPLINARIEDAD}

La interdisciplinariedad podría definirse como la habilidad y práctica de combinar e integrar actores, elementos y valores de múltiples áreas del saber, el conocimiento y la técnica práctica. A identificar sinergias, analogías, paradojas y enfoques desde múltiples puntos de vista y enfocados en distintos aspectos de los fenómenos y procesos que trabajamos.

La necesidad de dicho concepto en el marco educativo atiende a la importancia de abordar los contenidos de las diferentes áreas desde una perspectiva integradora que facilite la asociación, por parte del alumnado, de conceptos y que garantice una educación completa y global que huya de la fragmentación del conocimiento.

En el caso de esta UD, los contenidos trabajados han estado relacionados con las siguientes asignaturas:

- Lengua

Resulta obvia la relación de esta materia con el resto debido al papel del lenguaje como vehículo de expresión, comprensión y comunicación.

\section{- Geografía}

Los contenidos relacionados con el concepto de huella ecológica también trabajaron la dimensión geográfica de dicho concepto al comparar y analizar las huellas ecológicas de personas de diferentes países. También estuvieron relacionados la geografía los contenidos relacionados con la ocupación del territorio (comparando regiones de Europa) y la pérdida de biodiversidad (mediante la comparación de regiones españolas).

\section{- Educación física}

El mantenimiento de hábitos de vida saludable, mediante la disminución de la contaminación atmosférica, como tema transversal también tiene relación con la signatura de educación física.

- Matemáticas

Las conexiones establecidas con la asignatura de matemáticas fueron de tipo instrumental como fueron el manejo de gráficos tanto en algunas de las actividades como en la realización del informe de investigación.

- Economía

El concepto de obsolescencia programada trabajado durante la exposición del documental "Tirar, comprar, comprar" trabajó contenidos relacionados con la economía al establecer un modelo de desarrollo basado en la generación de riquezas y bienes de consumo responsables de un aumento económico sin tomar en consideración la destrucción del medio ambiente. 


\section{COMENTARIOS DIDACTICOS}

Las observaciones y comentarios surgidos a partir del desarrollo de las diferentes sesiones de clase durante la UD fueron las siguientes:

- La $1^{\circ}$ sesión se pudo desarrollar sin grandes incidentes en ambos grupos de bachillerato. Al principio ambas clases estuvieron inquietas, no obstante, esta situación inicial apenas duró unos minutos. Al poco tiempo del inicio de la sesión los alumnos/as se mostraron motivados y participativos ante los contenidos que se estaban trabajando. No obstante, un aspecto importante es que existieron diferencias apreciables con respecto a la motivación e interés, en relación a los contenidos que se explicaron, entre ambos grupos. Los alumnos y alumnas del bachillerato científico-tecnológico se mostraron más desinteresados, en general, que los del bachillerato de ciencias sociales, mostrando estos últimos una mayor motivación hacia la explicación y contenidos (nota: esta situación de mayor desinterés por parte del bachillerato científico-tecnológico fue una constante durante prácticamente todas las sesiones que duró la explicación de la UD).

En relación a las dificultades surgidas durante la sesión, estas se centraron en tener que estar pendiente del ordenador (debido a que se estaba trabajando con el libro electrónico online) mientras se realizó la explicación, lo que dificultó que se pudiese mantener un contacto visual directo con el alumnado. Este aspecto se subsanó durante la siguiente sesión intentando explicar de espaldas al ordenador y de cara a los alumnos/as para conseguir, mediante una mayor interactuación con ellos, captar su atención.

Además de ello, otro aspecto que presentó dificultades (en el grupo de ciencias sociales) fue llevar a cabo una clase en el laboratorio de Biología y Geología (aula de gran tamaño y en la que el alumnado puede dispersarse y distraerse fácilmente). Para solucionar este hecho se situó a los alumnos/as más habladores en los primeros sitios para impedir que distrajesen al resto de la clase y se separó a los compañeros que se distraían más.

- La $2^{\circ}$ sesión también se pudo desarrollar sin grandes dificultades. Un aspecto relevante que pudo apreciarse durante el transcurso de la misma fue la actitud tan favorable que mostraron los alumnos y alumnas ante una actividad (actividad 2.1 sobre el comentario crítico relacionando los modelos de desarrollo) que fácilmente podría haber dado pie a su distracción. Por tanto, pudo concluirse al terminar la misma que cambiar el transcurso de las sesiones convencionales mediante la incorporación de recursos audiovisuales (documentales, videos, etc.) propició que el alumnado mostrase un gran interés, motivación y predisposición a la realización de las tareas.

- La $3^{\circ}$ sesión también se pudo desarrollar sin grandes contratiempos. No obstante, una objeción encontrada fue que a la hora de realizar la actividad de situar y nombrar el dibujo (actividad 3.1) algunos alumnos/as se despistaron y no supieron muy bien lo que les pedía la actividad. Debido a ello, tuvo que explicarse la actividad en voz alta para toda la clase. Durante el transcurso de esta misma sesión en el otro grupo se corrigió este error explicándoles el objetivo de la actividad y lo que esta pedía justo después de repartirla.

- La $4^{\circ}$ sesión clase pudo desarrollarse sin dificultades, no obstante, pudo constatarse que cuando se trabaja con el libro de texto es necesario mantener una interacción constante con los 
alumnos/as para evitar que pierdan el hilo de la explicación. Debido a ello, se intentó aumentar dicha interacción mediante paseos (por la clase y entre las mesas) y preguntas acerca de los contenidos que se estaban explicando al alumnado.

- La $5^{\circ}$ sesión también pudo desarrollarse sin dificultades. Un aspecto que pudo comprobarse es que es esencial realizar una breve introducción a los alumnos y alumnas antes de la visualización de cualquier recurso audiovisual para conseguir una mayor comprensión durante el visionado. En relación a ello, se intentó realizar una mejor introducción antes de la visualización del documental con el segundo grupo al que se impartió esta sesión, introduciéndole los aspectos básicos del mismo y pidiéndoles que se fijasen en algunas partes concretas que posteriormente iban a comentarse en clase. De esta manera se captó su atención y se aumentó su curiosidad.

- La $6^{\circ}$ sesión también pudo desarrollarse sin dificultades, no obstante, la retrospectiva (actividad 6.2) tuvo que dejarse (en el caso del bachillerato de ciencias sociales) para la siguiente sesión debido a que el debate (actividad 6.1) duró toda la hora. En el caso del alumnado del bachillerato científico-tecnológico si se llevó a cabo la retrospectiva en la misma sesión de clase. En relación a dicha retrospectiva, ambos grupos supieron complementar las ideas previas que habían tenido durante la primera sesión, sabiendo aplicar los contenidos trabajados y reiterados en clase durante el desarrollo de la UD.

- Durante la $7^{\circ}$ sesión se llevó a cabo el examen (actividad 7.1). En dicha sesión se volvió a constatar la necesidad, algunas veces, de explicar detallada y previamente a su realización, lo que se pide en algunas actividades para evitar así que los alumnos/as se equivoquen o pregunten, de manera individual, la misma duda (aspecto que puede alterar el transcurso de la sesión cuando se trata de una actividad en el que el silencio es imprescindible para la concentración del alumnado).

- La $8^{\circ}$ sesión destinada a la exposición, por grupos, de los informes de investigación acerca de las prácticas de reciclaje en la sociedad se llevó a cabo sin dificultades. Al final de cada exposición grupal hubo unos minutos para preguntas y aclaraciones.

- La $9^{\circ}$ sesión no pudo llevarse a cabo por requerir de la planificación con el resto de grupos de bachillerato (a los que no se impartió docencia).

En resumen, puede concluirse que existieron algunas dificultades durante el transcurso de dicha UD (propias de cualquier proceso de enseñanza-aprendizaje) que intentaron solventarse durante el transcurso de las sesiones. Estas dificultades fueron principalmente la falta de contacto visual con el alumnado propiciada por la atención constante al ordenador durante algunas de las explicaciones; la mayor dispersión en el laboratorio de Biología y Geología, de mayor tamaño que el aula ordinaria y, por último, la necesidad de mayor explicación tanto en algunas de las actividades como previamente a la visualización de documentales, películas, etc.

No obstante, también se pudo apreciar la actitud tan favorable y motivadora que mostraron los alumnos/as ante la transformación, en algunas de las sesiones, de la clase convencional en otras caracterizadas por el uso de recursos TIC, actividades de aplicación e investigación y establecimiento de una atmósfera de debate y reflexión. 


\section{CONCLUSIONES}

Como se ha comentado en el apartado anterior, referido a los comentarios didácticos sobre el desarrollo de las diferentes sesiones llevadas a cabo, existieron algunas dificultades durante el transcurso de la UD. También es importante que se mencionen las limitaciones de tiempo a las que se enfrentó tanto a la hora de estructurar una sesión como a la hora de realizar varias acciones durante una misma clase (explicación, actividades, visualización de documentales, etc). Atendiendo a este hecho, se intentó que todas las actividades se ajustaran al tiempo disponible, siendo a veces necesaria la realización de las mismas en casa.

No obstante (y como se ha mencionado anteriormente), también pudo apreciarse la actitud tan positiva que mostró el alumnado frente al cambio en la dinámica de trabajo, por lo que dicho cambio podría considerarse un acierto.

Quizás una de las principales conclusiones a las que se llegó, a partir del análisis didáctico realizado durante el desarrollo de las sesiones, fue la necesidad de llegar a un término medio entre los nuevos recursos tecnológicos y la clase tradicional debido a que aunque hay contenidos y objetivos que es adecuado que se trabajen con materiales audiovisuales e interactivos (de hecho los resultados obtenidos con su uso fueron muy satisfactorios), no deberíamos relegar al olvido el uso de la tiza y las clases convencionales, aspecto que por otra parte sigue siendo imprescindible para la comprensión de otros contenidos. En este sentido, sería bastante positivo para todos, tanto alumnado como docentes, intentar llegar a un equilibrio entre ambas propuestas, un equilibrio en el que los alumnos y alumnas no den las clases a través de un ordenador, pero que puedan disponer, cuando sea necesario, de recursos didácticos y tecnológicos que posibiliten una mayor participación y motivación de los mismos además del esclarecimiento de algunas explicaciones que quizás sin estas medidas resultarían bastante difíciles de comprender.

Atendiendo a ello, como propuestas de mejora y cambio establecidas a partir del desarrollo de esta UD podrían enunciarse, por un lado, el establecimiento de este término medio entre novedad y tradición y, por otro y frente a las dificultades comentadas anteriormente, la necesaria organización de una atmósfera de interacción constante y respeto entre docente y alumnado.

Por otro lado, los resultados obtenidos a partir de la observación previa (a través de la actividad inicial para conocer las ideas del alumnado) realizada durante el desarrollo de la UD entre alumnos/as del bachillerato científico-tecnológico y del de ciencias sociales (establecida en el punto 7 del presente trabajo) arrojaron la conclusión de que ambos grupos tenían ideas bastante parecidas acerca de los problemas ambientales relacionados con un desarrollo no sostenible existentes en su entorno más cercano. No existió un conocimiento mayor, en este aspecto, por parte de los alumnos/as del bachillerato científico-tecnológico como hipotéticamente podría esperarse.

No obstante, si pudo constatarse al leer las respuestas de dicha actividad inicial que ninguno de los alumnos y alumnas contestó con la pérdida de biodiversidad o el desarrollo urbanístico descontrolado, ambos problemas medioambientales relacionados con el desarrollo no sostenible y que afectan en gran medida a Granada y su provincia. Otra consideración fue que los alumnos/as del grupo de ciencias sociales contestaron acertadamente que la contaminación 
acústica y lumínica también podían considerarse problemas ambientales relacionados con su entorno más cercano a diferencia de los del bachillerato científico-tecnológico que no lo hicieron. Por último, un aspecto que resultó bastante sorprendente fue el número ( 4 de 23 en el grupo científico-tecnológico y 5 de 27 en el de ciencias sociales) de alumnos/as que contestaron exclusivamente con la contaminación (sin especificar ningún tipo) como respuesta.

No obstante, a tenor de los resultados obtenidos tras las diferentes evaluaciones de la UD así como tras la actividad de retrospectiva de ideas previas constataron que la gran mayoría del alumnado experimentó una progresión conceptual, procedimental y actitudinal ante la problemática social y ambiental relacionada con el desarrollo no sostenible. Dicha progresión estuvo propiciada por la incorporación de conceptos básicos, la utilización de métodos interpretativos para entender las informaciones o la valoración de la necesidad de adoptar un modelo de desarrollo a escala planetaria entre otros aspectos. En este sentido, la UD consiguió dotar a los alumnos y alumnas de habilidades en otros campos diferentes al meramente memorístico además de valores necesarios para la concienciación ante los problemas ambientales existentes hoy en día. Por tanto, este aspecto transversal introducido creo que debería establecerse como base a la hora de la realización de otras programaciones didácticas.

Con respecto al análisis, tanto en el Real Decreto como en la Orden de Andalucía, de los libros de texto, se realizaron dos estudios comparativos, uno entre las diferentes unidades didácticas del libro de texto utilizado a lo largo de la explicación de la UD (de la editorial SM) y otro entre dicho libro y otros de diferentes editoriales (Vicens Vives, Bruño y ANAYA).

En el primer estudio se llegó a la conclusión de que aunque, en líneas generales, el libro recogía los contenidos establecidos tanto en el Real Decreto como en la Orden de Andalucía y además se establecía en el mismo una relación, secuenciación y complementación entre los contenidos de las diferentes unidades, algunos contenidos específicos, reflejados en la Orden de Andalucía y relacionados con el conocimiento de la realidad andaluza, no se recogieron. En este aspecto, por tanto, se llegó a la conclusión de que sería bueno ampliar algunas de las actividades del libro de texto para acercar al alumnado a la realidad de su comunidad autónoma (caso de la actividad en la que se tuvo que buscar información sobre los espacios naturales protegidos de Andalucía).

En el segundo estudio se estableció que según la editorial tratada, el rango de contenidos variaba en extensión, realizando cada editorial el tratamiento de los contenidos de una manera. El libro de la editorial Vicens Vives tuvo un mayor rango de contenidos, los de las editoriales SM y Bruño prácticamente el mismo rango que el de Vicens Vives (aunque algo inferior) y, por último, el libro que presentó un rango más reducido de contenidos fue el de la editorial ANAYA. En base a dichos resultados, se concluyó que era necesario realizar una revisión previa de los contenidos que trataba el libro de texto en relación a los mínimos establecidos para que, en el caso de que fuese necesario, pudiesen complementarse dichos contenidos a lo largo de las sesiones de aula. De hecho, el análisis previo del libro de texto utilizado para la explicación de la UD sirvió para constatar que los contenidos relacionados con los tipos de modelo de desarrollo no se encontraban en el mismo, por lo que dicha información tuvo que buscarse a partir de otras fuentes.

En definitiva, la actividad llevada a cabo a lo largo del presente trabajo ha servido para confirmar la necesidad de la existencia en toda planificación curricular de dos aspectos 
imprescindibles para llevar a cabo una adecuada intervención: la relación entre sus diferentes elementos y la interdisciplinariedad entre las diferentes áreas. En este sentido, el máster me ha aportado esa visión interdisciplinar e integradora que creo básica para la realización de cualquier planificación educativa, la consideración de todos los ámbitos (didáctico, psicológico, social, etc.) en los que se desarrolla y estructura la práctica docente y la importancia de no separarla de los mismos. Además de ello, el máster también me ha servido para comprender la necesidad de realizar una planificación curricular previa antes de la práctica docente. No se trata, sin embargo, de no poder desempeñar prácticas de innovación en el aula, sin duda imprescindibles en educación, sino de que incluso estas deben tener un concienzudo trabajo previo de elaboración y evaluación que les dé sentido y valor.

El docente debe tener un plan establecido, un plan detallado a seguir que le capacite para el adecuado desempeño de sus funciones y que propicie la consecución de los objetivos a alcanzar. En este sentido, la confección de una planificación curricular útil, que pueda servir de guía y apoyo, es requisito indiscutible para el desempeño de un proceso significativo de enseñanzaaprendizaje. 


\section{FUENTES Y REFERENCIAS BIBLIOGRÁFICAS}

- Alcalá del Olmo, M.J (2005). Hacia una definición de la educación en valores: los temas transversales del curriculum. Docencia e investigación, 5.

- Almaguer, A. y L.D. Labady (2010). Fundamentos de la Psicología de la personalidad que permiten desarrollar la educación ambiental en el preuniversitario. Innovación Tecnológica, 16.

- Ángel, A (1995). La tierra herida: Las transformaciones tecnológicas del ecosistema. Universidad Nacional de Colombia.

- Beck, U (1998). Políticas ecológicas en la edad del riesgo. Antídotos. La irresponsabilidad organizada. Barcelona: el roure.

- Caballero, J.J. Tema 1: Niveles de Concreción Curricular en Educación Primaria.

- Calvo, S. y J. Gutiérrez (2007). El espejismo de la educación ambiental. Madrid: ediciones morata.

- Caride, J. A. y P.A. Meira (2001). Educación Ambiental y Desarrollo Humano. Barcelona: ariel.

- Casassus, J. Estándares en educación: conceptos fundamentales. Laboratorio Latinoamericano de Evaluación de la calidad de le educación. LLECE-UNESCO.

- Delibes de Castro, M. Torres, M.D. et al (2008). Ciencias para el Mundo Contemporáneo. Bachillerato. Editorial Vicens Vives.

- García, J.E (2002). Los problemas de la Educación Ambiental: ¿es posible una Educación Ambiental integradora?. Investigación en la escuela, 46.

- Gutiérrez, J (1995). La educación ambiental. Fundamentos teóricos, propuestas de transversalidad y orientaciones extracurriculares. Madrid: la muralla (autor desconocido).

- Gutiérrez, J. y T. Pozo (2006). Modelos teóricos contemporáneos y marcos de fundamentación de la educación ambiental para el desarrollo sostenible. Revista Iberoamericana de Educación, 41, 1: 21-68.

- $\quad$ Leff, E (2002). Saber ambiental: sustentabilidad, racionalidad, complejidad, poder. México: siglo XXI editores.

- $\quad$ López, M. Modelo para la programación de una Unidad Didáctica. 
- Michelutti, E. y A. Pérez-Foguet (2007). Educación para el desarrollo sostenible entre educación para el desarrollo y educación ambiental: apuntes para el debate. I Congreso UPC Sostenible 2015: 131-134.

- Mora, W.M (2011). Fundamentos pedagógicos y didácticos en educación ambiental y educación para el desarrollo sostenible. Universidad de Bogotá.

- Moral, C (2012). Conocimiento didáctico general para el diseño y desarrollo de experiencias de aprendizaje significativas en la formación del profesorado. Profesorado. Revista de currículum y formación del profesorado, 16, 1: próxima publicación.

- Novo, M (1998). La educación ambiental: bases éticas, conceptuales y metodológicas. Madrid: universitas.

- Panadero, J.E. Argüello, J.A (2008). et al. Ciencias para el Mundo Contemporáneo. Bachillerato. Grupo Editorial Bruño S.L.

- Pedrinaci, E. Gil, C. et al (2008). Ciencias para el Mundo Contemporáneo. Bachillerato. Ediciones SM.

- $\quad$ Pérez, J.M. Aportes para la secuenciación de contenidos en las ciencias naturales.

- $\quad$ Rubio, N. Pulido, C. et al (2009). Ciencias para el Mundo Contemporáneo. Bachillerato. Grupo ANAYA S.A.

- Ruiz, A. De la teoría a la práctica: niveles de concreción curricular.

- Sánchez, M.A. Cuaderno de actividades: programaciones y unidades didácticas. Máster de Formación del Profesorado. Universidad de Granada.

- Sánchez, M.A. Cuestiones pedagógicas en la programación y en las unidades didácticas. Máster de Formación del Profesorado. Universidad de Granada.

- Wiggins, G. y J. McTighe (2005). Understanding by desing. New York: pearson. 
- Webgrafía:

- DECRETO 416/2008, de 22 de julio, por el que establece la ordenación y las enseñanzas correspondientes al Bachillerato en Andalucía.

- Evaluación. Ciencias para el Mundo Contemporáneo $1^{\circ}$ de bachillerato. Ediciones SM.

- Guía de Formación de Formadores: "Los Bosques Nativos Argentinos. Un Bien Social”. Secretaria de Ambiente y Desarrollo Sustentable de la Nación.

- http://issuu.com/filosofosflorida/docs/pesadilla_darwin

- http://naturalezaverdedellegolas.blogspot.com.es/2010/05/desarrollo-sostenible.html

- http://obrimunafinestralmon.blogspot.com.es/2011/01/mon-contaminacio.html

- http://portal.educar.org/creatividad/ciencias/multidisciplinariedad

- http://www.aeromental.com/2010/04/02/la-poblacion-mundial-6-692-030-277/

- $\quad$ http://www.dolceta.eu/espana/Mod4/1-3-1-1-Que-es-educacion-para-el.html

- http://www.juntadeandalucia.es/empleo/recursos/material_didactico/comun/sensibilizacion_ ambiental/pdf_sensibiliz_ambiental/ud0_3.pdf

- http://www.portalplanetasedna.com.ar/huella_ecologica.htm

- $\quad$ http://www.youtube.com/watch?v=fe9I_uKbzl8

- $\quad$ http://www.youtube.com/watch?v=ykfp1WvVqAY

- $\quad$ http://www.youtube.com/watch?v=3pb7HOfp8PU

- ORDEN de 5 de agosto de 2008, por la que se desarrolla el currículo correspondiente al Bachillerato en Andalucía

- Programación del departamento de Biología y Geología del I.E.S Padre Manjón. Curso académico 2011-2012.

- Programación del departamento de Biología y Geología Institutos de Enseñanza Secundaria Orientaciones metodológicas. Autor desconocido.

- Proyecto educativo del I.E.S Padre Manjón.

- REAL DECRETO 1467/2007, de 2 de noviembre, por el que se establece la estructura del bachillerato y se fijan sus enseñanzas mínimas.

- $\quad$ Reglamento de Organización y Funcionamiento del I.E.S Padre Manjón. 


\section{ANEXOS}

\section{$>$ ANEXO I: objetivos generales de etapa del bachillerato.}

El bachillerato contribuirá a desarrollar en los alumnos y las alumnas las capacidades que les permitan:

a) Ejercer la ciudadanía democrática, desde una perspectiva global, y adquirir una conciencia cívica responsable, inspirada por los valores de la Constitución española así como por los derechos humanos, que fomente la corresponsabilidad en la construcción de una sociedad justa y equitativa y favorezca la sostenibilidad.

b) Consolidar una madurez personal y social que les permita actuar de forma responsable y autónoma y desarrollar su espíritu crítico. Prever y resolver pacíficamente los conflictos personales, familiares y sociales.

c) Fomentar la igualdad efectiva de derechos y oportunidades entre hombres y mujeres, analizar y valorar críticamente las desigualdades existentes e impulsar la igualdad real y la no discriminación de las personas con discapacidad.

d) Afianzar los hábitos de lectura, estudio y disciplina, como condiciones necesarias para el eficaz aprovechamiento del aprendizaje, y como medio de desarrollo personal.

e) Dominar, tanto en su expresión oral como escrita, la lengua castellana y, en su caso, la lengua cooficial de su comunidad autónoma.

f) Expresarse con fluidez y corrección en una o más lenguas extranjeras.

g) Utilizar con solvencia y responsabilidad las tecnologías de la información y la comunicación.

h) Conocer y valorar críticamente las realidades del mundo contemporáneo, sus antecedentes históricos y los principales factores de su evolución. Participar de forma solidaria en el desarrollo y mejora de su entorno social.

i) Acceder a los conocimientos científicos y tecnológicos fundamentales y dominar las habilidades básicas propias de la modalidad elegida.

j) Comprender los elementos y procedimientos fundamentales de la investigación y de los métodos científicos. Conocer y valorar de forma crítica la contribución de la ciencia y la tecnología en el cambio de las condiciones de vida, así como afianzar la sensibilidad y el respeto hacia el medio ambiente.

k) Afianzar el espíritu emprendedor con actitudes de creatividad, flexibilidad, iniciativa, trabajo en equipo, confianza en uno mismo y sentido crítico.

1) Desarrollar la sensibilidad artística y literaria, así como el criterio estético, como fuentes de formación y enriquecimiento cultural.

m)Utilizar la educación física y el deporte para favorecer el desarrollo personal y social.

n) Afianzar actitudes de respeto y prevención en el ámbito de la seguridad vial. 
$>$ ANEXO II: objetivos generales de etapa del bachillerato en Andalucía.

El Bachillerato contribuirá a desarrollar en el alumnado los saberes, las capacidades, los hábitos, las actitudes y los valores que les permitan alcanzar, además de los objetivos enumerados en el artículo 33 de la Ley Orgánica 2/2006, de 3 de mayo, de Educación, los siguientes:

a) Las habilidades necesarias para contribuir a que se desenvuelvan con autonomía en el ámbito familiar y doméstico, así como en los grupos sociales con los que se relacionan, participando con actitudes solidarias, tolerantes y libres de prejuicios.

b) La capacidad para aprender por sí mismo, para trabajar en equipo y para analizar de forma crítica las desigualdades existentes e impulsar la igualdad, en particular, entre hombres y mujeres.

c) La capacidad para aplicar técnicas de investigación para el estudio de diferentes situaciones que se presenten en el desarrollo del currículo.

d) El conocimiento y aprecio por las peculiaridades de la modalidad lingüística andaluza en todas sus variedades, así como entender la diversidad lingüística y cultural como un derecho $\mathrm{y}$ un valor de los pueblos y los individuos en el mundo actual, cambiante y globalizado.

e) El conocimiento, valoración y respeto por el patrimonio natural, cultural e histórico de España y de Andalucía, fomentando su conservación y mejora. 
> ANEXO III: objetivos específicos de la asignatura de Ciencias para el Mundo Contemporáneo dentro de $\mathbf{1}^{\circ}$ de bachillerato.

La enseñanza de las Ciencias para el mundo contemporáneo en el bachillerato tendrá como objetivo el desarrollo de las siguientes capacidades:

a) Conocer el significado cualitativo de algunos conceptos, leyes y teorías, para formarse opiniones fundamentadas sobre cuestiones científicas y tecnológicas, que tengan incidencia en las condiciones de vida personal y global y sean objeto de controversia social y debate público.

b) Plantearse preguntas sobre cuestiones y problemas científicos de actualidad y tratar de buscar sus propias respuestas, utilizando y seleccionando de forma crítica información proveniente de diversas fuentes.

c) Obtener, analizar y organizar informaciones de contenido científico, utilizar representaciones y modelos, hacer conjeturas, formular hipótesis y realizar reflexiones fundadas que permitan tomar decisiones fundamentadas y comunicarlas a los demás con coherencia, precisión y claridad.

d) Adquirir un conocimiento coherente y crítico de las tecnologías de la información, la comunicación y el ocio presentes en su entorno, propiciando un uso sensato y racional de las mismas para la construcción del conocimiento científico, la elaboración del criterio personal y la mejora del bienestar individual y colectivo.

e) Argumentar, debatir y evaluar propuestas y aplicaciones de los conocimientos científicos de interés social relativos a la salud, el medio ambiente, los materiales, las fuentes de energía, el ocio, etc., para poder valorar las informaciones científicas y tecnológicas de los medios de comunicación de masas y adquirir independencia de criterio.

f) Poner en práctica actitudes y valores sociales como la creatividad, la curiosidad, el antidogmatismo, la reflexión crítica y la sensibilidad ante la vida y el medio ambiente, que son útiles para el avance personal, las relaciones interpersonales y la inserción social.

g) Valorar la contribución de la ciencia y la tecnología a la mejora de la calidad de vida, reconociendo sus aportaciones y sus limitaciones como empresa humana cuyas ideas están en continua evolución y condicionadas al contexto cultural, social y económico en el que se desarrollan.

h) Reconocer en algunos ejemplos concretos la influencia recíproca entre el desarrollo científico y tecnológico y los contextos sociales, políticos, económicos, religiosos, educativos y culturales en que se produce el conocimiento y sus aplicaciones. 
ANEXO IV: objetivos específicos de la asignatura de Ciencias para el Mundo Contemporáneo dentro de $\mathbf{1}^{\mathbf{0}}$ de bachillerato en Andalucía.

Esta materia debe dar prioridad al desarrollo de las competencias científicas más instrumentales y polivalentes. Así, deberá desarrollar la capacidad del alumnado para:

a) Analizar una situación y seleccionar algunos problemas que puedan ser investigados.

b) Buscar información relacionada con los problemas que van a trabajarse, valorar su fiabilidad y seleccionar la que resulte más relevante para su tratamiento.

c) Formular conjeturas e hipótesis y diseñar estrategias que permitan contrastarlas.

d) Alcanzar conclusiones que validen o no las hipótesis formuladas, y comunicarlas adecuadamente.

e) Elaborar argumentaciones utilizando un lenguaje preciso, de forma que las ideas se apoyen en hechos, observaciones o principios y establezcan relaciones entre sí y con las conclusiones finales. 
ANEXO V: criterios de evaluación de la asignatura de Ciencias para el Mundo Contemporáneo en $1^{\circ}$ de bachillerato.

a) Obtener, seleccionar y valorar informaciones sobre distintos temas científicos y tecnológicos de repercusión social y comunicar conclusiones e ideas en distintos soportes a públicos diversos, utilizando eficazmente las tecnologías de la información y comunicación, para formarse opiniones propias argumentadas.

b) Analizar algunas aportaciones científico-tecnológicas a diversos problemas que tiene planteados la humanidad, y la importancia del contexto político-social en su puesta en práctica, considerando sus ventajas e inconvenientes desde un punto de vista económico, medioambiental y social.

c) Realizar estudios sencillos sobre cuestiones sociales con base científico-tecnológica de ámbito local, haciendo predicciones y valorando las posturas individuales o de pequeños colectivos en su posible evolución.

d) Valorar la contribución de la ciencia y la tecnología a la comprensión y resolución de los problemas de las personas y de su calidad de vida, mediante una metodología basada en la obtención de datos, el razonamiento, la perseverancia y el espíritu crítico, aceptando sus limitaciones y equivocaciones propias de toda actividad humana.

e) Identificar los principales problemas ambientales, las causas que los provocan y los factores que los intensifican; predecir sus consecuencias y argumentar sobre la necesidad de una gestión sostenible de la Tierra, siendo conscientes de la importancia de la sensibilización ciudadana para actuar sobre los problemas ambientales locales.

f) Conocer y valorar las aportaciones de la ciencia y la tecnología a la mitigación de los problemas ambientales mediante la búsqueda de nuevos materiales y nuevas tecnologías, en el contexto de un desarrollo sostenible.

g) Diferenciar los tipos de enfermedades más frecuentes, identificando algunos indicadores, causas y tratamientos más comunes, valorando la importancia de adoptar medidas preventivas que eviten los contagios, que prioricen los controles periódicos y los estilos de vida saludables sociales y personales.

h) Conocer las bases científicas de la manipulación genética y embrionaria, valorar los pros y contras de sus aplicaciones y entender la controversia internacional que han suscitado, siendo capaces de fundamentar la existencia de un Comité de Bioética que defina sus límites en un marco de gestión responsable de la vida humana.

i) Analizar las sucesivas explicaciones científicas dadas a problemas como el origen de la vida o del universo; haciendo hincapié en la importancia del razonamiento hipotético-deductivo, el valor de las pruebas y la influencia del contexto social, diferenciándolas de las basadas en opiniones o creencias.

j) Conocer las características básicas, las formas de utilización y las repercusiones individuales y sociales de los últimos instrumentos tecnológicos de información, comunicación, ocio y creación, valorando su incidencia en los hábitos de consumo y en las relaciones sociales. 
D ANEXO VI: criterios de evaluación de la asignatura de Ciencias para el Mundo Contemporáneo en $\mathbf{1}^{\circ}$ de bachillerato en Andalucía.

a) Conocer conceptos y estrategias relevantes y su aplicación a situaciones concretas relacionadas con los problemas trabajados durante el curso

b) Reconocer situaciones problemáticas e identificar las variables que inciden en ellas

c) Elaborar argumentos y conclusiones así como comunicarlos a los demás utilizando códigos de lenguaje apropiados

d) Analizar y valorar los argumentos aportados por los demás 
$>$ ANEXO VII: contenidos de la asignatura de Ciencias para el Mundo Contemporáneo en $1^{\circ}$ de bachillerato.

4. Hacia una gestión sostenible del planeta:

- La sobreexplotación de los recursos: aire, agua, suelo, seres vivos y fuentes de energía. El agua como recurso limitado.

- Los impactos: la contaminación, la desertización, el aumento de residuos y la pérdida de biodiversidad. El cambio climático.

- Los riesgos naturales. Las catástrofes más frecuentes. Factores que incrementan los riesgos.

- El problema del crecimiento ilimitado en un planeta limitado. Principios generales de sostenibilidad económica, ecológica y social. Los compromisos internacionales y la responsabilidad ciudadana. 
$>$ ANEXO VIII: contenidos de la asignatura de Ciencias para el Mundo Contemporáneo en $1^{\circ}$ de bachillerato en Andalucía.

7. ¿Es sostenible nuestro desarrollo?

Analizar si es sostenible nuestro modelo de desarrollo, si nuestro comportamiento es solidario con los países en desarrollo y con las generaciones futuras, y valorar sus consecuencias, supone tratar cuestiones como:

- ¿de qué factores depende la sostenibilidad?

- ¿qué efectos está produciendo nuestro modelo de desarrollo en el medio físico y en los organismos?

- ¿cómo pueden corregirse los efectos negativos?

- ¿qué características debe cumplir un modelo de desarrollo para que sea sostenible? 
ANEXO IX: relación de actividades y tareas realizadas a lo largo de la UD.

- $\quad$ Actividad 1.1:

TEMA 11: HACIA UN DESARROLLO SOSTENIBLE

¿Qué entiendes por desarrollo sostenible?

De los problemas ambientales relacionados con el desarrollo insostenible, ¿cuál crees que afecta en mayor medida a tu entorno más cercano?

¿Podrías relacionar alguno de los acontecimientos internacionales sucedidos en los últimos días con el concepto de desarrollo sostenible?. Justifica tu respuesta.

- $\quad$ Actividad 2.1:

Realiza un comentario crítico del documental relacionándolo con los modelos de desarrollo desarrollista, conservacionista y sostenible vistos en clase. 
- $\quad$ Actividad 3.1:

Observa el siguiente dibujo. Ahora ponle un título que creas que lo define y situálo en una ciudad y en un año:

TITULO:

CIUDAD:

AÑO:

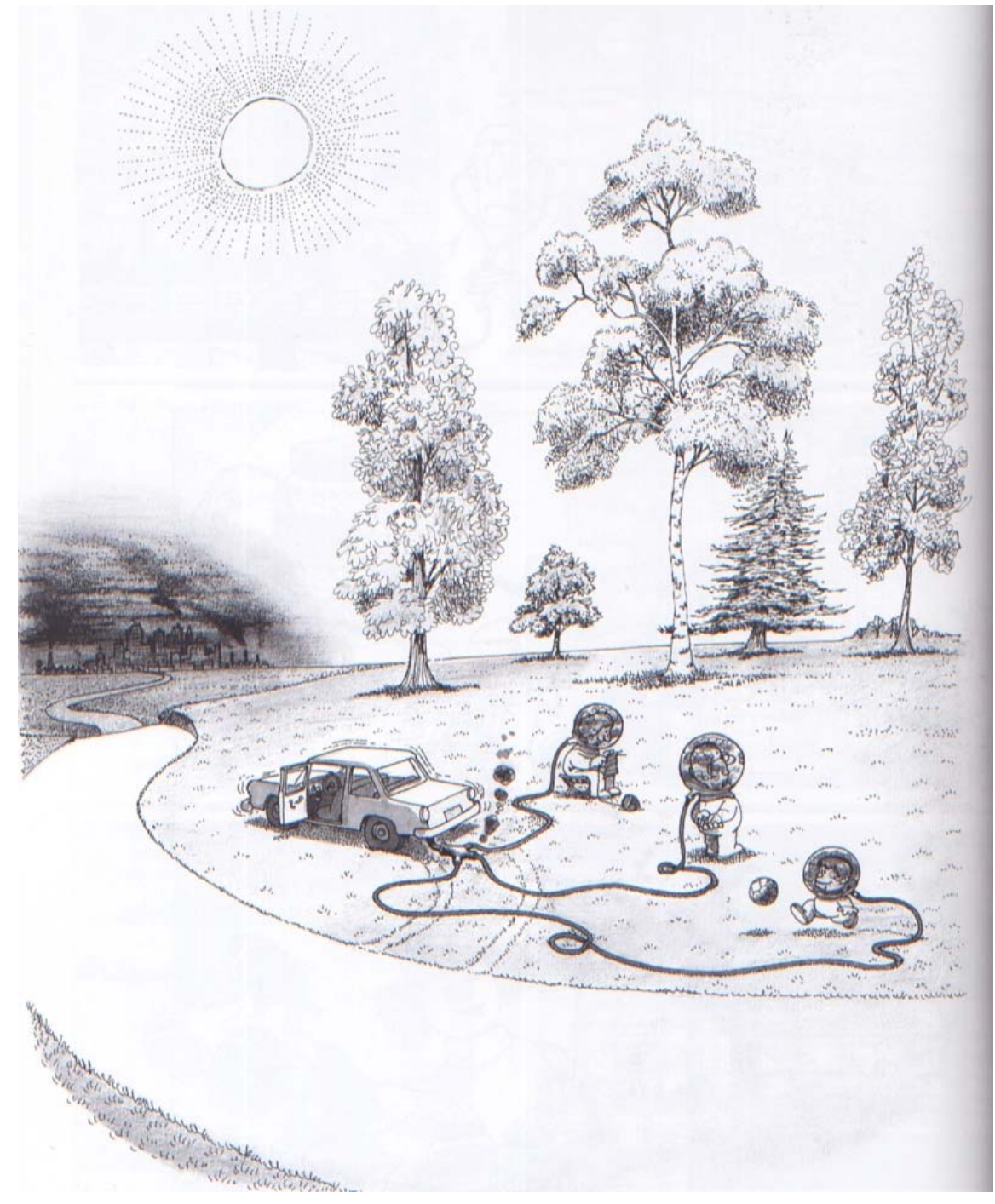

(*) Imagen sacada de internet. El enlace (http://obrimunafinestralmon.blogspot.com.es/2011/01/mon-contaminacio.html) queda referenciado en el apartado 14 de bibliografía anterior.

¿Qué aspectos y efectos crees que pretende criticar?. ¿Piensas que refleja la realidad actual?. Justifica tu respuesta. 


\section{- $\quad$ Actividad 4.1:}

Existen algunas características que hacen especialmente vulnerables a las especies que las presentan:

- Tasa reproductiva baja (caso de la ballena azul o el rinoceronte negro)

- Nicho muy especializado (ballena azul o panda gigante)

- Especies endémicas (lince ibérico o violeta africana)

- Patrones migratorios fijos (ballena azul o tortuga marina)

a) Indica razones que justifiquen la relación entre cada una de dichas características y la vulnerabilidad.

b) ¿Por qué crees que es especialmente vulnerable la ballena azul? 


\section{- $\quad$ Actividad 4.2:}

Uno de los indicadores de sostenibilidad ambiental es el porcentaje de espacios naturales protegidos. En las últimas décadas ha aumentado tanto el número de espacios como la superficie protegida en España. La gráfica inferior muestra el porcentaje de superficie terrestre protegida en las diferentes comunidades autónomas españolas.

a) Los organismos internacionales recomiendan que el espacio protegido supere el $10 \%$. ¿Qué comunidades cumplen con dicha recomendación? ¿Cuales se encuentran más lejos de cumplirla?

b) ¿Qué comunidades autónomas han mejorado más su situación durante el período recogido en la gráfica?

c) Busca información sobre los espacios protegidos en la comunidad autónoma andaluza.

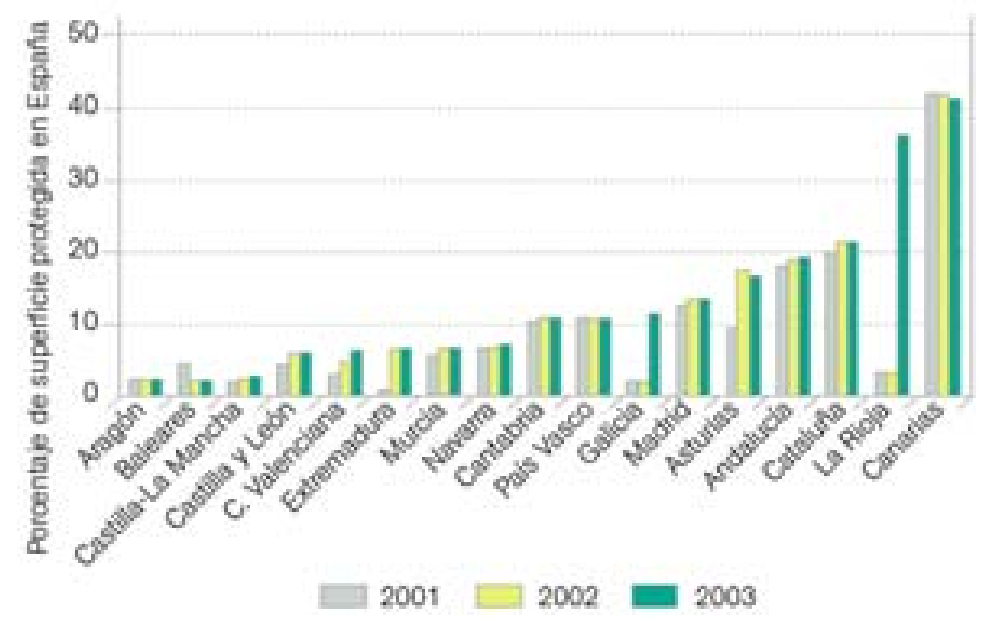

(*) Gráfico tomado del libro de texto que se utilizó en la UD (de la editorial SM). Dicho libro de texto queda referenciado en el apartado 14 de bibliografía anterior. 


\section{- $\quad$ Actividad 4.3:}

El Observatorio de la Sostenibilidad en España publicó (en 2006) un informe con datos sobre el cambio en la ocupación del territorio. En él se resumen los cambios producidos en una comunidad autónoma española:

- Tendencia a la ciudad dispersa.

- Crecimiento generalizado de zonas artificiales: urbano, aparición de centros comerciales, de ocio e industriales.

- Abandono de cultivos frente a expectativas urbanísticas.

- Pérdida de 1000 ha de regadío.

Valora la sostenibilidad o no sostenibilidad de cada uno de dichos cambios.

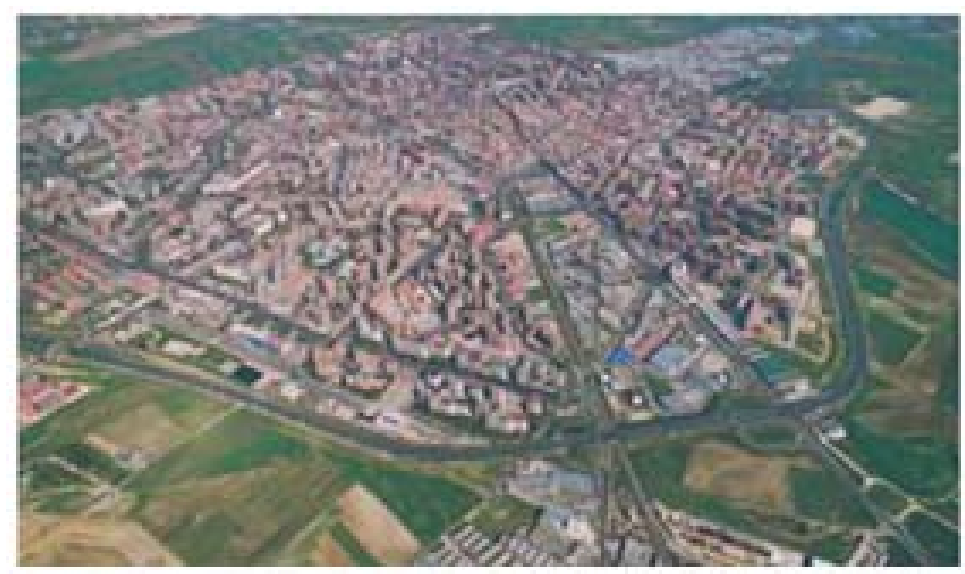

(*) Imagen tomada del libro de texto que se utilizó en la UD (de la editorial SM). Dicho libro de texto queda referenciado en el apartado 14 de bibliografía anterior. 
- $\quad$ Actividad 5.1:

Realiza el siguiente test y sabrás si tu modo de vida es respetuoso con el medio ambiente:

ALIMENTACIÓN:

¿Consumes frutas y verduras producidas en tu región?

- Sí, consumo aquellos que vienen sin envasar: 2

- Sí, aunque a veces suelo comprarlos envasados: 5

- No, compro productos de otras regiones que en muchas ocasiones están envasados: 10

¿Qué haces con los restos de comida que sobran?

- Los tiro directamente a la basura o al W.C.: 150

- Procuro aprovecharlos: 50

- Separo los restos dependiendo su reciclabilidad: 130

\section{TRANSPORTE}

¿Qué transporte utilizas para tus actividades diarias?

- Voy en transporte público: 5

- Voy andando, en bici o ciclomotor: 3

- Voy en mi coche: 70

\section{ELECTRICIDAD}

¿Cuándo usas la lavadora o el lavavajillas

- Espero a que esté lleno para poner el electrodoméstico en funcionamiento sin importarme su consumo: 85

- Lo utilizo en cuanto necesito utilizar algo sin preocuparme de la cantidad de ropa o vajilla que hay en el interior, ni de sus consumos: 100

- Los compré de bajo consumo energético y los pongo en funcionamiento únicamente cuando están llenos: 40

¿Qué tipo de energía utilizas en tu hogar?

- Uso la energía de la red: 45

- Uso algún tipo de energía renovable: 5

\section{CALEFACCION}

\section{¿Cómo usas la calefacción?}

- Me gusta poner la calefacción alta porque así puedo ir con poca ropa por casa: 15

- Pongo la calefacción y cuando hace mucho calor abro la ventana para no concentrar el calor: 40

- Pongo la calefacción de forma moderada, aunque tenga que abrigarme un poco más y ahorrando dependiendo de la temperatura: 5

\section{RESIDUOS}

¿Qué haces con los residuos que produces en tu hogar

- Los echo a una única bolsa de basura para tirarlos a un contenedor convencional: 70

- Intento reutilizar lo posible y el resto lo separo de manera que cada tipo de residuo va a su contenedor: 55 


\section{AGUA}

¿Mantienes el grifo abierto cuando te lavas los dientes?

- No, porque utilizo un vaso con agua para enjuagarme, o lo abro sólo lo necesario: 5

- Sólo tardo unos minutos en lavarme los dientes, por lo que dejo que corra el agua: 15 ¿Ducha o baño?

- Por supuesto me baño porque sienta mejor: 15

- Prefiero ducharme: 5

Ahora, suma la puntuación de todas tus respuestas para saber lo concienciado que estás con tu medio ambiente.

Conclusiones del test:

- Si tu puntuación es menor de 200 puntos, ¡enhorabuena!, te adaptas perfectamente a la capacidad de carga del planeta y no provocas déficit ecológico. Eres un buen ejemplo a seguir.

- Si tu puntuación se encuentra entre 200 y 400 puntos significa que te apropias de recursos que no te pertenecen. Si todas las personas llevasen un ritmo de consumo parecido al tuyo, serían necesarias más de 2 Tierras.

- Si tu puntuación es superior a 400 puntos significa que tu ritmo de vida es completamente insostenible, tu huella ecológica es superior a la media europea. Si todo el mundo consumiera los mismos recursos que consumes tú, serían necesarias más de $\mathbf{3}$ Tierras para mantener toda la población. 
- Actividad 5.2:

LA PESADILLA DE DARWIN (Darwin`s nightmare, 2005)

\section{$\underline{\text { FICHA TÉCNICA }}$}

DIRECCCIÓN Y GUIÓN: Hubert Sauper.

AÑO:

2004.

DURACIÓN:

$107 \mathrm{~min}$.

PAÍSES:

Francia, Austria y Bélgica.

GUIÓN:

Hubert Sauper.

FOTOGRAFÍA:

Hubert Sauper.

PRODUCCIÓN:

Eduard Mauriat, Antonin Svoboda, Martin Gschlacht, Barbara Albert, Hubert Toint y Hubert Sauper.

PREMIOS:

Nominado al Oscar como mejor largometraje documental en 2005, premio César al mejor debut cinematográfico en 2005, finalista a mejor documental en 2006 en la Asociación de Críticos de Los Ángeles, mejor documental europeo de 2004, premio Europa del Festival de Venecia, mejor Filme del Festival de Copenhague, premio ARTE y el Gran Premio del Festival de Friburgo. Diversos galardones en Montreal, Toronto y Belfort.

GÉNERO:

Documental. 


\section{SINOPSIS}

En la década de los años 60, a modo de experimento, se introdujo en el lago Victoria una nueva especie animal: la perca del Nilo, pero este pez resultó ser un depredador tan voraz que exterminó todas las especies autóctonas de este gigantesco lago. El nuevo pez se multiplicó rápidamente, y en la actualidad sus blancos filetes siguen siendo exportados a todo el mundo. Enormes aviones de carga de la antigua Unión Soviética llegan diariamente para recoger los últimos cargamentos de pesca y, a cambio, descargan su mercancía: kalashnikovs y munición para las innumerables guerras que tienen lugar en el corazón de África. Este explosivo comercio internacional ha creado una desoladora alianza global a orillas del lago tropical más grande del mundo: un ejército de pescadores locales, financieros internacionales, niños sin casa, ministros africanos, comisarios de la Unión Europea, prostitutas tanzanesas y pilotos rusos.

\section{$\underline{\text { ACTIVIDADES }}$}

1. ¿Por qué crees que el documental se llama “La Pesadilla de Darwin”?.

2. La introducción de este pez ha traído numerosas consecuencias ambientales, ¿crees que las consecuencias han sido también humanas?. El próximo día se realizará un debate en clase sobre las consecuencias humanas de este desastroso experimento. 
- $\quad$ Actividad 7.1:

TEMA 11: HACIA UN DESARROLLO SOSTENIBLE

Nombre Grupo: Fecha:

1. Indica con que concepto corresponde cada definición (2 puntos):

a) Satisface las necesidades de la generación presente sin comprometer la capacidad de las generaciones futuras para satisfacer sus propias necesidades

b) Proceso de degradación de las tierras en zonas áridas y semiáridas producido por variaciones climáticas o por actividades humanas

c) Máxima población de una especie que puede soportar

d) Proceso de formación de un suelo

e) Variedad de especies existente en un área determinada o en todo el planeta

f) Área biológicamente productiva que se necesita para generar los recursos que consume una persona y absorber los residuos que origina

g) Conjunto de buenas prácticas relacionadas con la producción, uso y eliminación de productos (según la ONU)

h) Suelo originado sobre la roca madre

i) Suelo constituido por materiales arrastrados de otras zonas

j) Desechos que incluyen los domésticos, los comerciales y de servicios y otros, como los derivados de la limpieza de calles, mercados

2. En los siguientes dibujos aparecen representadas las causas responsables de un uso abusivo de los suelos en las laderas (3 puntos).

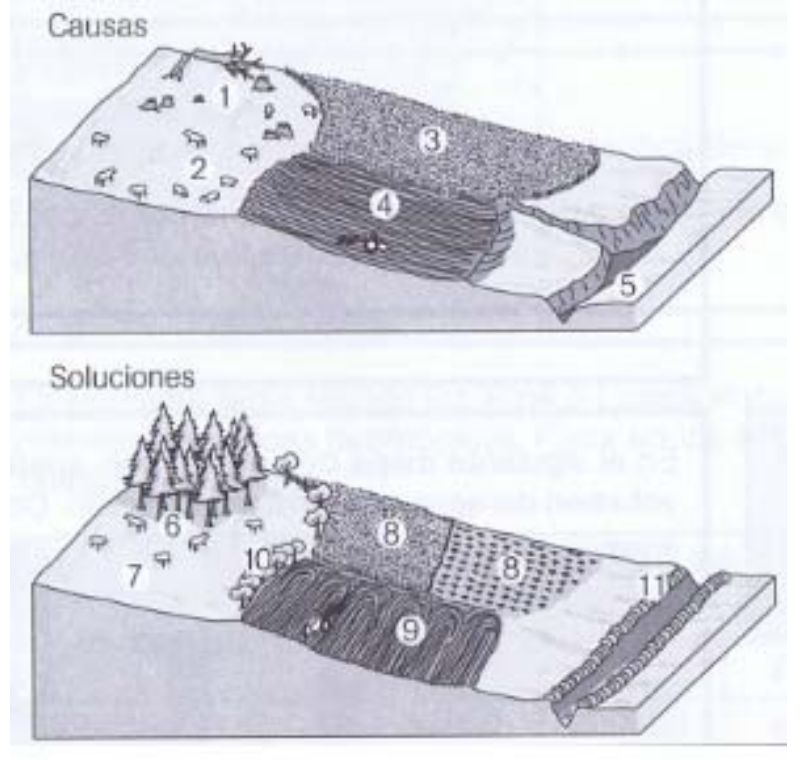

(*) Imagen tomada del cuaderno de evaluación (de la editorial SM) utilizado en la UD. Dicho cuaderno queda referenciado en el apartado 14 de bibliografía anterior. 
a) ¿Qué factor natural favorece la erosión del suelo en el dibujo superior?

b) Indica los riesgos de erosión que se aprecian en dicho dibujo superior.

c) En el dibujo inferior aparecen correcciones a las prácticas que favorecen la degradación de los suelos. Menciónalas.

3. España es el país europeo que más incumple los índices de seguridad para los niveles de ozono. El tráfico es el principal responsable del ozono troposférico, que irrita las vías respiratorias. El 99\% de la población está expuesto en algún momento del verano a más de 180 microgramos, el umbral que obliga a informar a la población. Contesta a las siguientes preguntas (2 puntos):

a) En algunos lugares del sur de Francia, en verano, es frecuente que se limite en las autopistas la velocidad por debajo de los $120 \mathrm{~km} / \mathrm{h}$. ¿Por qué crees que se toma esa medida?

b) ¿Qué enfermedades lleva asociado el aumento en la contaminación atmosférica debido al tráfico?

4. Explica mediante un esquema la separación y el destino de los RSU (0,5 puntos)

5. Enumera las ventajas que reúne la ciudad de tamaño medio y concentrada sobre la urbanización dispersa ( 0,5 puntos $)$.

6. De las siguientes causas que amenazan a especies protegidas, como el lince, el oso pardo, las posidonias y los corales, indica cuál crees que se corresponde con cada una (2 puntos):

- La pérdida o fragmentación de sus hábitats por la deforestación y ocupación del territorio

- La introducción de especies

- La caza furtiva

- La contaminación de las aguas dulces y marinas 